\title{
Use of Reflective Practices to Improve Self-Awareness in Youth Sport Coaches
}

\author{
Stephanie R. McWilliams \\ West Virginia University, stephanie.mcwilliams@mail.wvu.edu
}

Follow this and additional works at: https://researchrepository.wvu.edu/etd

Part of the Health and Physical Education Commons

\section{Recommended Citation}

McWilliams, Stephanie R., "Use of Reflective Practices to Improve Self-Awareness in Youth Sport Coaches" (2019). Graduate Theses, Dissertations, and Problem Reports. 3770.

https://researchrepository.wvu.edu/etd/3770

This Dissertation is protected by copyright and/or related rights. It has been brought to you by the The Research Repository @ WVU with permission from the rights-holder(s). You are free to use this Dissertation in any way that is permitted by the copyright and related rights legislation that applies to your use. For other uses you must obtain permission from the rights-holder(s) directly, unless additional rights are indicated by a Creative Commons license in the record and/ or on the work itself. This Dissertation has been accepted for inclusion in WVU Graduate Theses, Dissertations, and Problem Reports collection by an authorized administrator of The Research Repository @ WVU.

For more information, please contact researchrepository@mail.wvu.edu. 
Use of Reflective Practices to Improve Self-Awareness in Youth Sport Coaches

\author{
Stephanie R. McWilliams
}

Dissertation submitted to the College of Physical Activity and Sport Sciences at West Virginia University in partial fulfillment of the requirements for the degree of Doctor of Philosophy in Kinesiology: Coaching and Teaching Studies

\author{
James Wyant, Ph.D., Chair \\ M. Ryan Flett, Ph.D., Co-Chair \\ Damien Clement, Ph.D. \\ Suzanne Hartmann, Ph.D \\ Department of Coaching and Teaching Studies \\ Morgantown, West Virginia
}

2019

Keywords: youth coaching, coach education, reflection, self-awareness, counseling, motivational interviewing, behavior change

Copyright 2019 Stephanie R. McWilliams 


\begin{abstract}
Use of Reflective Practices to Improve Self-Awareness in Youth Sport Coaches
\end{abstract}

Stephanie R. McWilliams

In this dissertation, I explore the use of reflective practice among a group of youth sport coaches. More specifically, reflective practice as facilitated through use of videos and repeated interviews, with the intent to inspire greater awareness, malleability, and positive behavior change is presented. To synthesize this research, the following topics: coaching identity and the role of the coach, coach education and its misalignment with the goals of youth coaches, counseling as a means of mentoring, self-awareness and reflection, and behavior change, are discussed. In the current coach education literature, there is a gap in the types of education volunteer youth coaches are receiving, as it does not align with their coaching goals (McCullick et al., 2009; Trudel, Culver, \& Werthner, 2013). Also, there tends to be a misuse or minimal use of reflective practices in the coaching field, which may limit positive behaviors (Tripp \& Rich, 2012; Rosaen et al., 2008; Kinsella, 2010; Mann, Gordon, \& MacLeod, 2009; Gilbert \& Trudel, 2001). Since increasing self-awareness has been found to be an effective behavior change agent, it is logical to employ with youth sport coaches of varying education and ability (Lemyre, Trudel, \& Durand-Bush, 2007). Closing the intention-behavior gap in coaching was the primary goal of this study. In doing so, this study may serve as a template for new practices that may be explored further to benefit coaches and youth sport participants alike.

Participants included five head coaches of youth basketball leagues who were 38.4 years of age on average with 4.6 years of coaching experience, and 101 players, ages 7-10, from 10 teams in the league. The study incorporated four coach interviews, a quantitative coach satisfaction survey, and quantitative surveys for players in the league. An abductive approach was used to develop thematic categories from the interview data (Miles, Huberman, \& Saldana, 2014).

Quantitative results revealed players rating in coach commitment and connection as significantly increasing over time, and coach caring and complementarity increasing minimally. More importantly, results indicated that increases were greater for players on teams with coaches involved in the intervention. Participant coaches endorsed the usefulness and supportiveness of the reflection intervention used in this study.

Qualitative results revealed coaches have common goals of positive sport experience for youth, and with repeated interview, increase in their self-awareness by using reflection in their coaching. Additionally, using reflective practices through repeated dialogue and video review led to moderate behavior changes in participant coaches, that increased over time throughout the season. 


\section{Acknowledgments}

To my husband, Sean, and my wonderful children, Sean Jr., Ella, Liam, and Charlotte- I know this journey has been a challenge for all of you. My stress became your stress, and my lack of time became your extra efforts on many fronts. I most certainly would not have gotten through this without your love, hugs, and words of encouragement... always right when I needed them most. You are my whole world! Sean, you have been my rock throughout this and so many other life challenges. I am so grateful for you, forever and always.

Ryan- thank you for your tireless patience through this arduous process. Your balance of correction and commendation has made the dissertation process all the more possible. I suppose that is what makes a good mentor! You have put so many things aside to help me achieve this life-long goal, and I appreciate your time, attention, sincerity, and efforts more than you know.

Sue, Damien, and James- your willingness to jump on board an already moving train was not only brave, but quite selfless. I am so appreciative of your support and guidance. Many, many thanks. James, you took on the lion's share of mentorship to assist me in finishing this project, and for that I am very grateful.

To Aaron Metzger and Emily Deming in the WVU Department of Psychology, thank you for being my consultants and sounding boards in the final stages of this process. Your help is immensely appreciated!

This dissertation is dedicated to my father, and first mentor in life, Stephen Turi. I wish so much you could have seen the final product, but I know that my motivation to succeed is based in your life lessons. You encouraged me to be strong, confident, driven, and diligent, and I just hope that in finally completing this portion my journey, I have made you proud. 


\section{Table of Contents}

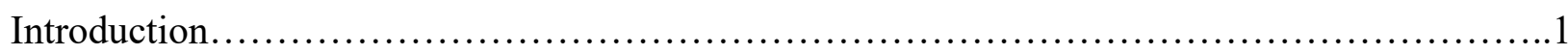

Research Questions......................................................

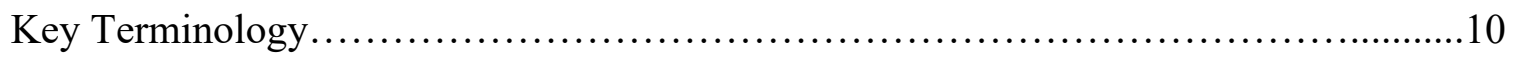

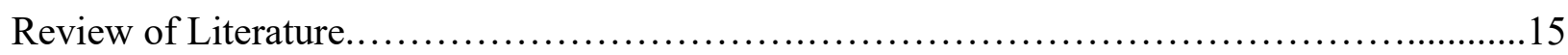

The Role of the Coach in Youth Sport............................................ 16

Developmental Support.............................................16

Coach as Mentor...................................................... 17

Aligning Goals and Actions....................................................19

Coach Education...What It Is and What Can It Be.............................21

The Learning Process toward Coach Effectiveness and Goal Achievement........22

Reflection as a Learning Practice.....................................24

Counseling Techniques as a Plausible Solution to Educational and Behavioral Gaps....26

Person-Centered Focus.............................................27

Counseling Techniques as a Link to Behavior Change........................... 30

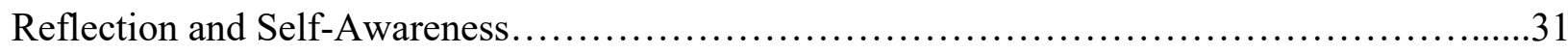

The History and Progress of Reflective Practice....................................31

The Reflective Process...What Works and What Works Better.......................35

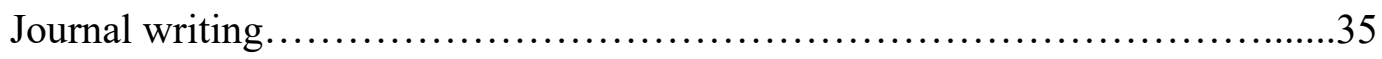

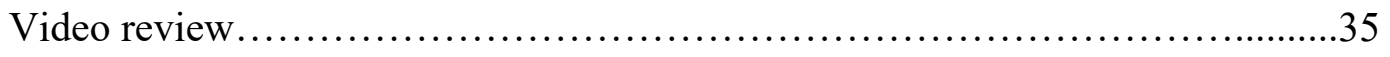

Reflective Practice in Coaching................................................ 37

Behavior Change is Possible with Increased Self-Awareness.........................40

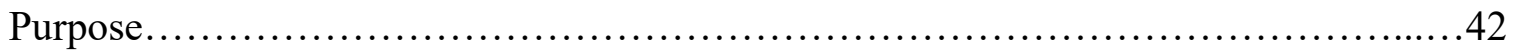




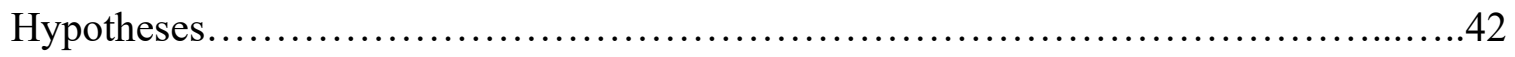

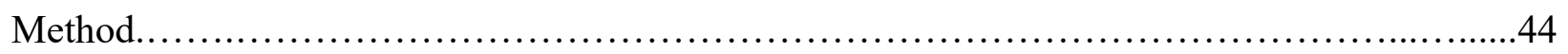

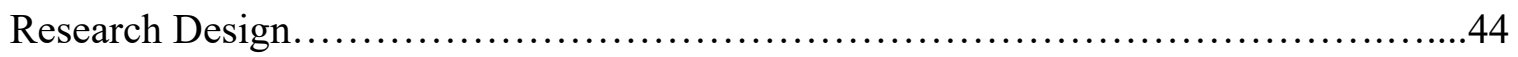

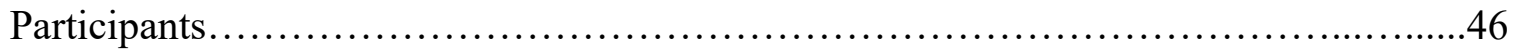

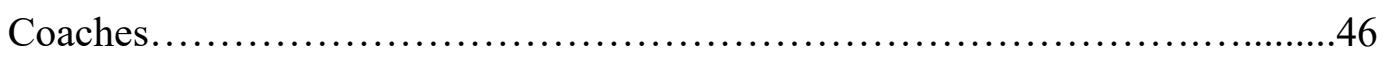

Coach demographics. .................................................. 47

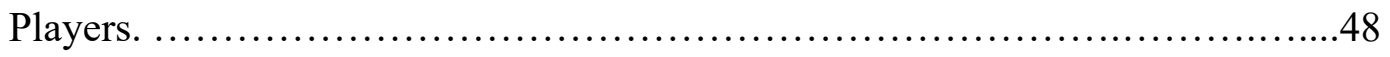

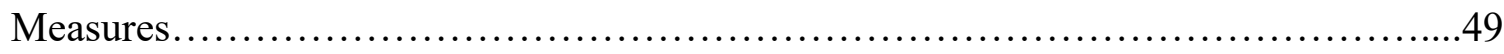

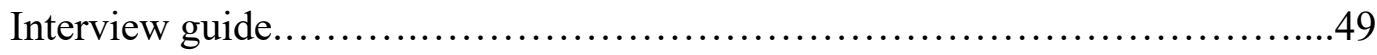

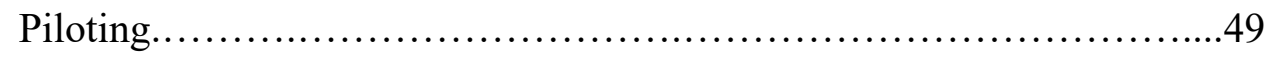

Bracketing.......................................................... 49

Application of counseling strategies in interviewing. ......................49

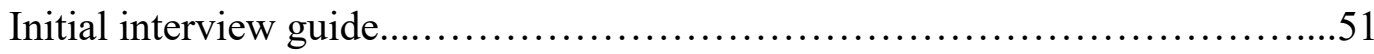

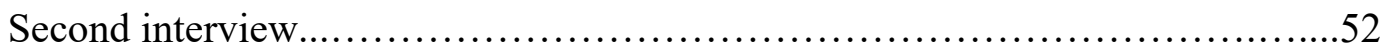

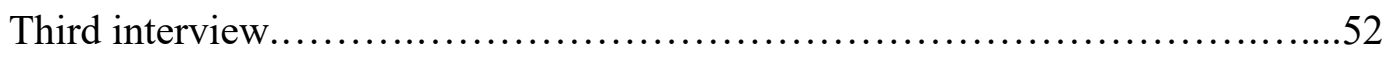

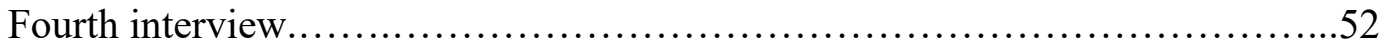

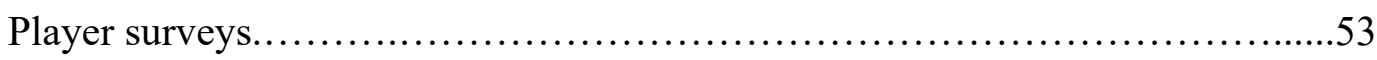

Coach-Athlete Relationship Questionnaire (CART-Q) ..................53

Caring Climate Scale (CCS),........................................5

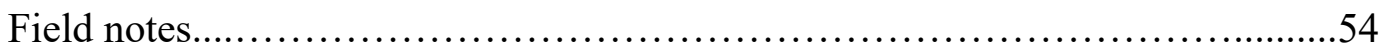

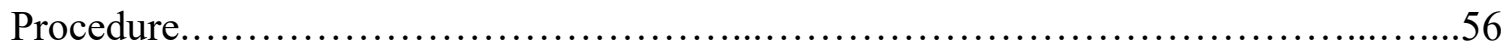

Coach background information............................................56

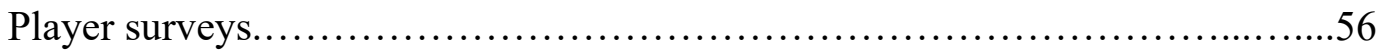




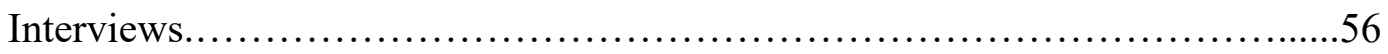

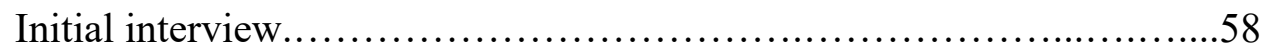

Follow-up (second, third, and fourth) interviews......................58

Video recordings..............................................58

Practice..................................................58

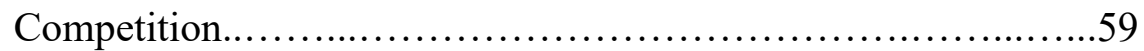

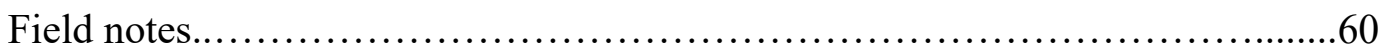

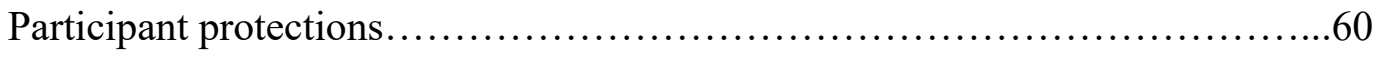

Data Analysis...........................................................60

Quantitative Design...............................................60

Quantitative Procedures.............................................6 61

Qualitative Analysis...................................................61

Trustworthiness and Authenticity...............................62

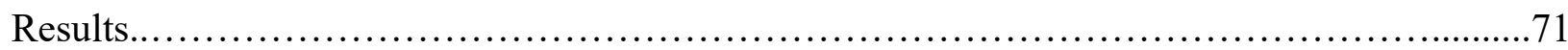

Overview.............................................................. 71

Participant Numbers, Measurement Reliabilities, and Assumptions....................71

Coach Athlete Relationship Questionnaire.................................... 73

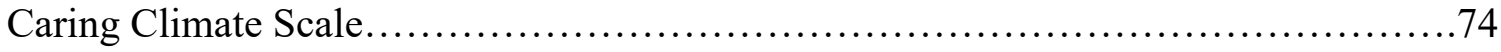

Research Question One...................................................... 76

Research Question Two................................................... 80

Research Question Three................................................... 87

Discussion, Implications, and Conclusions.......................................... 90

Self-Awareness and Intentionality- Addressing RQ $1 \ldots \ldots \ldots \ldots \ldots \ldots \ldots \ldots \ldots \ldots . . . \ldots 2$ 


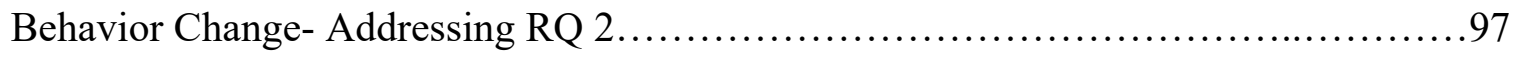

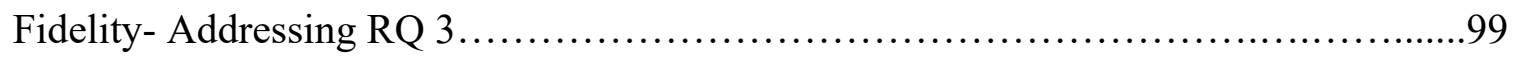

Worldview of the researcher................................................ 99

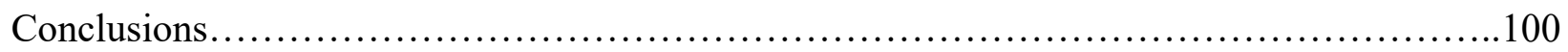

Limitations........................................................... 101

Framework of Intervention for Future Use...................................... 102

Broader Scope....................................................... 104

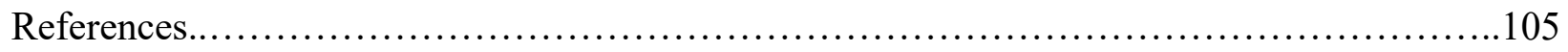

Appendices.................................................................... 125

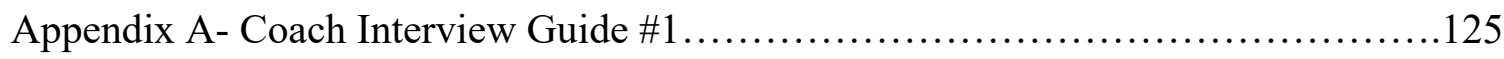

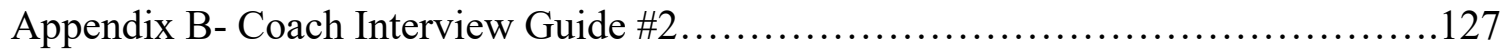

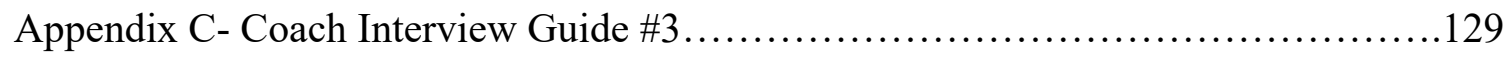

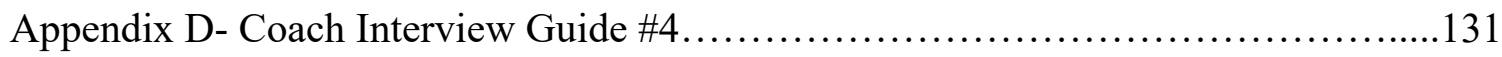

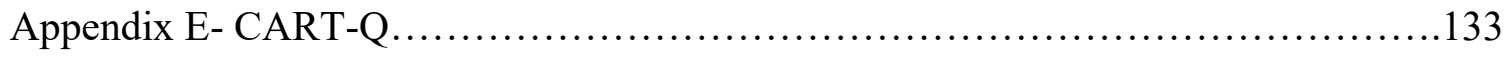

Appendix F- CCS..................................................... 134

Appendix G- Field Notes Form............................................ 135

Appendix H- Coach Demographics Questionnaire...............................136

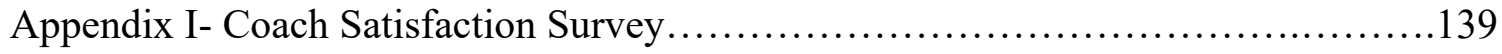

Appendix J- Parental Consent with Youth Assent Form..............................140 


\section{Overview of the Chapters}

Chapter 1 introduces the statement of the problem, purpose of the study, the importance of the study, limitations and delimitations. Additionally, the conceptual basis of the study is established, along with clarification of the research questions. Chapter 2 contains an overview of related literature on the role of the coach, coach education, counseling techniques as they relate to mentorship, behavior change, and reflection as a means to improving self-awareness. Methodology for this study is presented in Chapter 3 and includes the research design, selection of the sample, data collection tasks, and data analysis procedures. Results of both quantitative and qualitative methodologies are available in Chapter 4. The final chapter, Chapter 5, is a discussion of the study. 


\section{Chapter I}

\section{Introduction}

Despite popular opinion, psychosocial development through sport is not automatic for all youth. Rather, positive gains are a function of the coach's goals and related behaviors (Holt, 2016). For example, emotionally supportive communication fosters a sense of caring, increases engagement, and encourages prosocial behaviors in youth participants. Such engagement must be intentional (Gould, Flett, \& Lauer, 2012). In other words, it is a choice on the part of the coach that determines the child's developmental experience. Coaches, however, are not inherently aware of how important their role is, and how deep of a positive (or negative) influence they can potentially have on youth players. Previous literature clearly states that the behaviors a coach engages in directly effects the youth sport experience (Mageau \& Vallerand, 2003; McGladrey, Murray, \& Hannon, 2010; Washington \& Reade, 2013). For example, FraserThomas, Côté, \& Deakin (2005) highlight Lerner and colleagues' Five C's Model (2005), specifically connection, caring, and character, as the primary positive attributes for youth coaches to focus on. If the goal of the coach is to be positively impactful, it is important that each coach purposefully engages in behaviors that have positive effects, and for league directors and managers to encourage such purposeful behaviors in coaches.

\section{Positive Coaching Behaviors Are Not Automatic}

In order for coaches to be the mentor youth require in sport, they must act the part. Lack of self-awareness in coaches can limit intentional positive behaviors, which may have detrimental effects on coach goal achievement and limit positive development potential for youth (McCallister, Blinde, \& Weiss, 2000; Millar, Oldham, \& Donovan, 2011). Therefore, understanding how to alter self-awareness in coaches is a gap in the sport and coaching research 
that requires attention (Partington \& Cushion, 2013). By increasing a coach's selfawareness, that coach was more intentional and deliberate about fostering developmental goals in youth players. This opens the door for more opportunities for a positive experience and positive development (Millar et al., 2011). Without awareness of the importance of their role, coaches cannot be the mentor their young players need them to be. Therefore, the goal of this dissertation was to explore new methods of increasing self-awareness in volunteer coaches working with children, in order to promote behavior change in coaches and a positive experience for youth sport participants.

Changing behavior can be challenging. Unfortunately, traditional coach education is most heavily focused on what coaches do and minimally focused on why coaches do what they do (i.e., their purpose and motivation) (Fry \& Gano-Overway, 2010). Workshops and lectures for coach learning, whether in-person on in an online format, are the most common forms of coach education, and are structured around theory and specific sport skill building (McCullick, et al., 2009; Trudel, Culver, \& Werthner, 2013). While theory and skills are important, misalignments between desired coaching behaviors and actual coaching behaviors are the more serious issue for positive youth development. And those misalignments are not solved in a passive learning environment. Therefore, a new approach is needed. Increased self-awareness is the missing piece that may help youth coaches find harmony, as self-awareness leads to greater knowledge, acceptance of fault, and an increased willingness to change (Knowles, Borrie, \& Telfer, 2005;). Self-awareness is different from traditional coaching skills, so traditional educational approaches may not be the best way to develop, alter, or nurture it. Self-awareness is also the key ingredient for behavior change (Lemyre et al., 2007). 


\section{How to Assist Coaches in Gaining Self-Awareness}

So how can coaches get the applied information they need to fulfill their mentorship role? Smith, Smoll, and colleagues have previously focused on self-awareness in their examination of education for youth coaches (Barnett, Smoll, \& Smith, 1992; Smith \& Smoll, 1997; Smith, Smoll, \& Curtis, 1979; Smith, Smoll, \& Cumming, 2007; Smoll, Smith, Barnett, \& Everett, 1993). The scholars Coach Education Training (CET) program used a workshop setting to help coaches apply coaching principles that are in accordance with cognitive behavioral techniques. More specifically, the coaching behaviors central to CET are giving praise, role modeling good behavior, giving immediate feedback, promoting team spirit, etc. (Conroy \& Coatsworth, 2006). In their studies, they examined children who played for trained coaches and compared them to a control group. While some changes were found from pre to post season in coach behaviors and in youth outcome measures, feasibility, cost (both as funding and time), and ease of use for the CET program were not assessed. In order for a coaching intervention to be most successful, accessibility is key (Lemyre et al., 2007). Coaches, especially volunteers, often find workshops to be cumbersome and then fail to actually utilize the ideas learned (Gilbert, Cote, \& Mallett, 2006). By moving away from a cognitive behavioral model of coach education (i.e., focused primarily on what coaches need to know and how to apply that knowledge), coaches can look to their goals (i.e., why coaches do what they do) to attach more meaning to principles learned, making sustained behavior change more likely (Ghaye et al., 2008).

One idea to promote self-awareness that has not been utilized with sport coaches but has been successfully implemented with school teachers and medical professionals is the use of counseling-based interventions. Such interventions give goals and behavior meaning, and increase understanding (Kinsella, 2010; Mann, Gordon, \& MacLeod, 2009; Russell, 2005). For 
example, combining repeated interviews with video reflection as a means of increasing awareness has been successful with school teachers (Tripp \& Rich, 2012). And while awareness of the disconnect between goals and behaviors for those teachers increased over time with each interaction, uncovering the path to changing behavior efficiently and effectively was not examined. Efficient, effective behavior change to better align goals and actions is a gap to be explored with sport coaches.

Coaches often fail to acknowledge their faults or deny them altogether, likely due to the inherent competitive nature of the sporting environment (Smoll, Cumming, \& Smith, 2011). Therefore, increasing self-awareness may be quite challenging. Counseling techniques, however, can foster autonomy in the learner (i.e., coach), making it the coach's choice to change, and not a situation where change is imposed. Sport coaches are likely to be more engaged and more willing to make changes when they feel autonomous control over changes being made (McCallister et al., 2000).

Counseling approach has been proven to increase self-awareness. While previous research justifies the need to increase coach self-awareness, the most effective method of achieving such awareness remains unclear. For this dissertation, counseling-style interviews and video primers were used to provide a method of self-reflection for coaches. Active learning techniques with a person-centered foundation were employed. This is different than traditional approaches, which are more passive and cognitive-behavioral in nature (Tripp \& Rich, 2012; Rosaen, Lundeburg, Cooper, Fritzen, \& Terpstra, 2008). Humanistic interactions that are reflective and free from judgement will help in identifying the positive outcomes that coaches want to achieve with their players. Such an approach requires acknowledgment of what the coach is doing (i.e., actual self), what he or she wants to be doing (i.e., ideal self), and what he or 
she should be doing (i.e., ought self; Rogers, 1945). By holding up a mirror with the help of the researcher, inward reflection can become a sounding board for increased understanding. Rogers (1945) referred to this as congruence: an alignment of all aspects of the self. More recently, in a study of 11 youth sport coaches with an average of eight years of coaching experience, Partington and Cushion (2013) uncovered a pattern of misalignment between stated coaching goals (i.e., develop the whole player) and actual coaching behaviors (i.e., making decisions for the players rather than being a facilitator of decision making so players could learn). They concluded that with increased self-awareness, more positive and intentional coaching behaviors will result.

Figure 1. Coaching and Counseling Interaction.

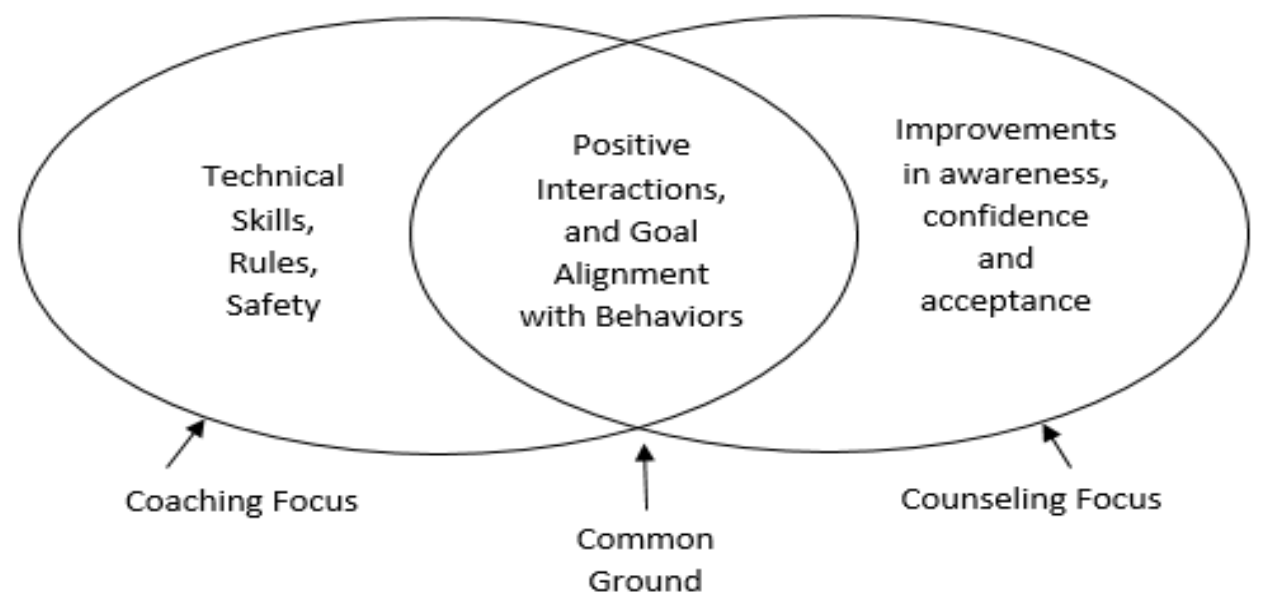

Figure 1. The interaction between the goals of coaching and the goals of counseling justifies the use of counseling techniques with coaches as an intervention for improved awareness and behavior change.

Reflection. In short, reflection is a counseling technique that leads to increased selfawareness. By using Motivational Interviewing (MI) techniques where the coach guides the process, he or she were more likely to develop rapport with the researcher, and were more open to changes in thought and behavior from one interview to the next. MI is borrowed from the 
person-centered counseling methodology, and it intended to increase one's consciousness of thoughts, ideas, and related actions. A humanistic approach may be more useful in the context of coaching than CBT techniques (which is the norm in traditional coach education) because coaches need to own what they discover, not necessarily be taught to perform techniques by the book. For this intervention, the use of supportive communication techniques, such as active listening, allowed the interviewer to act as a mirror for the coach. Such guided reflection opens the door to being self-critical, increasing openness to change (Prochaska, Norcross, \& DiClemente, 1995). Acknowledging faults and reframing purpose allows for psychological and behavioral changes to occur. More specifically, a less directive and more reflective technique may help coaches find answers on their own, which is more beneficial for eventual behavior change (Miller \& Mount, 2001).

Since reflection is a form of education (Dewey, 1938), the alternative idea to be explored is an intervention combining dialogue with video prompts and feedback from players. Reflection techniques have been used at length with school teachers (Tripp \& Rich, 2012; Rosaen, et al., 2008), as well as medical professionals (Kinsella, 2010; Mann, Gordon, \& MacLeod, 2009), but have not been used consistently with sport coaches. In one study, Gilbert and Trudel (2001) found that model youth coaches already engage in reflection in order to stay focused. Such a finding provides a basis for exploring the use of reflection with youth coaches further. For this study, the primary means of reflection for youth coaches were in the form of repeated interview and reflection on video. To add some additional information regarding coach behavior to the MI-based dialogue, players will complete the Caring Climate Scale (CCS; Newton, Fry, Watson et al., 2007) and the Coach-Athlete Relationship Questionnaire (CART-Q; Jowett \& Ntoumanis, 
2004), at the beginning and end of the season. Direct feedback from players' surveys will help coaches to become more aware of misalignments between their goals and their actual behaviors.

\section{A Different Approach: Dialogue-Based Intervention}

Multiple interviews across the season were used as the primary intervention to facilitate reflective practice among volunteer youth coaches (Guest, Bunce, \& Johnson, 2006). The first interview aims to establish the goals and understand the behaviors of each participant coach. Coaches will then be encouraged to review and reflect upon videos of their behavior(s) during actual practice and game situations. Three conversational interviews will then take place as a follow-up to the video reflection exercises. The interviews were explained to participants as a means of learning more about how coaches reach their season goals, but the true intention of promoting self-awareness and behavior change will not be explicitly clear until the post-season interview. Initially, coaches will simply be asked to share their thoughts and experiences, and to ponder the impact that they have on youth players. Interviews will incorporate counseling micro-skills and were combined with reflective video of the coaches.

In summary, character, life skills, and other positive developmental outcomes aren't automatic in youth sport because those outcomes rely on coaching behaviors (Gould et al., 2012). Even coaching behaviors aren't automatic because not only do many coaches lack the necessary skills to foster positive youth development, but more importantly, they lack selfawareness of goals and behaviors (Hodge, 1989). These shortcoming then, such as the lack of self-awareness in coaches, are not only prevalent based on the literature, but because they connect to positive developmental outcomes in youth sport. As a final point of emphasis and support for the importance of this study, traditional and modern approaches to coach education are fundamentally and theoretically limited in their potential to facilitate reflection and self- 
awareness. As such, a different means of fostering self-awareness is not only valuable to coach education, but it is necessary as current approaches appear to be inadequate.

Several limitations exist for this proposed study. First, limitations exist for the implementation of the intervention. With research of this nature, getting all parties involved to "buy in" prior to having promising results in hand can be a challenge. Also, the intervention outlined in this study can be very time consuming, especially early on. This may negatively impact some participants' opinion of the intervention before positive results are realized. As for transferability, there are other limitations that may be present. The proposed technique will require some training to have a mentor or point person driving continued discussion. It is uncertain how this would work with new coaches coming in, and the reflective element may be too cumbersome while still learning the sport/coaching basics. And since the details of the dialog, player feedback, and video are the key to their success and to replication, potentially not all educators will do these things the same way and with the same effect therefore.

The objectives of affecting coaching behavior and improving self-awareness have been important goals for decades, but there has been little progress. So the significance of the goals of the intervention may be a barrier of their own. Finally, we don't know what coaching variables might be the most important in determining the impact of the intervention: age, experience, gender, sport type, etc. Different coaches have a variety of experiences, both personal and professional, that they bring to the role. How each coach interprets and implements the intervention presented may vary based upon those experiences. Specifically, this dissertation will not study how the intervention may be more or less effective, or how it may have to be modified, based on the age, experience, gender, sport type, or style of the coach. This study will 
not answer the question of which coaches benefit most from the intervention, but instead, the mere presence or absence of positive responses.

\section{Research Questions}

Based on the review of literature (described in more detail in chapter 2), there are several research questions that drive the method (chapter 3). The over-arching question driving this study is: Does a reflection-based intervention that utilizes dialogue, video review, and player input facilitate self-awareness, intention to improve coaching behaviors, and positive behavior changes in youth coaches?

\section{Does the intervention facilitate Self-Awareness and Intentionality?}

1. Does a reflection-based intervention increase youth coaches' self-awareness and intention of their coaching behaviors?

1a. Does dialogue in a reflection-based intervention increase coaches' self-awareness of developmentally supportive behaviors?

1b. Does video review in a reflection-based intervention increase coaches' selfawareness of developmentally supportive behaviors?

1c. Does input from players in a reflection-based intervention increase coaches' selfawareness of developmentally supportive behaviors?

\section{Does the intervention facilitate Behavior Change?}

2. Based on player- and self-report does a reflection-based intervention change coaches' developmentally supportive behaviors (i.e., their positive coaching of children)?

2a. If yes, what specific changes occur in coaches' self-reported behaviors?

2b. If yes, does coaches' behaviors change as measured by players' perception of change? 
2c. Does video review in a reflection-based intervention affect coaches' implementation of developmentally supportive behaviors?

2d. Does input from players in a reflection-based intervention affect coaches' developmentally supportive behaviors?

2e. Specifically, for player perceptions, do perceptions of positive rapport and caring coaching improve more over the season for teams who participate in the study than for other teams in the league?

Fidelity: Was the intervention done the way it was supposed to be done?

3. Do coaches believe that the reflection-based intervention, which utilized dialogue, video review, and input from players, made them willing to self-report fault in their coaching behaviors?

3a. Do coaches believe the intervention was supportive?

3b. Do coaches believe the intervention was useful?

3c. Do coaches believe the intervention was free from judgment?

\section{Key Terminology}

Congruence. Congruence is a counseling term referring to the agreement or alignment among the actual, perceived, and ideal selves (Rogers, 1945). In this study, congruence refers to the alignment of coach goals as compared to their actual and perceived intentions and behaviors.

Effective coaching. Effective coaching is defined by Côté and Gilbert (2009) as "the consistent application of integrated professional, interpersonal, and intrapersonal knowledge to improve athletes' competence, confidence, connection, and character in specific coaching contexts" (p. 316). 
Mentorship. Mentorship is guidance by an experienced person to aid in learning and problem-solving. Mentorship defines the primary objective of model youth sport coaches (Gilbert \& Trudel, 2001).

Micro-skill. A micro-skill is a subset of a behavioral competency that serves a direct purpose (Ridley, Mollen, \& Kelly, 2011). For example, in this study, the researcher will use Motivational Interviewing (MI) to put coaches at ease and to obtain detailed accounts of coaches' experiences. The way the listener responds to the speaker will ultimately influence how the speaker responds. To use encouragement rather than judgement, is a micro-skill in this case.

Motivational Interviewing (MI). MI is a goal-oriented, client-centered counseling style for eliciting behavior change by helping clients to explore and resolve a lack of understanding and connection to a problem via a facilitative relationship. MI is more focused and goal-directed than typical person-centered psychology techniques, but still follows the same principles (Rollnick \& Miller, 1995).

Person-centered psychology. Person-centered or humanistic psychology is a nondirective, empathic approach that empowers and motivates the client in the therapeutic process (Rogers, 1942). A compassionate facilitator who listens without judgement is key for success.

Reflection. Reflection is an active process of exploration and discovery, which often leads to new and unexpected outcomes (Boud, Keogh, \& Walker, 2013).

Self-awareness (SA). SA is conscious knowledge of one's own intentions, goals, emotions, and behaviors achieved by directing attention inward on the self (Duval \& Silvia, 
2002); SA affords individuals the opportunity to deliberately control one's behavior, and when necessary, act contrary to one's automatic inclinations (Leary \& Buttermore, 2003).

Table 1

Summative Chart of Literature Gaps and Alignment to Research Questions.

\begin{tabular}{|c|c|c|}
\hline Issue / Gap in Lit & Literature / Citations & RQs \\
\hline $\begin{array}{l}\text { Developmental support } \\
\text { and increasing positive } \\
\text { experiences should be the } \\
\text { focus of youth coaching }\end{array}$ & $\begin{array}{l}\text { Mageau \& Vallerand, } \\
\text { 2003; McGladrey, } \\
\text { Murray, \& Hannon, } \\
\text { 2010; Washington \& } \\
\text { Reade, 2013; Gould, } \\
\text { Flett, \& Lauer, 2012); } \\
\text { Holt, } 2016\end{array}$ & $\begin{array}{l}1 \mathrm{~b}, 1 \mathrm{c}-\text { developmentally supportive } \\
\text { behaviors (supporting why I've } \\
\text { created an intervention designed to } \\
\text { increase coaches use of developmental } \\
\text { support) }\end{array}$ \\
\hline $\begin{array}{l}\text { According to model } \\
\text { coaches, behaviors are the } \\
\text { key to creating positive } \\
\text { experiences. Behaviors } \\
\text { must be focused on the } \\
\text { outcomes for the youth, } \\
\text { caring in nature, and } \\
\text { allow the coach to } \\
\text { connect to the youth. }\end{array}$ & $\begin{array}{l}\text { McCallister, Blinde, \& } \\
\text { Weiss, 2000; Petipas, } \\
\text { Cornelius, Van Raalte, \& } \\
\text { Jones, 2005; DuBois, } \\
\text { Holloway, Valentine, \& } \\
\text { Cooper, 2007; Gould \& } \\
\text { Carson, 2011 }\end{array}$ & $\begin{array}{l}\text { 2- Focus on developmentally } \\
\text { supportive behaviors; are coaches } \\
\text { aware of alignment of goals and } \\
\text { related behaviors }\end{array}$ \\
\hline $\begin{array}{l}\text { Positive coaching } \\
\text { behaviors are not } \\
\text { automatic, so } \\
\text { intentionality is the key; }\end{array}$ & $\begin{array}{l}\text { Hodge, 2006; Gilbert \& } \\
\text { Trudel, 2001; Lemyre, } \\
\text { Trudel, \& Durand-Bush, } \\
2007\end{array}$ & $\begin{array}{l}\text { 1, 2b- Addressing intentionality; } \\
\text { effectiveness of the proposed } \\
\text { intervention at increasing SA }\end{array}$ \\
\hline $\begin{array}{l}\text { Coaches perceived } \\
\text { behaviors and actual } \\
\text { behavior are often } \\
\text { misaligned. }\end{array}$ & $\begin{array}{l}\text { Cushion, Armour, \& } \\
\text { Jones, 2003; Knowles, } \\
\text { Borrie, \& Telfer, 2005; } \\
\text { Lemyre, Trudel, \& } \\
\text { Durand-Bush, 2007; } \\
\text { Kinsella, 2010; Mann, } \\
\text { Gordon, \& MacLeod, } \\
\text { 2009; Russell, 2005 }\end{array}$ & $\begin{array}{l}\text { 1d- implementation of behaviors, and } \\
\text { also helps explain why you're } \\
\text { examining } \\
\text { 2a- coaches' self-reports of their } \\
\text { behaviors and 2c- players' reports of } \\
\text { coaches' behaviors }\end{array}$ \\
\hline $\begin{array}{l}\text { Furthermore, SA is a } \\
\text { foundation for behavior } \\
\text { change in non-sport } \\
\text { health care and } \\
\text { counseling literature. }\end{array}$ & $\begin{array}{l}\text { Prochaska, Norcross, \& } \\
\text { DiClemente, 1995; } \\
\text { Church \& Bracken, } \\
\text { 1997; Hinyard \& } \\
\text { Kreuter, 2006 }\end{array}$ & \\
\hline
\end{tabular}

(continued) 


\section{Issue / Gap in Lit Literature / Citations RQs}

So, in summary, if we want to promote youth develop through positive sport experiences, the key may be promoting selfawareness in youth coaches. However, conventional coach education is not effective at enhancing SA. Self-awareness piece is missing from traditional coaching ed

Traditional coaching ed focuses mostly on skills and drills, not youth outcomes

SA is critical, but conventional coach education falls short because these methods of reflection are too [finish]... So how can an alternative paradigm foster SA and behavior change?

SA could be fostered using a humanistic paradigm, rather than an educational one. As such, a counseling but makes sense and has not been used before in coach education; includes reflection Coaches respond better to a non-judgmental, supportive environment when learning; need to
Partington \& Cushion, 1- Increase in SA 2013; Smoll, Cumming, \& Smith, 2011; Moon, 1999; Knowles, Borrie, \& Telfer, 2005

Fry \& Gano-Overway, 2010; McCullick, et al., 2009; Trudel, Culver, \& Werthner, 2013

Weakness in journal writing: Levine et al., 2008; Carson, 2008;

Bolton, 2010; Scannell, 2002; Charon, 2001

Tripp \& Rich, 2012;

Rosaen, Lundeburg, Cooper, Fritzen, \&

Terpstra, 2008; Rogers, 1945

Camiré, Trudel, \& Forneris, 2014; Gould \& Carson, 2011
1- Reflection as basis for intervention

(continued) 


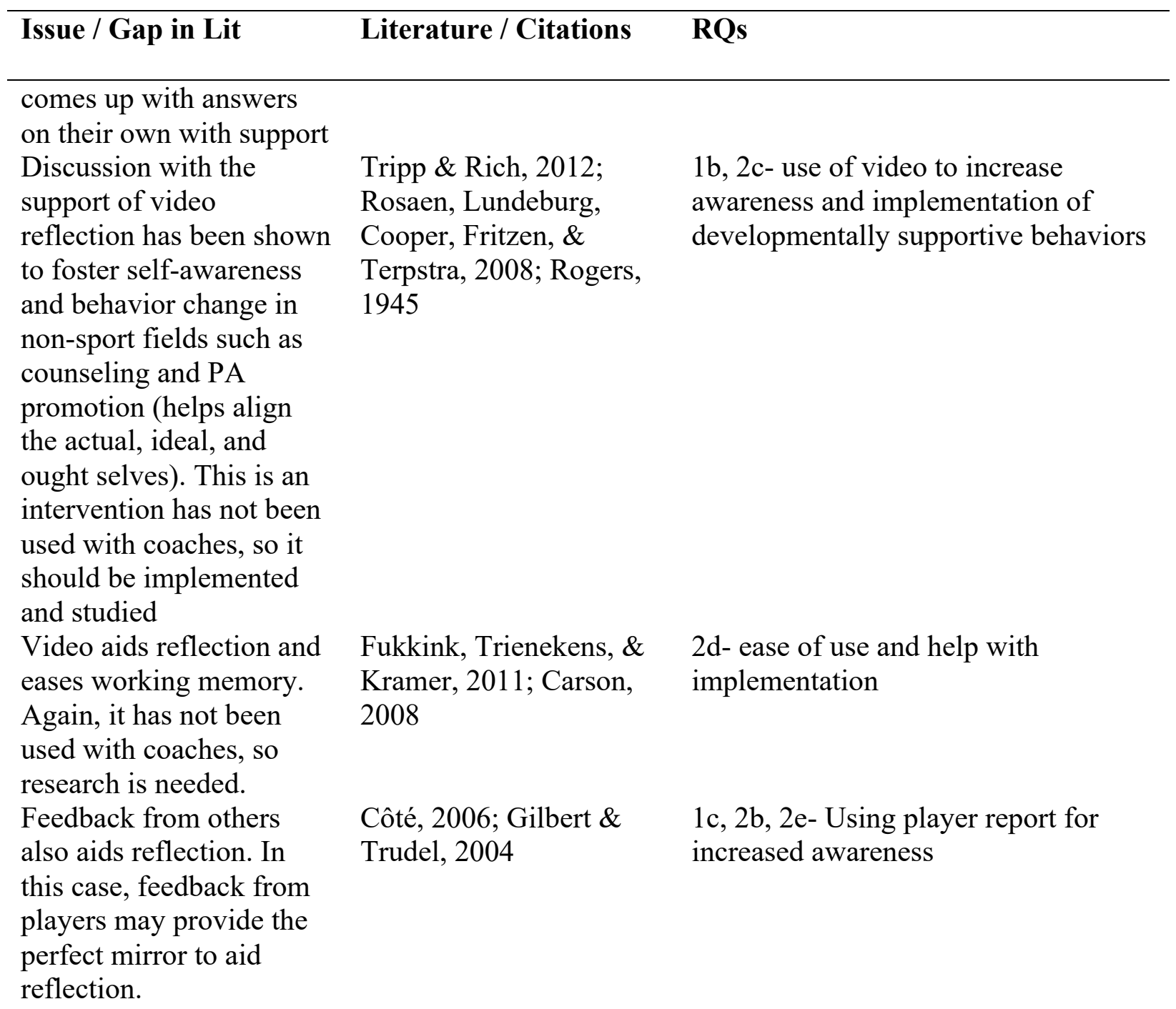




\section{Chapter II}

\section{Review of Literature}

Despite popular opinion, the psychosocial skills that youth can acquire through sport are not automatic. Rather, positive gains are a function of the coach's goals, choices, and actions (Holt, 2016). For example, emotionally supportive communication with coaches fosters a sense of caring, increasing engagement, and prosocial behaviors in youth participants (Robbins \& Rosenfeld, 2001). Using emotionally supportive techniques to interact with players, however, is an intentional choice that coaches must make. Despite the important role coaches play, there is often a lack of knowledge and understanding of their effect on youth outcomes (Cushion, Armour, \& Jones, 2006). By increasing a coach's self-awareness, that coach was more intentional and deliberate about fostering his or her developmental goals. As a result, there were more opportunities for positive development through intentional positive coaching behaviors.

The purpose of this dissertation is the goal of this dissertation is to explore a humanistic approach using dialogue, video reflection, and player feedback. Such an intervention will increase the self-awareness of volunteer coaches working with children, helping to promote behavior change in coaches and a positive experience for youth sport participants. Put simply, without self-awareness, as well as the acknowledgment of the importance of their role, coaches cannot be the mentor youth sport participants need. By increasing coach's knowledge of understanding, a coach becomes more malleable, and change becomes more meaningful and more likely to occur (Cushion et al., 2003). The goal of this dissertation was to increase behavioral self-awareness of volunteer coaches working with children and to promote a positive experience for youth sport participants. 


\section{The Role of the Coach in Youth Sport}

As a teacher, disciplinarian, critic, safety officer, manager, administrator, and trainer, a sport coach adopts a variety of roles. Included within those roles are many opportunities to impact the sport environment. Each of these coaching roles are influential in participants' sportrelated experiences. Whether a coach is working with elite, experienced athletes, or with children experimenting with sport for the first time, the coach is a buffer between the individual's sport experience and the plethora of external sport-related variables (Washington \& Reade, 2013). Coaches shape the perspectives, goals, and the experiences that youth have in sport. Therefore, the focus of this dissertation is on the coach's role as a mentor and exploring a method to enhance that role. Children rely on positive interactions with their coaches to make sense of the sport, to fit in, to grow and gain skills, and to develop mentally, emotionally, and socially (Holt, 2016). The impactful nature of these positive interaction (or lack thereof) are why the coach is such a key variable in youth sport.

Developmental support. In sport, it is vitally important that children have the opportunity to be guided through the initial elements gently, as there is as much potential for negative experiences as for positive (Barnett et al., 1992; Fraser-Thomas, Côté, \& Deakin, 2005; Gilbert \& Trudel, 2001; Merkel, 2013). When a coach fosters a caring climate, such efforts have been linked with gains in emotional regulation, improved social skills and interpersonal relations, increased prosocial behaviors, and expanded support networks of guiding adults (Fry \& GanoOverway, 2010; Gano-Overway et al., 2009; Gould et al., 2012). Early negative sport experience, on the other hand, may lead to failure in having these positive outcomes realized. Negative sport experience may also lead to quitting sport participation altogether, which in turn leads to missed opportunities for positive developmental growth (Fraser-Thomas \& Côté, 2009; Smith \& Smoll, 
1997; Merkel, 2013). These reasons are precisely why each coach embracing his or her role as a mentor is vitally important to the early sport experience for youth.

Coach as mentor. By embracing mentorship, coaches have the opportunity to positively influence psychosocial change in youth sport participants (Holt, 2016). A mentor will aid youth in mastering new physical abilities, as well as gaining confidence, improving overall mental functioning, supporting new and existing friendships, and instilling work ethic. As stated previously, the coach can assist in the development of youth participants through support and teaching. If the coach understands mentorship and has outlined what behaviors will lead to positive outcomes, then youth participants will feel supported and in control of their sport experience (McCallister, Blinde, \& Weiss, 2000). This sense of control increases independence, confidence, and overall life skills (Petipas, Cornelius, Van Raalte, \& Jones, 2005). Put simply, with a youth-centered dynamic as the blueprint for what occurs within sport, the opportunity for positive outcomes significantly increases (McGladrey et al., 2010).

From coach to coach, approaches to mentorship may vary. Some adopt a more developmental (or youth-driven) style, whereas others are more prescriptive in nature. Mentors using a developmental approach tend to devote their efforts in the early months to establishing a strong connection with their players. Mentors place a high value on making the relationship enjoyable, and set developmentally appropriate expectations that are informed by the youth's preferences and interests (DuBois, Holloway, Valentine, \& Cooper, 2007). Model youth coaches follow this strategy in establishing the coach-player relationship (Gilbert \& Trudel, 2001, 2004). Coaches who are more rigid and self-focused place primary emphasis on their own goals — rather than what is best for youth players - often fail to have much positive impact (Gilbert, Gallimore, 
\& Trudel, 2009). These coach-centered goals are often unrealistic and not developmentally appropriate, and they do not focus on building an emotional, interpersonal connection.

In a meta-analysis of 73 formal mentoring programs, DuBois and colleagues (2011) found that only 40 percent of youth labeled their mentor as a "significant" adult in their lives. A strong and meaningful personal connection between the young person and mentor was still noted as being the most important building block for an impactful relationship in this review. Unfortunately, that connection is often not the primary focus of assigned relationships in formal mentoring programs. In response to this finding, the authors propose a mentorship model wherein the social support provided by the significant adult serves as an intervention in the developmental process (DuBois, Portillo, Rhodes, Silverthorn, \& Valentine, 2011). This connection directly links mentoring to positive psychosocial and behavioral outcomes. Without a meaningful, interpersonal connection, the relationship is significantly less valuable. In the current study, the mentorship relationship was the primary focus. Increased awareness in the coach will lead to a greater connection between the coach and player, promoting a caring climate and positive developmental outcomes.

Other dimensions of the mentor's approach that may contribute to relationship quality are positive regard, authenticity, empathy, warmth, and the provision of appropriate challenge (as in the case of sport) (Spencer, 2004). Mentors who are sensitive and consistent in their relationships help mentees feel worthy of care and effective in attaining it (Rhodes, Spencer, Keller, Liang, \& Noam, 2006). The reality, however, according to the Youth Sports National Report Card, is that coaches are only receiving a C- for their effort, and an abysmal D for utilizing a child-centered philosophy (Citizenship Through Sports Alliance, 2005). Embracing the role of mentor, therefore, is not a priority for all youth coaches, though it should be. Perhaps 
there is a misalignment between goals and actions. Or perhaps this failure is due to a lack of awareness of how their behaviors actually impact youth players.

Martens (1996) suggests that coaching goals are expressed and achieved not only by what the coach says, but also by what the coach does. It is when the coach takes on the role of dictator that positive intentions get lost. Intentional efforts are essential to guide youth sport participants toward what truly matters for their development as related to sport. Specifically learning to follow directions and making friends should be prioritized early as coaching goals. Also, dealing with disappointment, and fostering a drive to improve oneself are skills that a coach can and should foster in sport participants.

\section{Aligning Goals and Actions}

By focusing on interpersonal interaction, and not merely the development of sport skills, the coach creates a working relationship that can guide the child over time. When the sport environment is one free of (negative) judgment, and the youth feels comfortable expressing him or herself, there is an opportunity for growth and development of the entire individual, as well as the sport environment (Gould \& Carson, 2011). If the environment is structured in a supportive and nurturing way, producing a caring climate, the youth participant may even rely on a sport coach for guidance or advice equally as they would a parent or teacher (Mageau \& Vallerand, 2003).

Unfortunately, possibility and opportunity do not translate into reality when it comes to what coaches convey to their youth sport participants. Sport coaches, especially volunteer youth coaches, often have very little awareness of their impact on youth. In a study examining perceived versus actual instructions given by a coach to athletes, Millar and colleagues (2011) found that coaches were wrong $36 \%$ of the time when assessing their actual instructional 
behaviors as compared to their perceived behaviors when interacting with athletes. Partington and Cushion (2013) examined 11 youth soccer coaches in a practice setting, and found that coaches were unable to recognize or explain the differences in types of behavior they engaged in from practice to competition. Coaches engaged in high levels of prescriptive coaching techniques, despite knowing that such a method is not best for their players. In other words, just giving orders without showing support does not benefit youth players. These researchers highlight the need to increase coach self-awareness, as well as the epistemological gap between understanding and practice.

Misalignment between coach goals and behaviors is a common thread in sport research. McCallister, Blinde, and Weiss (2000) interviewed 22 youth coaches about their coaching beliefs and behaviors. One major area of inconsistency emerged when the coaches were discussing the emphasis placed on winning. The majority of the coaches reported that their coaching philosophy tried to emphasize "playing to the best of your ability," "it's okay to lose as long as you tried your best," "having fun," and keeping the competition in perspective because "it's just a game." However, further discussions with the coaches revealed several examples of coaching behaviors contrary to those philosophies. An area of conflict sometimes surfaced between the goals of winning and having fun. Although some coaches made it clear that having fun was the priority, there was a tendency to assume that having fun was the result of winning (McCallister et al., 2000). It was also found that many coaches start out with good intentions, such as keeping competition in check and maintaining a healthy playing environment. But as competition increases, some of the youth coaches experience a lapse in their positive philosophy where a win-at-all-costs attitude would take over. 
Most coaches appear to embrace their role as a mentor, but circumstances and environmental factors can be distracting and interrupt the coach-player connection. Parents, opposing teams, personal issues, and the excitement of the game can all distract the coach from the focus on mentorship (Apache, 2004; Trudel, Côté, \& Bernard, 2013). So how do we help youth sport coaches be more intentional with their behaviors in order to remain true to their stated values and purpose? The key is to develop self-awareness through reflective activities. But traditional approaches to coach education have not proven to effectively, efficiently, and consistently develop coaches who are more intentional and self-aware. As such, a change may be needed in the coach education system, as well as a focus on more personal aspects, such as introspection and behavior change.

\section{Coach Education... What Is It and What Can It Be?}

By regularly engaging in both formal (i.e., conferences, workshops) and informal (i.e., discussions with fellow coaches, reading to learn new techniques) education opportunities, coaches are better prepared to frame their role. More specifically, coaches can maximize the depth and breadth of their role, and positively impact more athletes when they are knowledgeable and open to learning (Gould, Collins, Lauer, \& Chung, 2007). Research has shown, however, that effective coaches invest very little time in formal coach education programs. This is likely due to the inability of large scale programs to modify coaches' behaviors and philosophies in actual coaching situations (Côté, 2006). Traditional coach education is especially undesirable to youth coaches because of the high time commitment and low utility of lecture, seminar, or workshop-style educational opportunities (Lemyre et al., 2007). Youth coaches are typically volunteering their time and often have very different objectives than elite coaches (Mallett, Trudel, Lyle, \& Rynne, 2009). Therefore, opportunities for new and different 
ways to convey important knowledge to coaches would be beneficial not only for coach success, but also for the increased positive impact on the youth sport participants they are interacting with.

Formal programs are typically structured around lessons in coaching theory, sport specific skills and drills, and general safety and injury prevention. Formal coach education programs focus on exposing coaches to the knowledge and skills required to be a "competent coach" (McCullick et al., 2009, p. 323). However, coach competency is not merely a result of formal or theoretical knowledge, especially for coaches working with youth (Gilbert \& Trudel, 2001; Bell, 1997; Douge \& Hastie, 1993). The idea that experience or education does not make someone a competent coach is reinforced by the fact that expert athletes do not become expert coaches by means of having participated in sport at a high level (Abraham \& Collins, 1998). Content and pedagogical knowledge, while admittedly valuable, are not the key attributes that create a supporting and caring coach (Fry \& Gano-Overway, 2010). Without the ability to translate or transform coaching knowledge into effective coaching, what purpose does that knowledge serve? The inability to modify coaches' behaviors is a significant criticism of traditional coach education programs (Côté, 2006). Youth coaches are only partially prepared and capable to fulfill the potential of their coaching role, unless they can merge practical knowledge with a means of achieving the desired developmental outcomes of youth sport participants.

The learning process toward coach effectiveness and goal achievement. The act of learning is by definition the 'taking in of ideas'. It is the expression of what has been learned that is significantly more important in coaching (Moon, 1999). In traditional coach education, the learning experience often stops after the information is delivered (Knowles et al., 2005). 
Once coaches are seen as capable of teaching a drill or creating a play, they are considered competent. But without comparing the coach's knowledge with sport participant outcomes, it is difficult to quantify the effectiveness of any coach's efforts or success in applying that knowledge. In traditional coach education classroom settings, instructors are limited in how they can convey important information. It is only through the representation of what one has learned (i.e., behaviors) that the success (or failure) of knowledge gain can be determined. The quality or quantity of learning is therefore only then evidenced in the coach's use of the newfound knowledge, and the impact it has on sport participants.

If coaches need to learn about health and safety, listening to the protocol and understanding the necessary steps to follow will achieve the desired goal (Committee on Sports Medicine and Fitness, \& Committee on School Health, 2001). Likewise, learning to teach a skill requires understanding the steps and being able to recreate them in order to use the drill or exercise effectively (a.k.a., procedural knowledge). For other elements of sport, however, the more traditional mode of educating coaches does not work. This is because psychosocial development is complicated, so simply knowing 'what' and 'where' (i.e., declarative knowledge) is not sufficient. Coaches who understand 'how' and 'why' are much more impactful and successful in promoting a positive environment (Lemyre et al., 2007). Improving the overall experience for youth participants requires coaches to make effective coaching choices and to connect with youth, which cannot be fulfilled by merely possessing experiential, procedural, or conceptual knowledge (Anderson \& Krathwohl, 2001). Therefore, a one-size-fits all approach to coach education will inevitably leave gaps in understanding and application. 
Reflection as a learning practice. Reflection is a key technique that has been used for many years in many professions. Reflection is actually a mode of learning that has been explored at length, but has been underutilized with volunteer coaches (Gilbert \& Trudel, 2001). John Dewey was one of the first to formally examine reflection as an educational technique. The underlying tenant of Dewey's (1938) conceptualization of education is that experience plus reflection equals learning. Dewey's concept has become well-established and accepted over time (Jarvis, 2004). Reflection as a mode of learning has been used frequently in the medical field with doctors and nurses (Clarke 2006; Fowler, 2008), as well as in schools of education (Fendler, 2003; Tripp \& Rich, 2012; Valli, 1996). Experiential learning is presented as an active process, which involves doing followed by reflecting (Burnard, 1991; Lisko \& O'dell, 2010). Within this process, the control then lies with the learner, increasing the potential for change in both thought and behavior in a 'bottom up' manner (Fowler, 2008). Kolb (1984) took Dewey's idea further by defining experiential learning as not only an active transformational process, but an attempt to resolve conflict between two conflicting ideas, abilities, or intentions. Moon (2004) notes that the in-depth reflection to resolve conflict actually is an act of continued learning, deepening understanding and opening the door for further change. This idea of conflict resolution will connect further with the counseling techniques proposed in this study later in this chapter.

Gilbert and Trudel (2001) examined experiential learning specifically with six youth team sport coaches. They found that model coaches not only reflected post-experience, but they cycled through the reflective process more than once and gained valuable insights through spontaneous revelations in reflective conversation (Côté, 2006). Conversations that occurred in Gilbert \& Trudel's (2001) study were typically spontaneous and did not occur naturally for all coaches. Therefore, this study only scrapes the surface of what can be achieved through 
reflective conversation and informal/conversational learning, opening the door for much needed further inquiry. If reflection through conversation can be encouraged by peer coaches, league directors, and team managers, it may prompt change toward more model coaching values and behaviors. Such action may also provide the necessary drive for volunteer coaches to begin engaging in reflective practice.

Opportunities to share ideas and learn through experience have already been found to be more effective with volunteer coaches overall. Wiersma and Sherman (2005) revealed through focus group discussions with 25 volunteer youth coaches that coaches often struggle with behavior management and organization. Educational opportunities they were offered, however, had many barriers, in that they were too time consuming or inconsistent with their coaching needs. Discussions with other coaches were noted as the most useful form of learning, and the researchers recommended peer coach mentoring and roundtable discussions as more desirable options for growing as a coach. Gilbert and colleagues (2009) suggest incorporating coach development into pre-existing learning communities, such as youth leagues or sporting organizations. A review of prior research in coach education shows that it is not a worthwhile endeavor to require more resource investment (i.e., time and money) from youth sport coaches in the form of extensive continuing education requirements. Rather, time should be allocated in regularly scheduled league / coaching meetings for coaches to engage with other coaches about how to resolve current coaching issues. Interactions that are integrated into the coaching practice would make the educational experience more convenient, and perhaps more relatable for coaches. Reflecting on participant gains to determine next steps in the learning process would aid coaches in staying on task to goal achievement. 
By implementing a more social means of reflection, coaches will likely be more open to engaging in informal education, as it is not only beneficial for their coaching goals, but also enjoyable, seeming less like an educational experience and more like a social one (Cassidy, Jones, \& Potrac, 2008). Previous research has provided support for the desire of volunteer youth coaches to engage with other coaches in order to learn more efficiently and effectively, and put meaning to their experiences (Wiersma et al., 2005; Nelson, Cushion, \& Potrac, 2006; Gilbert \& Trudel, 2001). In this study, I strived to create a relaxed atmosphere for fellow coaches to engage in reflective conversation, transitioning this experience from purely introspective to collective. This not only increases the potential for self-growth, but the results can be far more widespread in terms of the potential impact on youth sport participants (Fowler, 2008). When the entire coaching community embraces the need for awareness and the benefits of potential change, the possibilities for positive development grow exponentially.

\section{Counseling Techniques as a Plausible Solution to Educational and Behavioral Gaps}

If awareness of behavior is key for ensuring a positive sport experience, then a lack of awareness is a related concern. As previously stated, coaches are not inherently aware of shifts that occur in their behavior and communication with sport participants, and more specifically, when or how it occurs (Kenow \& Williams, 1999; Cushion et al., 2003). This lack of awareness leaves the coach-participant relationship open to a number of issues. Not only will the participant lose out on potential positive development that quality coach-mentor interaction can provide, but there also may be more instances of negative coaching behaviors among coaches who lack awareness (Weiss \& Fretwell, 2005). Such negative behaviors may result in decreased sport enjoyment, resentment, frustration, and even burnout (Merkel, 2013; Fraser-Thomas et al., 
2005). In summary, negative coaching ultimately damages the quality of youth's experiences and limits their positive development.

A shift in mindset to ensure that children remain the primary focus in youth sport would undoubtedly be beneficial for many coaches. Preventing the focus from reverting back to the self requires a new connection to the purpose and values each coach has laid out for him or herself — one that is more altruistic in nature. In counseling - the person-centered or humanistic therapeutic approach, to be specific - the underlying principal is that for a person to "grow", they need an environment that provides them with genuineness (openness and self-disclosure), acceptance (being seen with unconditional positive regard), and empathy (being listened to and understood; Flett, Sackett, \& Camiré, 2016). This environment is precisely what youth sport should provide for children.

Person-centered focus. Within this person-centered therapeutic approach, there is a well-documented concept called congruence. Rogers (1945) conceptualized that the personality is like a triangle made up of the real self, the perceived self, and ideal self. And according to Rogers, when there is a good fit between all three components, the person has achieved congruence. This is a healthy state of being and helps people continue to progress toward selfactualization (Rogers, Lyon, \& Tausch, 2013). As such, it helps individuals align their goals and values with intentional behaviors; a technique that would be possibly beneficial for youth sport coaches.

A person-centered therapeutic approach implies the individual increases consciousness of his or her thoughts and ideas (and related actions), rather than the counselor placing interpretation on those thoughts, ideas, and actions (Rogers, 1945, 1986). 
The counselor endeavors to hold up to the client a verbal mirror which enables the latter to see himself more clearly and which at the same time indicates that he is deeply understood by a counselor who is making no evaluation of him or his attitudes (Rogers, 1945, p. 279).

Rogers coined this as non-directive interviewing. Since 1945, there have been changes and improvements, of course, but the idea of reflection as a means of educating the client and assisting them in opening up to new ideas remains the central pillar to the person-centered technique

Motivational interviewing (MI) is a similar, albeit newer, technique that aims at fostering understanding and creating an interviewer-client partnership that is conducive to change (Miller \& Rollnick, 2004). The person-centered approach holds the therapeutic relationship as central and essential to effective counseling (Kirschenbaum \& Jourdan, 2005). Through MI, the relationship can truly be equal, as the client is not controlled or directed by the interviewer. Rather, clients are assisted in discovering the most appropriate solutions to their problems through reflective conversation. In the person-centered model, the counselor is required to acknowledge pre-conceived biases and intentions for the client, and assist the client in achieving a new level of understanding and appreciation (Miller \& Rollnick, 2003). For this study, the researcher, an experienced coach and counselor, acted as the guide. However, this technique can be utilized by league directors, team managers, and peer coaches alike to improve self-awareness and provide support.

For sport coaches working with youth sport participants, the goal for the coach-athlete relationship is quite similar to the person-centered therapeutic relationship (Wright, Trudel, \& Culver, 2007). Rather than imposing expectations and goals on the child, the coach should 
listen, reflect, and embrace the purpose of sport for that child. Throughout those reflective conversations, keeping the ideal self in mind is the goal. In many cases, the perceived self may not align with the actual and ideal selves, however. This disconnect then makes achieving goal awareness a major challenge. Understanding that maintenance and monitoring are required is key. Engaging only in intentional behaviors that support the aforementioned values laid out by the coach will help to limit the shifts in alignment.

Unfortunately, coach education and the ways in which coaches are encouraged to act do not necessarily support the objective of increased self-awareness. Traditional education opportunities for coaches are founded in cognitive-behavioral paradigm, not person-centered (Smith et al., 1979; Smoll \& Smith, 2006). Why might this be? Perhaps because the world of academia tends to follow the trend of the medical model; identify and fix the problem at hand. While fixing the problem may be useful in the short term, it does not solve the overarching issue of the lack of self-awareness. Without providing coaches, especially those whose primary goal is positive impact on youth sport participants, with the proper tools to handle the challenge of misaligned values and behaviors, behavior change was virtually impossible.

In cognitive-behavioral therapy (CBT), the individual is required to be an active participant in the problem-solving process to test and challenge the validity of maladaptive cognitions and to modify maladaptive behavioral patterns (Hofmann, Asnaani, Vonk, Sawyer, \& Fang, 2012). Again, while this technique is useful, especially for severe psychological disorders, the CBT model is lacking the human element. As previously stated, the coach-participant relationship is the central hub in the wheel of positive sport experience for kids, providing further evidence of the need for coach education options that support the role and purpose of youth sport coaches. 


\section{Counseling Techniques as a Link to Behavior Change}

One such example of alternative educational techniques is motivational interviewing. The fundamental purpose of MI is to create an atmosphere of constructive conversation about behavior change, in which the counselor uses empathic listening initially to understand the client's perspective and minimize resistance (Rollnick \& Miller, 1995). Acknowledging faults and reframing purpose through reflective conversation can allow for positive (psychological and behavioral) change (Prochaska, Norcross, \& DiClemente, 1995). Youth sport coaches would benefit greatly from such techniques as a form of coach education / support, in order to improve their own level of self-awareness. Once learned, the benefits may even trickle down to help coaches communicate more effectively with their players. Such counseling techniques also open the door to being critical, which is required in order to initiate change (Tripp \& Rich, 2012). However, the coach must be critical of him or herself, rather than have criticism imposed upon him or her. In this dissertation, MI techniques were used in interviews with coaches in order to encourage constructive conversation.

Motivational interviewing (MI) is often used to initiate behavior change in those with addictive disorders, health issues, or anyone else who may benefit from behavioral alterations (Miller \& Rollnick, 2012). The goal of the clinician in conducting an MI session is to instill hope and assist the client in exploring barriers to change, while handing over the responsibility for change to the individual (DiClemente \& Velasquez, 2002). The clinician does not give the client answers, but rather goes along on the journey supporting the client to find the necessary solution(s). Overall, MI has been found to be effective for a variety of individuals and varying levels of readiness for change (Lundahl, Kunz, Brownell, Tollefson, \& Burke, 2010). One pertinent study is by Miller and Mount (2001), in which they organized a training for 22 
counselors to assist them in learning motivational interview techniques. The problem at hand was addressing clients' behavioral issues, and in response, developing an intervention that would increase motivation for change, provide the appropriate skills for the desired behavior, and support ongoing change. For each counselor, the researchers tracked the total reflections per minute, the ratio of reflections to questions, and MI consistent and inconsistent responses. What they found was that counselors believed they were engaging in appropriate responses more often than the observations showed, revealing a misalignment in actual versus perceived behaviors. Increased practice with the MI skills increased the frequency and ease of use. Reducing or eliminating preexisting counseling behaviors that were found to be less effective, however, presented as a challenge for participants. Suggestions for improving this technique included repeated interactions and reflections utilizing MI techniques (Miller \& Mount, 2001). In this study, repeated interactions and reflections is precisely what was used with coaches. Repeated use of reflective techniques may increase understanding, assist in further learning, and lend itself to behavior change where needed.

\section{Reflection and Self-Awareness}

The history and progress of reflective practice. In recent years, reflective practice has become a prominent instrument in various forms of professional education, such as healthcare and teaching. Within different disciplines and intellectual traditions, what is understood by the term 'reflective practice' varies considerably (Finlay \& Gough, 2008). Reflective practice can be understood as the process of learning through and from experience in order to gain new insights of the self and one's choices and behaviors (Boud, Keogh, \& Walker, 1985; Boyd \& Fales, 1983; Mezirow, 1981; Jarvis, 1992). Reflective practice often involves examining assumptions of everyday thoughts and behaviors, and acknowledging that those preconceived 
ideas may be incomplete or incorrect. Rigid assumptions can inhibit new introspections, limiting learning and growth (Larrivee, 2000). Reflective practice also tends to involve the individual practitioner being self-aware while critically evaluating his or her responses to practical experiences. The goal of the reflective practitioner is to recall experiences and reprocess them critically in order to gain new understandings and potentially improve future practice (Finlay \& Gough, 2008).

Dewey (1933) was among the first to identify reflection as a specialized mode of thinking, with the aim of prompting purposeful inquiry and problem resolution. In doing so, reflection moves people away from routine thinking and behaviors, which are guided by tradition or external authority, and moves them towards reflective action, which is focused on careful, critical consideration of implicit knowledge (Finlay \& Gough, 2008). Schön (1987) has suggested that professional education undervalues knowledge in-action. In his earlier seminal work, Schön (1983) identified ways in which professionals could become aware of their implicit knowledge and learn from their experience. Often, intellectually scientific and rational knowledge forms are put on a pedestal, which allows the spotlight to remain on what may only be marginally relevant to practical application of that knowledge, limiting a complete understanding of human phenomena (van Manen, 1995). For Schön and those proceeding him, reflection guides 'professional-artistry', a concept that contrasts the 'technical-rationality' demanded by the formal, academic way of thinking, whereby problems are only solvable through the rigorous application of science (Finlay \& Gough, 2008).

As society has progressed, reflective capacity has become regarded by many as an essential characteristic for professional competence (Mann et al., 2009). As a result, reflective practice has been widely adopted by education, health, and social care professions over the past 
20 years (Kinsella, 2010). Professional educators now advocate reflective practice by adopting explicit strategies for helping new professionals experience the potential benefits of reflective practice through specialized preparation (Russell, 2005).

Reflection can be a useful learning strategy, helping students to make the necessary connections between existing knowledge and new skills. Making such connections may also apply to a professional role that has various aspects that must be integrated and balanced, much like coaching (Mann et al., 2009). Expertise is a combination of professional knowledge (i.e., education) and practical experience (Knowles, Gilbourne, Borrie, \& Neville, 2001). Reflection creates a bridge between the application of professional knowledge and craft knowledge achieved through practice. The bridge creates allows the knowledge to become a usable commodity, rather than just words on a page. Schön (1983) notes there is an art to the use of such knowledge, especially in action. For teachers, it is thought that unless they develop the practice of critical reflection, they "stay trapped in unexamined judgments, interpretations, assumptions, and expectations" (Larrivee, 2000, p.293). By fusing personal beliefs and values into a professional identity, the teacher can become truly reflective, opening new doors for insight and change. Coaches have similar intentions and expectations as teachers, and therefore would equally benefit from increased reflective practice as a part of their coaching routine.

Ghaye and colleagues (2008) present a theory in which developing an appreciative 'gaze' is the primary objective. Reframing lived experience, building practical wisdom, and achieving forward momentum are the goals. By actively engaging in reflection, professionals can make a change in direction from one way of thinking and practicing to another (Ghaye et al., 2008). Educators assert that reflective practice helps to acknowledge the need for students to act and to think professionally as an integral part of learning throughout their courses of study, 
connecting theory and practice from the outset. This is likely the reason why activities to promote reflection are now being incorporated into undergraduate, postgraduate and continuing education, and across a variety of health and social professions (Mann et al., 2009).

For mentors in a variety of contexts, reflective practice helps to widen perspective, so that they can look appreciatively at their work, making them better able to make wise and ethical decisions about how to support their mentees (Ghaye \& Lillyman, 2008). By establishing the crucial links between emotions, thoughts, and actions, sport coaches are better able to embrace a shift in mindset as self-awareness increases, and allow that shift to impact behaviors and interactions (Dixon, Lee, \& Ghaye, 2013). Reflective practice, therefore, can and should be taught. Explicit instruction has been found to be far more productive than merely advocating reflective practice and assuming that individuals will understand how reflective practice differs profoundly from our everyday sense of reflection (Russell, 2005).

For experiential learning, which fosters meaning and increases motivation to learn, the reflective process is a necessary aspect to engage the learner (Kolb, 2014). For teachers, the goal of reflection is to break away from unexamined judgments, interpretations, assumptions, and expectations and engage in critical thinking to promote ongoing discovery (Larivee, 2000). In the medical profession, reflective practice to improve self-awareness enables physicians to practice medicine more efficiently, to manage their personal stress more effectively, and helps doctors and nurses find deeper meaning in their work (Levine, Kern, \& Wright, 2008). Failing to look inward may cause professional competence to suffer. Relying solely on inferred knowledge may cause professionals to ignore information that does not fit into a pre-existing framework (Schön, 1983). By making the framework more engaging and dynamic, the application of knowledge gained in new contexts becomes more meaningful (Boud et al., 1985). For youth 
coaches, understanding that information beyond the score and the plays is more important to the eventual outcome can increase positive developmental outcomes for youth sport participants and help coaches fulfill the role of mentor more meaningfully.

\section{The Reflective Process... What Works and What Works Better}

Journal writing. Reflection is clearly useful, but how do professionals best achieve a purposeful, reflective experience? Writing is a very common means of engaging in reflection. In previous studies with medical students, writing was found to promote elevated awareness and provide a level of catharsis (Levine et al., 2008). These studies, however, have focused more on the content of participants' writing and less on the active process of reflective writing (Bolton, 2010; Scannell, 2002; Charon, 2001). Though many participants in such studies report a feeling of release by writing, only small numbers of participants report a significant increase in selfawareness or motivation to improve behaviors. Therefore, it may be gleaned that the process of writing is too passive to promote lasting changes in thought or action.

Reflective journal writing may include other challenges as well. Ethical issues are a concern, as documenting personal information that concerns others may lead to a breach of confidentiality (Charon, 2001). Also, apprehensions regarding the implicit evaluation of writing may decrease the effectiveness of the reflective exercise (Ghaye, 2007). Finally, by feeling constrained by the instrument of writing, reflection may occur without learning, making it less impactful. Over-intellectualizing due to a fear of evaluation, or "recipe following" in order to adhere to the reflective process may be argument enough to make writing a less-than-ideal mode of reflective practice (Mann et al., 2009).

Video review. Video reflection has been used in other professions as a method of learning, as well as increasing understanding and self- awareness. By seeing themselves on 
video, professionals are able to identify, process, and make changes to their receptive, informative, and relational skills (Fukkink, Trienekens, \& Kramer, 2011). In the medical profession, use of video for reflection has been found to improve communication skills and deepen the meaning of supervisor feedback (Roter et al., 2004). In education, video aids have been used not only in the in-depth study of behavior, but also in helping to modify it.

Previous researchers have identified video as a powerful tool for bringing the complexities of the environment into focus and helping professionals make a more meaningful connection between existing knowledge and practice (Whitehead \& Fitzgerald, 2007; Perry \& Talley, 2001; Copeland \& Decker, 1996). Video provides immediate feedback and gives a more realistic picture of skills, behaviors, and interactions (Fukkink et al., 2011). Tripp and Rich (2012) studied seven teachers from various educational settings. They outlined teaching goals, video recorded live teaching sessions, then reviewed the videos while following a reflection guide. The guide encouraged citing moments when the teacher did or did not meet listed goals. Discussions were then held in a casual setting with peer teachers, which concluded with refining current goals and setting new ones when appropriate. The researchers conducted repeated interviews after the analysis of video clips which revealed several relevant findings. First, teachers said they were more likely to change their behavior because they were able to see the need for change with their own eyes. Second, the prompts for behavior change were more apparent both individually and within the group after video reflection occurred. Finally, the vivid images, the focused dialogue, and the acceptance of accountability provided valuable proof that behavior change was necessary and would be impactful in relation to goal achievement (Tripp \& Rich, 2012). 
The findings of Tripp and Rich's 2012 work are especially encouraging as they show the importance of combining video reflection with a collaborative discussion. Rosaen and colleagues (2008) also used video as a means to facilitate reflection, but paired it with written exercises instead of conversation. They found that video helped participants make specific behavioral observations, but written exercises did not. Teachers in this study also paid more attention to the children, whereas they were more self-focused in the writing-only condition. The fact that teachers rated their reflections more accurate and more useful with the video condition speaks to the applicability of this updated technique.

Time and cost are noted as challenges to using video, however, those issues are decreasing steadily as technology is becoming increasingly more accessible and affordable. Therefore, the pros appear to outweigh the cons. Video as a means of reflective practice can cut back on the load to working memory, which may increase the user's 'knowledge of understanding" (Abraham \& Collins, 1998). By analyzing actual occurrences, both verbal and non-verbal behaviors can be assessed from the professional's viewpoint; journals do not accomplish that (Carson, 2008). The concept of analyzing oneself also ties back to the Rogerian notion of aligning elements of the self, making the use of video ideal for the proposed intervention.

\section{Reflective Practice in Coaching}

Much like classroom teachers and medical doctors, sport coaches are regularly immersed in complex situations in which awareness and quick decision making are required (Levine et al., 2008; Loughran, 2002). However, this can be especially challenging when personal feelings and biases are involved. In essence, a lack of self-awareness leads to a failure to provide the appropriate care or instruction required for the situation at hand (Novack et al., 1997). This also 
rings true for sport coaches. Therefore, increasing self-awareness would be especially useful for this group.

Depending on previous experience, as well as underlying core beliefs, coaching behaviors may look vastly different from one coach to the next. And even within the coach, there may be significant variance between perceived and actual behaviors (Kenow \& Williams, 1999). Gilbert and Trudel (2004) found that coaches' reported belief systems and actions during training or competition often do not align. Understanding which coaching behaviors lead to more independent, motivated, and healthy youth sport participants requires much more insight to ensure the promotion of a positive and supportive environment (Camiré, Trudel, \& Forneris, 2014; Hollembeak \& Amorose, 2005; Stein, Bloom, \& Sabiston, 2012). In order to create an environment that supports positive youth development, increased self-awareness of the coach's objectives and methods of communication is required (Allen \& Hodge, 2006; Smith, Smoll, \& Cummings, 2007). With that in mind, it must be noted that self-awareness cannot be improved as effectively via traditional coach education as compared to more dynamic and engaging strategies. Therefore, new ideas ought to be explored that are effective and efficient for youth coaches.

The process of reflection has long been used with athletes as a means of performance enhancement and to provoke critical thinking about their performance (Ives, Straub, \& Shelley, 2002; Gilbert \& Trudel, 2004). Through reflective practice, coaches are able to point out both positive and negative performance examples, have players give insight and thought to what they are watching, and hopefully, make an impact on the thought processes and behaviors moving forward. Therefore, use of video for reflection and response should not be foreign. And since 
reflective practices are best utilized in a flexible setting, they are an ideal fit for youth sport coaches (Gilbert \& Trudel, 2001).

In coach education studies that focus on reflective practices, many use journal writing as the primary reflective activity (Spalding, Wilson, \& Mewborn, 2002; Lew \& Schmidt, 2011). Others emphasize more "traditional" coach education as a means of reflection, such as lecture and discussion-type settings (Cushion et al. 2003; Nelson \& Cushion, 2006). These methods, however, have been found to be less attractive to volunteer youth sport coaches (Lemyre, et al., 2007). Coach education initiatives have also been found to be minimally impactful on behavior change when they do not include a collaborative element (Hubbs \& Brand, 2005). Carson (2008) used video as a means of reflective practice with inexperienced sport coaches. The use of video added a collaborative dynamic to the reflective process, increasing the effectiveness of the practice versus being lectured at or other passive learning techniques. By reducing the reliance on memory, novice coaches were better able to break down practice and competition sessions and analyze actual occurrences. For this study, however, the most common areas of critique were communication, timing, and confidence when utilizing reflective techniques to improve self-awareness in sport coaches (Carson, 2008). These limitations signal the need for reflective practices to be learned and used frequently in order to improve proficiency and value.

Experience alone does not lead to learning. Rather, learning outcomes stem from reflecting on the meaning behind the experiences, thoughts, emotions, and actions related to events. Coming to appreciate that there are many ways to view a single problem will help coaches to avoid assumptions and misconceptions, and examine their experiences with purpose (Loughran, 2002). 


\section{Behavior Change is Possible with Increased Self-Awareness}

Self-awareness is the key component for facilitating behavior change in coaches by recognizing what change is necessary and why. According to Rogers (1945) Humanistic Model, self-awareness is enhanced not by means of the individual receiving information about how others perceive him or her, but through the exploration of his or her own perceptions and experiences. As was laid out earlier in this paper, traditional coach education does not go far enough with this exploration. With the traditional coach educational model, there has been a failure to demonstrate a change in coaching behaviors (Gilbert et al., 2009; Conroy \& Coatsworth, 2006). Without evidence for change, the knowledge that has been gained is significantly less valuable.

Behavior change is an established topic in other areas of study. Specifically, health psychology provides insight into behavior change models and interventions. In a meta-analysis of health psychology behavior change literature by Schwarzer (2008), the success of behavior change is directly linked to intention. It is when there is an "intention-behavior gap" that people do not achieve their desired goals. Based on this finding, we can assume that for efficient and effective behavior change, both motivation and intention should be considered in order to have a chance at success. The primary message is that for goals and good intentions to be translated into consistent action, constant renewed attention is required (Schwarzer, 2008).

Increased awareness has been shown to be effective in initiating and maintaining changes in behavior (Church \& Bracken, 1997). Motivational Interviewing techniques lead to increased change talk and acknowledgment of discrepancies, which has been shown to lead to the best change outcomes (Apodaca \& Longabaugh, 2009). For example, Poirier and colleagues (2004) found that in a group of 42 first-year medical students participating in a health behavior change 
educational course, MI-based interactions with instructors increased their confidence in providing counseling to patients. With 33 organizational leaders, Higgs \& Rowland (2010) uncovered through in-depth interview that leaders tasked with enacting change felt more competent and confident when self-awareness was high and behaviors were intentional. Perhaps more importantly, participants acknowledged that lack of change, or feeling 'stuck', was the result of poor self-awareness, which trickled down to decreased self-confidence and selfefficacy. In another health psychology article, Hinyard and Kreuter (2006) examined human interaction (i.e., discussion) as a primary intervention for behavior change. This intervention style is supported by empirical evidence that the brain processes human interaction differently than tacit learning. There is increased understanding and overall influence with discussion, which is likely the reason for increases in positive behavior changes. These scholars have found that narrative communication, as in telling a story about the situation at hand and then asking related questions, was a reliable and effective intervention to prompt behavior change.

In general, cueing is an important environmental element in behavior change. In the presence of impactful cues, awareness is increased, as is the urgency of change. In their work with smoking cessation patients, McBride, Emmons and Lipkus (2003) assert that a cueing event is considered a "teachable moment" in that it a) increases perceptions of risk and positive or negative outcome expectations, b) produces a strong emotional response, and c) causes a redefinition of an individual's self-concept or social role. For coaches, if the goal of positive impact on players is stated, and the risk of not achieving that goal is realized, the resulting frustration or disappointment may be enough to prompt changes in behavior.

As mentioned earlier, coaches often have limited awareness of their actual behaviors (Smith \& Smoll, 1996; Cushion et al., 2003). Specifically, there is often significant variance 
between perceived and actual coaching behaviors (Kenow \& Williams, 1999). Staying true to coaching goals, despite inevitable distractions, can be made possible through increased selfawareness. By reflecting on coaching goals at regular intervals keeping priorities at the forefront were easier. Receiving feedback via video and discussion, variance is likely to decrease even further.

\section{Purpose}

This dissertation proposes that the process of change should be coach-specific and goal oriented. By providing alternative means of education through interview- and video-based reflection, the dynamic of learning changes. The literature has revealed gaps in coach education, which suggest that more informal and experiential opportunities would be beneficial, but are often not available. Despite there being a disconnect between coaching goals and actual behaviors, there has been little study of the best way to assist volunteer youth coaches in changing behavior to improve goal achievement. With this in mind, there is a need for a viable, sustainable way for youth coaches to improve awareness and better utilize newly gained information. A tailored approach to reflection through the use of video and counseling-based reflective conversation may be ideal to improve insight and understanding. Such an improvement is awareness should enhance motivation to change behaviors (Lustria et al., 2013). This directly addresses the gap in the types of education volunteer youth coaches are receiving, which do not align with their coaching goals. This study can serve as a template for new practices that may be explored further to benefit coaches and youth sport participants alike.

\section{Hypotheses}

The three research questions and related sub-questions in this study rely on qualitative and qualitative information. And while not all of the research question warrant hypotheses, 
several that include quantitative data do. Each hypothesis described below is related to its corresponding research question and null hypothesis are provided with each (alternative) hypothesis.

Research question 2f. Specifically, for player perceptions, do perceptions of positive rapport and caring coaching improve more over the season for teams who participate in the study than for other teams in the league?

Hypothesis: For preseason and postseason player surveys, including the CCS and CARTQ, responses from players on intervention coach teams will improve more than those on control group teams.

Research question 3. Do coaches believe that the reflection-based intervention, made them willing to self-report fault in their coaching behaviors? 3a. Do coaches believe the intervention was supportive? 3b. Do coaches believe the intervention was useful? 3c. Do coaches believe the intervention was free from judgment?

Hypothesis: Coaches will positively endorse the usefulness and supportiveness of the intervention in their completion of the Coach Satisfaction Survey. 


\section{Chapter III}

\section{Method}

\section{Research Design}

Data collection was conducted in two ways: through player surveys at the beginning and end of the sport season, and four interviews with the coaches conducted throughout the season. Players on the coaches' teams, ages 7-11, will complete surveys in order to assess behavior change in the coaches participating in this study. Surveys will also be completed by a control group of players whose coaches are not participating in the study. Surveys were used to provide quantitative information about coaches' behaviors and goal achievement. Pre-season survey results were shared with coaches at the first interview. Post-season survey results were shared during the final interview.

Interviews with coaches were used both to increase purposeful behavior toward the achievement of coaching goals, as well as to assess and potentially improve the coaches' selfawareness. Video was recorded while the coaches are actively coaching, both in practice and in competition. Three of the best clips averaging one minute in length were then sent to coaches for review. The videos will then be discussed at the beginning of interviews two and three. Each interview with coaches were semi-structured, and questions were based on Motivational Interviewing (MI) technique (Miller \& Rollnick, 2004). Motivational Interviewing allows for the participant, rather than the researcher, to lead the discussion and to point out flaws. This will open the door for coaches to acknowledge problematic behaviors and move toward change with less resistance (Miller \& Rollnick, 2012). The influence of the players' perspective, as shared through the survey results, may increase the likelihood of coaches to be aware of and willing to change negative coaching behaviors. 
A sequential exploratory strategy (Creswell, 2013) were used to combine qualitative data, in the form of coach interviews, with supportive quantitative player survey data, over one entire sport season. The primary goal of this strategy is to explore a new phenomenon or an idea in its early stages. By analyzing the qualitative data first, themes were established. Quantitative data will then help in interpreting the qualitative findings further. According to Morgan (1998), this strategy will allow qualitative findings to be more generalizable to different samples. Each phase will build to reveal connections between coaching behaviors and self-awareness, or lack thereof (see Figure 2). Behavior change due to increased self-awareness is the goal of the reflection-based intervention (Smith, Smoll, \& Curtis, 1979).

Figure 2. Sequential Exploratory Strategy

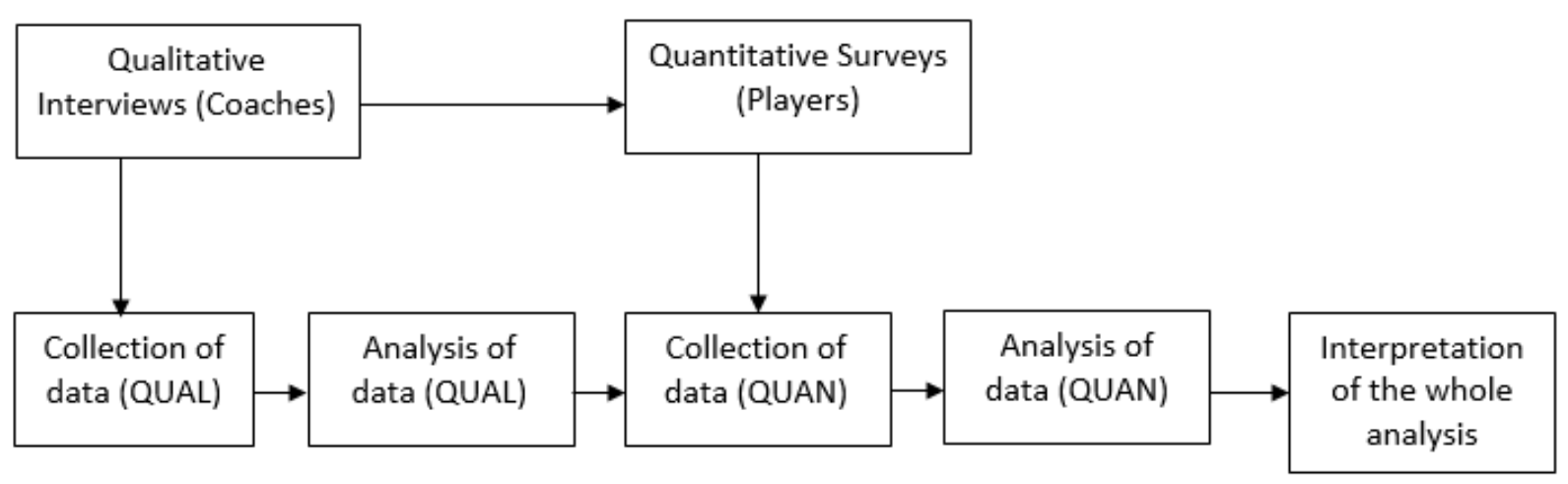

Figure 2. A sequential exploratory strategy for data collection and analysis. Adapted from Creswell, W.J. (2003). Research design: qualitative and quantitative, and mixed approaches. Thousand Oaks, CA: Sage.

Confidentiality for participants were assured to the best of the researcher's ability. Since some interaction will occur in a public setting, however, complete privacy cannot be assured. While this risk will likely not put participants in harm's way, the risk was clearly stated on 
consent forms signed by each coach when they agree to participate. It will also be reiterated at the start of the first interview.

\section{Participants}

Coaches. Seven volunteer youth coaches were selected from two youth basketball leagues in a mid-Atlantic state. One league consists of all-male players, and the other consists of all-female players. Five of the coaches completed the study; as one dropped out after the first interview, and the other became unreachable. A small sample size in this study will allow the researcher to pay closer attention to the respondents and will enhance the quality of the in-depth inquiry afforded by repeated interview. With an idiographic objective, the suggested sample guidelines are 3-25 participants for a single study (Crouch \& McKenzie, 2006).

As rapport builds, the dynamic qualities that exist for coaches working with youth was explored. Interviews are phenomenological in nature, and thus are aimed at understanding each coaches' experience (Creswell, 1998; Creswell, Hanson, \& Plano, 2007; Polkinghorne, 1989; van Manen, 1990). Few studies with youth coaches have implemented repeated interview as the primary source of data. Those that did, however, completed their studies with a sample size of six (Falcão, Bloom, \& Gilbert, 2012; Smith \& Cushion, 2006; Weiss \& Fretwell, 2013). Many more studies have been completed using a single or multi case study approach with one to six coaches (Gilbert \& Trudel, 1999, 2001, 2004; Groom \& Cushion, 2004; Holt, Tink, Mandigo, \& Fox, 2008; Nelson \& Cushion, 2006). For the current study, however, a case study approach would not allow for a complete picture of the coach experience working with youth.

Exclusion criteria. Coaches with over six years of coaching experience were excluded, as they have the potential to already be considered a model coach based on Gilbert and Trudel's (2001) findings. Model coaches would likely already be engaging in reflective practices and 
exhibit less fluctuation in self-awareness as a result of this study's intervention; and very experienced coaches might be less open to reflective practice. (In future studies, if this method of coach education is effective, a sample that is more generalizable should be studied.) Coaches who reported having less than one season of coaching experience will also be excluded, as basic coaching responsibilities may overwhelm participants' potential to develop skills like selfawareness. Stated simply, new coaches may be too busy treading water to worry about swimming. Finally, coaches with fewer than one season of coaching or playing experience in the sport, either recreationally or competitively, were excluded, as they may not know the rules well enough to focus solely on positive coaching behaviors.

Coach demographics. The participant youth basketball coaches were 38.4 years of age on average ( $S D=2.07)$, with 4.6 years of coaching experience $(S D=1.14)$. Two coaches had formal education or certification in coaching through youth leagues that they have previously coached in, primarily consisting of little league seminars. All participant coaches reported being Caucasian, and all coaches have or currently coach other sports than basketball.

Sport experience varied for participant coaches, with a range of 4-9 years of involvement as a player. All coaches reported having at least one year of basketball playing experience at the recreational level and at the high school level, with a maximum of nine years. Zero participant coaches reported playing experience at the collegiate level or above. Minimum play experience is considered a necessary developmental activity before engaging in higher levels of coach education (Erikson, Côté, \& Fraser-Thomas, 2007). All coaches will have volunteered to participate in the video analysis and interview processes for this study. Coaches were informed that their participation or decision not to participate would have no impact on their coaching status for each of the respective leagues. 
Table 2

Demographic Information for Coaches

\begin{tabular}{lllll}
\hline $\begin{array}{l}\text { Coach's Pseudo- } \\
\text { Name }\end{array}$ & Gender & Age & $\begin{array}{l}\text { Years of } \\
\text { Coaching } \\
\text { Experience }\end{array}$ & $\begin{array}{l}\text { Coaching } \\
\text { Education }\end{array}$ \\
\hline Coach A & Female & 38 & 5 & No \\
Coach B & Male & 37 & 3 & No \\
Coach C & Male & 38 & 4 & Yes \\
Coach D & Female & 37 & 6 & Yes \\
Coach E & Male & 42 & 5 & No \\
\hline
\end{tabular}

Players. Youth players of both non-participant coaches and participant coaches were asked to participate in this study. A sample of 53 youth players from the five intervention teams and 55 youth players from teams with coaches who did not participate in the interview were included. A total of 108 youth agreed to participate, and a total of 101 players completed both surveys at pre- and post-season. Players were permitted to participate by a parent or guardian.

Youth participants were 7-10 years of age, with 1-5 years of basketball playing experience. Children still in the sampling phase of sport were the focus, therefore, any players outside of the age or experience range were excluded (Côté, Yardley, Hay, Sedgwick, \& Baker, 1999; Baker, Côté, \& Abernethy, 2003). Prior to specialization, deliberate play is the primary activity, which depends to a large extent on the dynamic set by the coach (Côté \& Hay, 2002). This age range of youth is also likely to experience the most positive developmental gains related to coaching behavior, in accordance with Bronfenbrenner's (1999) Bioecological Model. Côté and colleagues (2002) also outline in the Developmental Model of Sport Participation (DSMP) that the sampling years are essential building blocks for all sport experiences to follow. The support and encouragement of coaches and a key determinant for future participation, performance, and enjoyment (Fraser-Thomas et al., 2005). 


\section{Measures}

Interview guide. Four semi-structured interview guides were developed based on Miles, Huberman and Saldana's (2013) key decision factors. Specifically, understanding the human dynamic in a social setting, collecting rich description, and defining context were extremely important factors in this study. Several previous studies (i.e., Camiré et al., 2014; Vella, Oades, \& Crowe, 2011; Gilbert \& Trudel, 2004) also influenced the guide in that they each used a similar open ended question structure with items divided by category. Questions are intended to build upon one another and establish rapport with the researcher in the process. Motivational Interviewing (MI) techniques were used to allow the coaches to guide the discussion and ask clarifying questions when necessary. MI focuses on exploring and resolving ambivalence and centers on motivational processes within the individual that facilitate change (Miller \& Rollnick, 2012).

Piloting. The scripts were pilot tested with one of the key informants to verify the length of the interview process and the relevance of the questions. Questions were also reviewed by university colleagues, experienced in interview techniques, to reduce bias (Miles et al., 2013). The scripts were reviewed by one league director for understanding and accuracy. The initial and follow-up phase of the study were pilot tested with two coaches who fit the criteria for participation. Each was interviewed on two occasions and was sent one round of video clips. One clip was from a live practice and the other was from a competition. As a result of the pilot, minor changes were made to the interview questions to increase understanding and accuracy. No items were eliminated.

Bracketing. In order to limit the researcher influence on interview questions and responses, bracketing was performed in the form of memos. The researcher will note 
observational comments throughout data collection and analysis as a means of examining and reflecting upon the researcher's engagement with the data (Cutcliffe, 2003)

Application of counseling strategies in interviewing. Table 3 shows how counselingbased techniques informed interview questions, along with the rationale for such questions (i.e., why that question and counseling strategy were included in the interview guide). For example, by asking coaches to outline their goals, that is the first step to awareness. By then asking coaches to discuss barriers to goal achievement, there will likely be some resistance initially. Responses may be brief and have little purpose or depth. By using MI strategy to help the coach engage in deeper reflection on the true nature of barriers, as well as the cause of those barriers, solutions will gradually present themselves. This will allow for coaches to consider change as an option to overcome barriers.

Table 3

Interview questions to be used as intervention, including question structure, purpose and relationship to counseling technique, and rationale

\begin{tabular}{lll}
\hline Interview Question & Purpose & Rationale
\end{tabular}

\begin{tabular}{ll}
\hline $\begin{array}{l}\text { Of your top } 3 \text { goals listed, have } \\
\text { you been successful in reaching } \\
\text { any of them (or are you getting } \\
\text { close)? If yes, which ones and } \\
\text { how? }\end{array}$ & $\begin{array}{l}\text { Formalize goals and estab } \\
\text { purpose }\end{array}$ \\
$\begin{array}{l}\text { You mentioned that } \\
\text { might get in } \quad \text { Open question + } \\
\text { microskill (MI) }\end{array}$ & $\begin{array}{l}\text { Acknowledging barriers; } \\
\text { problem solving }\end{array}$ \\
$\begin{array}{l}\text { the way of you reaching your } \\
\text { combating that disruption? }\end{array}$ & \\
$\begin{array}{l}\text { Have you used your previously } \\
\text { stated "helpful" behaviors (from }\end{array}$ & \\
$\begin{array}{l}\text { Interview \#1, question 5)? } \\
\end{array}$ &
\end{tabular}




\begin{tabular}{lll}
\hline Interview Question & Purpose & Rationale
\end{tabular}

What new behaviors have you tried since we spoke last to help

you achieve (or get closer to

achieving) those goals?

What behaviors have you been trying to avoid that hinder you reaching your goals since we last spoke?

What did you find useful about the videos? Why?

Have you made any changes (internal or external) since watching the videos? If yes, please explain.

For changes you have made or intend to make, why are those changes important to you?
Awareness assessment Reflection on self

Open question; counseling microskill

Acknowledging barriers

Open question; counseling microskill

Finding solutions to overcoming barriers Awareness assessment Relate reflection to change
Open question; counseling microskill
Reason behind change increases meaning and understanding

Initial interview guide. The initial interview guide consisted of 11 open-ended questions, designed to elicit subjective, conversational responses (see Appendix A). The guide included four sections: (a) background and introduction; (b) beliefs and roles (i.e., coaching philosophy); (c) self-awareness of coaching behaviors and communication techniques; and (d) influence of coaches on youth. The interview process was relatively flexible and probing were frequently employed to allow participants to clarify certain ideas and to explain in further detail certain themes. Open ended questions such as, "What do you feel your primary responsibilities are as a youth coach?" and "What behaviors do you engage in that help you achieve (or get closer to achieving) your coaching goals?" were asked and discussed. At the conclusion of the 
interview, coaches were informed of how video recording, sharing, and review will proceed; including when and how they would receive clips, as well as what to do upon receipt.

Second interview. The guide for the second interview consisted of 13 open-ended questions, designed to elicit subjective, conversational responses (see Appendix B). The guide included four sections: (a) review from previous interview; (b) intention (i.e., coaching goals); (c) behavior; and (d) reflection (in reference to video clips). Open ended questions, such as "How did you feel while watching the video of you coaching?", and "What thoughts do you have about how you handled that situation?" were asked and discussed. The second interview assessed if coaches engaged in reflection and are projected to last 40 minutes on average.

Third interview. The third interview guide consisted of 12 open-ended questions, designed to elicit subjective, conversational responses (see Appendix C). The guide included four sections: (a) review from previous interviews; (b) intention (i.e., coaching goals); (c) behavior; (d) reflection (in reference to video); and (e) behavior change. Open ended questions, such as "What are you doing differently now, if anything, then you would have done at the start of the season?", and "What are the primary factors that have prompted you to think differently about your coaching? How have those thoughts impacted your coaching behaviors in practice? Games?" were asked and discussed.

Fourth interview. The fourth and final interview guide also consisted of 12 open-ended questions, designed to elicit subjective, conversational responses (see Appendix C). The guide included four sections: (a) review from previous interviews; (b) intention (i.e., coaching goals); (c) behavior; (d) reflection (in reference to video); and (e) behavior change. Open ended questions, such as "What are you doing differently now, if anything, then you would have done at the start of the season?", and "What are the primary factors that have prompted you to think 
differently about your coaching? How have those thoughts impacted your coaching behaviors in practice? Games?" were asked and discussed. The final follow-up interview assessed if coaches engaged in reflection and/or made behavioral changes by using MI-based questions and is projected to last 60 minutes.

Player surveys. Youth athlete members of the coach participants' teams completed surveys throughout the first two weeks of the season. A control group of youth from nonparticipant coach teams completed the surveys as well. They then repeated those surveys during the final week of the season. Confidentiality were ensured, though the overall findings were reported to the coaches as well as the league directors. Collecting survey data from the players allowed for assessment of their coach relationship development through sport participation and their perception of supportiveness from their coach (Gould et al., 2012). This allowed for comparison between the coaches' perceptions and the players' perceptions early and late in the sport season.

Coach-Athlete Relationship Questionnaire (CART-Q). The Coach-Athlete Relationship Questionnaire (CART-Q) is a brief, simple, self-report instrument that measures affective, cognitive, and behavioral interpersonal aspects in the coach-athlete relationship: closeness, commitment, and complementarity. The CART-Q was used to assess affective, cognitive and behavioral aspects of the coach - athlete relationship (Jowett \& Ntoumanis, 2004). The 7-point response scale were adopted for all 11 items. The scale ranges from 1 (Not-at-all), to 7 (Extremely). Cronbach's alpha coefficients were $\alpha=.82$ for Commitment, $\alpha=.87$ for Closeness, and $\alpha=.88$ for Complementarity. The alpha for the higher-order Coach-Athlete Relationship scale was .93 . All coefficients exceeded the minimum level of $\alpha=.70$ recommended by 
Nunnally and Bernstein (1994). Participants were encouraged to think about what their sport experiences under their current coach is typically like when responding (see Appendix D).

Caring Climate Scale (CCS). The Caring Climate Scale (CCS) was administered to assess the extent to which the athletes perceive the environment that their coach provides were inviting and supportive. The CCS is a 13-item measure that assesses individuals' perceptions of caring within a specific context (Newton et al., 2007). Newton and colleagues define the caring climate as the extent to which individuals perceive a particular setting to be interpersonally inviting, safe, supportive, and able to provide the experience of being valued and respected.

The scale focuses on how supportive and receptive the group members and leaders are within the sport context and how much the players feel valued and accepted by their coaches. Participants indicated on a 5-point Likert scale ( 1 strongly disagree to 5 strongly agree) how much they agreed with each statement. The scale was found to be internally reliable with a Cronbach alpha coefficient $\alpha=.92$, inter-item correlations ranging from $r=.24$ to $r=.66$, and corrected item-total correlations ranging from $r=.56$ to $r=.72$ (Newton et al., 2007). Participants again were encouraged to think about what their sport experiences under their current coach are typically like when responding (see Appendix E).

Field notes. Field notes were used to add trustworthiness to the qualitative data. The researcher noted any behaviors of relevance when reviewing the video clips to be sent to coaches. For example, if a coach repetitively yells at players, that is information that influenced what questions are asked during the interviews and were recorded in the field notes. If a player gets injured, however, that is not relevant to this study and was not noted. The researcher also observed the behavior of each coach throughout each of the interviews. Field notes regarding specific responses or behaviors throughout the process were included in the final analysis. All 
field notes were dated and included contextual information such as location, those present, physical setting, type of social interactions and who composed them, and activities (Patton, 2005). Both descriptive and reflective content were included (Schwandt, 2014). The field notes were reviewed and expanded continually, especially after interview sessions (see Appendix F). Figure 3. Timeline for Data Collection and Analyses

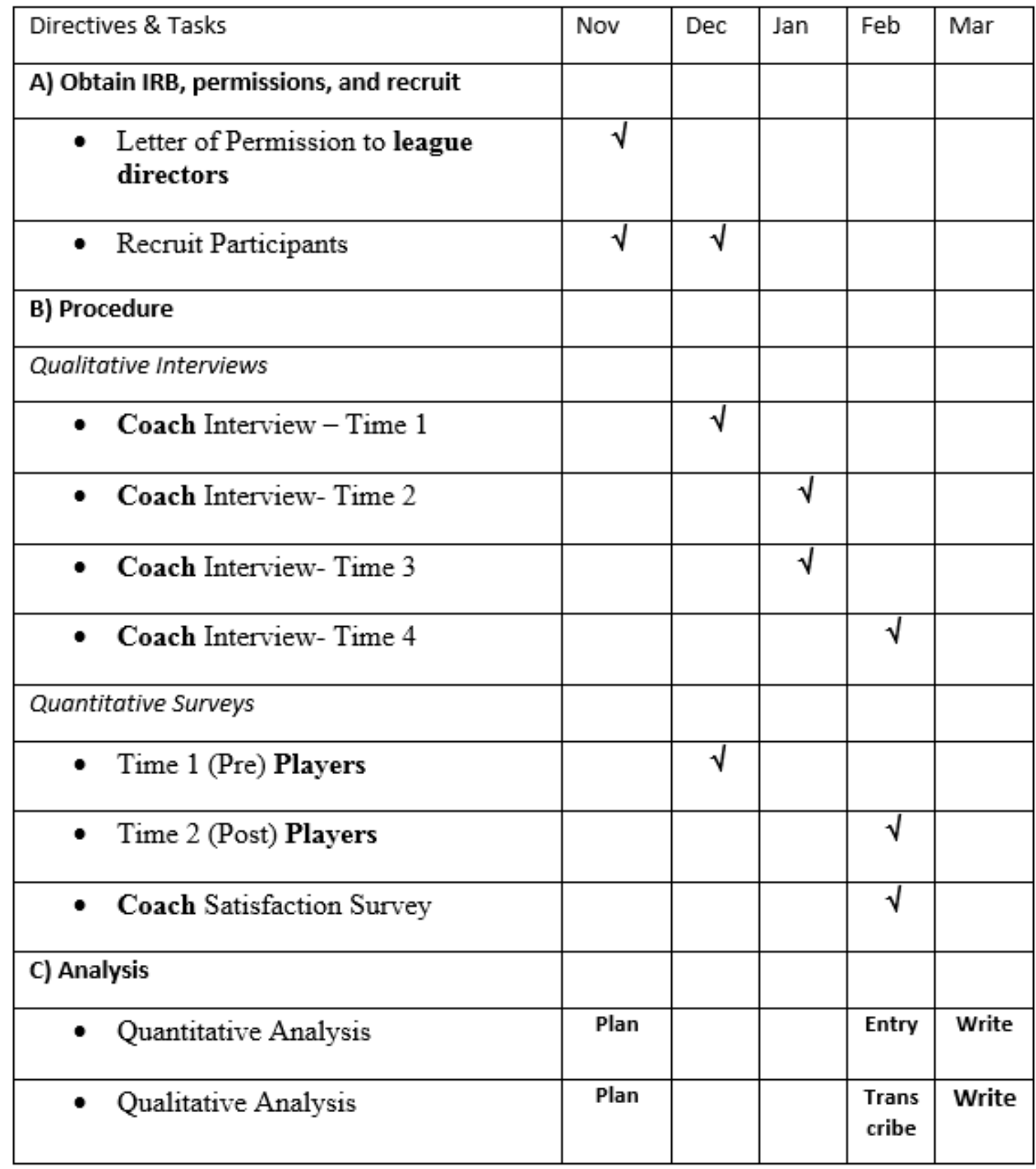


Figure 3. The timeline for data collection and analyses for this dissertation project organized by month throughout one basketball season.

\section{Procedure}

Approval to conduct this study was granted by the Institutional Review Board (IRB) at West Virginia University. Coaches were recruited by contacting representatives of local youth basketball organizations via email or in person, who provided contact information for potential candidates. The researcher recruited coaches at the coaches' meetings for each respective league at the start of the season. Coaches who meet the criteria within reasonable geographical proximity were contacted by email by the researcher and asked to participate in the study. Those who do not respond within seven days received a follow-up phone call. Ten coaches were contacted in total and ideally seven agreed to participate. Three sources of information were used: a collection of background information through demographic survey, semi-structured interviews, and player survey responses. Five coaches completed the study after attrition.

Coach background information. Background information were collected from coaches via a demographic survey at the start of the season. Coaches provided information regarding how long they have coached, coach education they have received, experience with basketball as an athlete, and average time spent coaching (see Appendix G).

Player surveys. Parental consent and youth assent forms were collected just prior to survey distribution and completion. Players completed the CCS and CART-Q during the first two weeks of the season and again during the final two weeks.

Interviews. All interviews were conducted in-person in a university office or in a private area at the sporting facility, and were $25-35$ minutes in length on average. A digital audio recorder was used to record each interview. All interviews were transcribed verbatim by the first 
author. The most important aspect of the interviews, and perhaps of the entire study, were how the interviews were conducted (such that they not only acquired information from each participant, but that the interviews also foster self-awareness in coaches). The following paragraphs describe how counseling techniques were integrated with interview research techniques.

The primary forms of questioning used in the interviews were Motivational Interviewing (MI). Motivational Interviewing is a person-centered counseling technique intended to foster understanding and creating an interviewer-client partnership that is conducive to change (Miller \& Rollnick, 2003). In this study, the researcher aimed to assist the coach in making insights about his or her behavior, and how they might be detrimental to achieving the previously outlined coaching goals. MI is centered around using guiding verbiage when discussing issues, especially surrounding behavior change. The researcher avoided using 'directing' as a communication style. For example, an expert may say, "I know what you should do, and here is how to do it". The researcher instead said something like, "I hear what you are experiencing. Do you have any thoughts as to why that might be happening?". The intention is to eventually reach an 'ah-ha' moment where the coach points out something he or she wasn't seeing prior to engaging in active reflection. The researcher also avoided 'following' the participant down a path that is not useful. For example, rather than implicitly accepting what the participant says is completely true, listening intently and questioning when appropriate is key for MI to be successful. Whereas directing is active and following is passive, guiding is cooperative. The language to be used is on a continuum and the researcher must maintain equilibrium (see Figure 4). 
Figure 4. Continuum of Communication for Motivational Interviewing

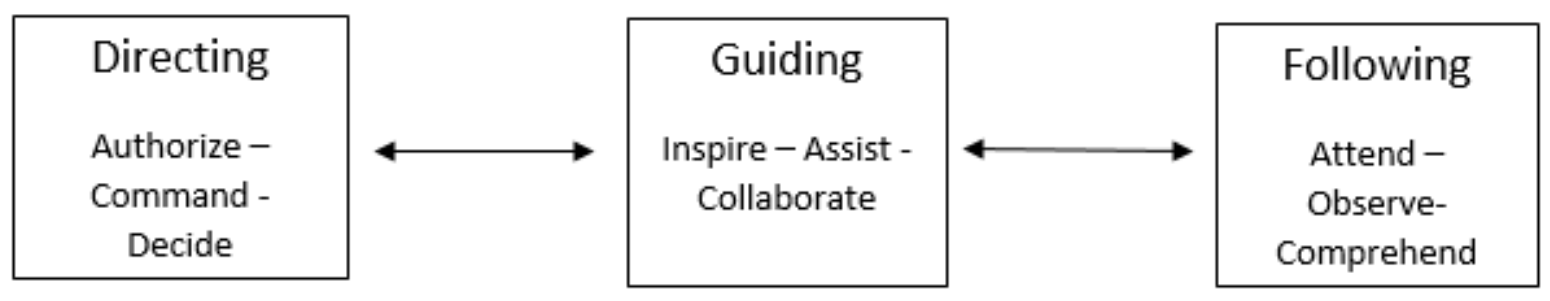

Figure 4. Demonstrates the continuum of communication for Motivational Interviewing. Adapted from Miller, W. R., \& Rollnick, S. (2012). Motivational interviewing: Helping people change. New York, NY: Guilford Press.

Initial interview. The initial interviews were conducted at the very start of the season with each coach. The objective was to assess coaching goals and behaviors, prior to any intervention.

Follow-up (second, third, and fourth) interviews. Subsequent interviews with coaches were conducted one week after coaches have received video feedback for review, on average. These reflective interviews occurred during mid and late season. The goals were to assess changes in coaching goals, perceptions, and behaviors after engaging in reflection.

Video recordings. In order to increase the quality and depth of reflection, coaches were provided with video clips on three occasions; one week after the first interview, and one week prior to the second and third interviews, which took place in mid and late season. Two practices and two games were recorded for each coach. The best three clips from those recordings, edited to one minute in length on average, were sent to each respective coach via a private Vimeo link within two days after recording (http://vimeo.com). Coaches were then asked to review the videos prior to the next interview, which occurred one week later, on average. 
Practice. Early in the season, each coach was videotaped at a regularly scheduled practice. Deliberate practice, as defined by Côté and colleagues (2007) allows for the learning and rehearsal of new skills.

Competition. Video of the coach were also collected at two regularly scheduled games during mid- and late season. Competition allows for the execution of those rehearsed skills under pressure (Frey et al., 2003). Play activities (i.e., hours spent in competition) are what determine progression to a more elite status, not practice time (Ford et al., 2009). For this study, it is expected that coaches exhibited enhanced performance when using their newly acquired skills of awareness in competition settings after having practiced them briefly.

Figure 5. Study Design

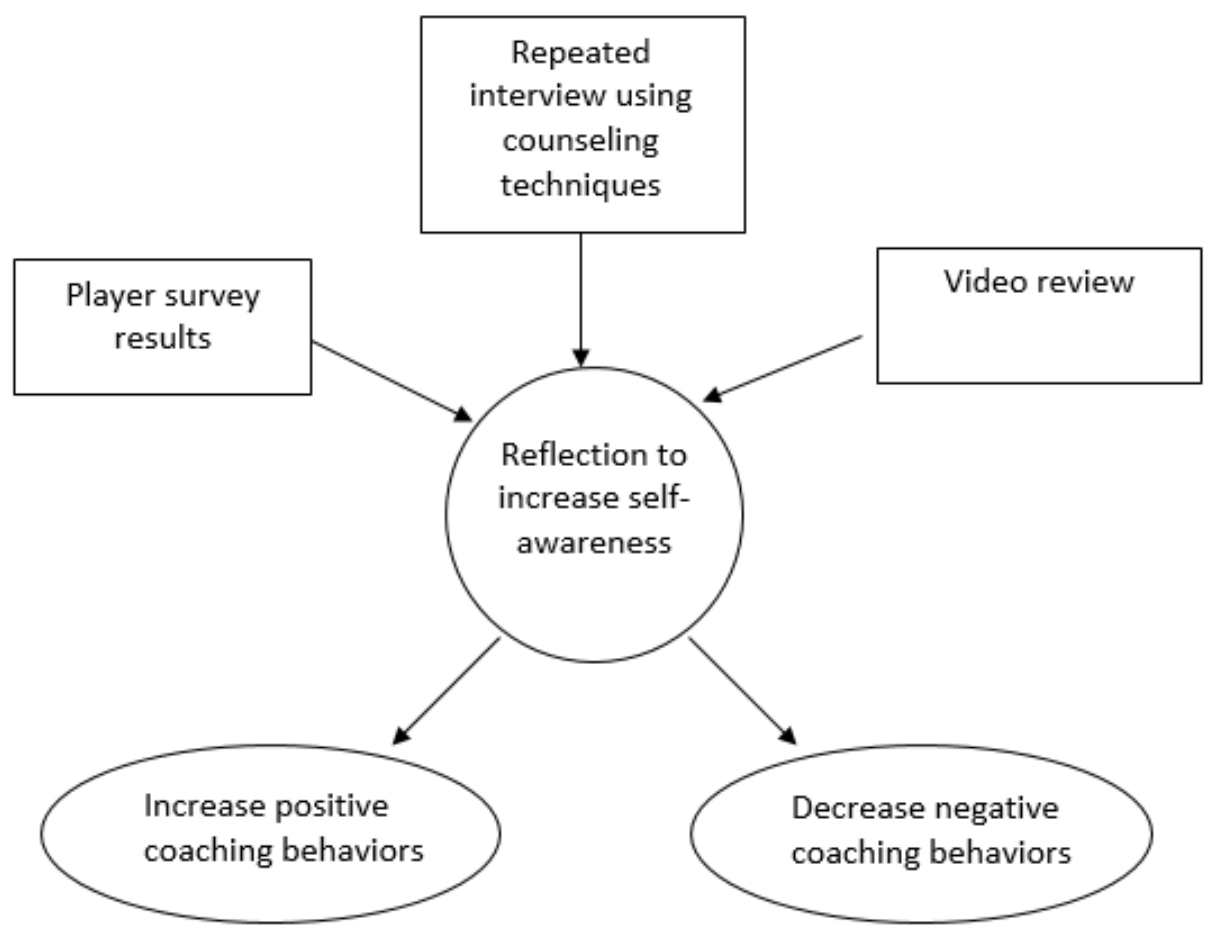

Figure 5. Flow chart to display measures used to provide reflection intervention and expected results. 
Field notes. Field notes were recorded by the researcher while editing the video clips, as well as after each interview interaction. Notes were recorded in memo form and revisited before each coach interview session.

Participant protections. Consent were attained at coaches' meetings and at parents' meetings for the participating youth leagues. Youth assent were obtained prior to players completing surveys. The primary Investigator/researcher were obtaining consent from all subjects. As the form for consent/assent is distributed, the researcher read the instructions aloud and indicate that participation is voluntary.

Interviews took place in a private setting, such as an office or conference room. Coaches were identified by number, and names were kept private. Surveys were collected before or after practice, in the cafeteria of the facility, separate from non-participants. Players were assigned a number, only so that pre and post surveys can be matched.

\section{Data Analysis}

Quantitative design. All statistical analyses were performed using IBM SPSS Version 21. To minimize type I error, only results that indicated a $p$-value of .05 or less were considered statistically significant. The following sections propose an appropriate analysis for the research questions, and then describe the procedures taken to ensure a thorough process of analyses.

To examine if there were changes over time in players' perceptions of the coach's level of caring. Four 2x2 (time $\mathrm{x}$ group) ANOVA was run with repeated measures on time and control vs. intervention as the group factors. In this study, there were five dependent variables (DVs) which include caring (from the CCS) and relationship (with coach, from CART-Q), and the CART-Q subscales of closeness, commitment, and complementarity. There were also two 
independent variables (IVs) including time (pre-and post-intervention) and group (intervention and control).

Quantitative procedures. All data was entered directly into Microsoft Excel and sorted. Information was then exported into an SPSS file and proofread as a random check for accuracy. Frequencies and descriptive statistics were then examined for each variable to ensure accurate range and values. Levene's test for homogeneity was performed to assess variances. Z-scores were then checked to detect the presence and magnitude of outliers (Raykov \& Marcoulides, 2008). Normality was tested using skewness and the absolute value of two. Kurtosis equal to or less than three signaled standard normal distribution. Independent t-tests were performed with the intervention and control group data. The cutoffs used were $\mu \pm 2 \sigma$. The researcher used various methods to aid improve and enhance internal and external validity. Test-retest reliability was ensured by administering the same tests to each group over time. To control the error rate, a post hoc Bonferroni test was run ( $8 \mathrm{df}, \alpha=.05, \mathrm{~A}=1.397)$.

After these preliminary analyses and before the inferential statistics are run, the reliability of each psychometric measure were confirmed by determining Cronbach Alpha values for each of the DVs. A critical value of X must be met or exceeded in order to conclude that the items in each measure (i.e., CCS; Newton, Fry, Watson et al., 2007, \& CART-Q; Jowett \& Ntoumanis, 2004 CART-Q; Jowett \& Ntoumanis, 2004) are internally consistent and therefore, statistically reliable.

Qualitative analysis. The researcher reviewed the audio and transcribed each interview verbatim using Microsoft Excel ${ }^{\circledR}$ (Hahn, 2008). Qualitative data was analyzed through abductive content analysis, or using previous research to aid in the search for common themes. The aided in finding emerging themes (according to question topics) by summarizing or understanding 
meanings and context (Lederman, 1991). The researcher used in Vivo coding for each interview transcript to find short phrases or key terms in the participants own language. Responses from participants were then compared to develop common themes (this is the bottom-up or inductive process). The inductive (bottom-up) approach allowed the researchers to find emergent raw themes from each semi-structured interview and compare them to create common themes (Brinkmann \& Kvale, 2009). The researcher organized data into categories according to the topic of the interview questions through open codes (this is the top-down or deductive processing). The data was grouped both deductively and inductively into lower and higher order themes (Miles, Huberman, \& Saldana, 2014). Combined together, these inductive and deductive processes formed an abductive analysis.

Field notes were converted to a neater, more detailed format to ensure legibility and clarification of all abbreviations clarified. These notes acted added structure to the emerging ideas and themes during preparation and after completion, and aided in shifting attention when necessary. The researcher noted any behaviors of relevance when reviewing the video clips to be sent to coaches. Both audio and video were used to check accuracy. Finally, a comparison of themes in field notes to those found in interviews was performed.

Trustworthiness and authenticity. To ensure trustworthiness and authenticity, the researcher used various methods. In order to limit the researcher influence on interview questions and responses, bracketing was performed in the form of memos. The researcher noted observational comments throughout data collection and analysis as a means of examining and reflecting upon the researcher's engagement with the data (Cutcliffe, 2003). Field notes were used to add trustworthiness to the qualitative data. The researcher noted any behaviors of relevance when reviewing the video clips to be sent to coaches. All field notes were dated and 
included contextual information such as location, those present, physical setting, type of social interactions and who composed them, and activities (Patton, 2005). Both descriptive and reflective content were included (Schwandt, 2014).

Throughout the qualitative analysis process, two critical friends were used. The first critical friend was a doctoral candidate and trained in qualitative research. This reviewer was not present during the interviews or coding analysis process. The reviewer examined the raw data codes in context to each transcript and provided detailed constructive feedback. Additionally, the reviewer provided feedback on the organization of codes and development of themes. After changes were made to the organization of codes and development of themes, the researcher met with the reviewer to make sure lower, middle, and higher order themes reflected the narrative data, as well as the purpose of the interview guide and the corresponding themes. Reviewing of codes for consistency, clarity, and incidences of bias was completed in order to increase rigor. One higher order theme, one middle order theme, and two lower order themes were added after reviewer feedback. One lower order theme was also changed after review to increase clarity.

The second critical friend was the doctoral advisor of the PI. He was not present during interviews, coding analysis process, or during the initial thematic analysis, but critiqued the completed analysis. The second reviewer required the researcher to provide more descriptive labels for higher order themes, and insisted that the PI focus solely on the purpose of the dissertation, when identifying, organizing, and presenting results (Long Pantaleon, Bruant, \& d'Arripe-Longueville, 2006). Additionally, the researcher met with the reviewer to outline qualitative results and receive guidance on how to tell a logical and complete story that centered around the purpose of the study. 
Finally, a member check was completed post analysis to ensure that interpretations and reorganization of narrative themes aligned with the intended views of the participants. The results were triangulated by employing several methodological steps that produce a variant of data sources. More specifically, since data is grouped by time and by source (i.e., information from coaches as well as players, in both intervention and control groups) bias was reduced and a more holistic picture of coaching behaviors, intentions, and intervention effectiveness was provided. In addition, member checking and peer debriefing was utilized to corroborate the researcher's descriptions and interpretations of the context, coaching style, and player outcomes (Long et al., 2006).

Table 4

Summative Chart Connecting Research Questions to the Methodology

\begin{tabular}{|c|c|c|c|}
\hline $\begin{array}{l}\text { Research } \\
\text { Questions }\end{array}$ & $\begin{array}{l}\text { Method } \\
\text { How will the RQ be } \\
\text { answered? }\end{array}$ & $\begin{array}{l}\text { Variables / } \\
\text { Themes } \\
\text { What data will } \\
\text { answer the RQ? }\end{array}$ & Analyses \\
\hline $\begin{array}{l}\text { 1. Does } \\
\text { a reflection- } \\
\text { based } \\
\text { intervention }\end{array}$ & $\begin{array}{l}\text { Participants were youth } \\
\text { sport coaches with 2-6 } \\
\text { years of experience }\end{array}$ & $\begin{array}{l}\text { Interview } \\
\text { guides/questions } \\
\text { are focused on hoe } \\
\text { dialogue, with the }\end{array}$ & $\begin{array}{l}\text { QUAL: Thematic } \\
\text { analysis of transcribed } \\
\text { interviews. }\end{array}$ \\
\hline $\begin{array}{l}\text { increase youth } \\
\text { coaches' self- } \\
\text { awareness of } \\
\text { their coaching }\end{array}$ & $\begin{array}{l}\text { Dialogue-based } \\
\text { interviews will assess } \\
\text { changes in self-awareness } \\
\text { over time - interview as }\end{array}$ & $\begin{array}{l}\text { help of video and } \\
\text { player feedback, } \\
\text { increase self- } \\
\text { awareness }\end{array}$ & $\begin{array}{l}\text { Looking for subthemes } \\
\text { that speak to changes in } \\
\text { awareness of behaviors. }\end{array}$ \\
\hline behaviors? & data collection & & $\begin{array}{l}\text { Begin with subthemes } \\
\text { for awareness of } \\
\text { behavior goals / } \\
\text { intentional behavior. }\end{array}$ \\
\hline
\end{tabular}




\begin{tabular}{llll}
\hline $\begin{array}{l}\text { Research } \\
\text { Questions }\end{array}$ & $\begin{array}{l}\text { Method } \\
\text { How will the RQ be } \\
\text { answered? }\end{array}$ & $\begin{array}{l}\text { Variables / } \\
\text { Themes } \\
\end{array}$ & $\begin{array}{l}\text { What data will } \\
\text { answer the RQ? }\end{array}$ \\
\hline
\end{tabular}

1a. Does
dialogue in
a reflection-
based
intervention
increase
coaches' self-
awareness of
developmentally
supportive
behaviors?

Procedure: Dialoguebased interviews (with MI techniques)

Measures: Interview questions about awareness of developmentally supportive behaviors

1b. Does video review in a reflectionbased intervention increase coaches' selfawareness of developmentally supportive behaviors?
Procedure: Review of video from practice and competition individually

Measure: Interviewbased (with MI techniques)
Interview

Questions:

What new behaviors have you tried since we spoke last to help you achieve (or get closer to achieving) those goals?

What behaviors have you been trying to avoid that hinder you reaching your goals since we last spoke?

Did you have an opportunity to look over the videos I sent? If yes, how often?

What did you find useful about the videos? [Get 2-3 examples]

Was there anything you saw in the videos that really surprised you?
2 Qual Analyses:

1 - looking at changes in participant's changes in awareness-related comments over first 3 interviews.

$2-\operatorname{In} 4^{\text {th }}$ interview, ask metacognitive question about interview leading to more awareness of behavior.
QUAL: Thematic analysis of transcribed interviews.

Looking for subthemes that speak to changes in awareness of behaviors.

Begin with subthemes for awareness of behavior goals / intentional behavior. 


\begin{tabular}{|c|c|c|c|}
\hline $\begin{array}{l}\text { Research } \\
\text { Questions }\end{array}$ & $\begin{array}{l}\text { Method } \\
\text { How with the RQ be } \\
\text { answered? }\end{array}$ & $\begin{array}{l}\text { Variables / } \\
\text { Themes } \\
\text { What data will you } \\
\text { answer the RQ? }\end{array}$ & Analyses \\
\hline \multirow[t]{2}{*}{$\begin{array}{l}\text { 1c. Does input } \\
\text { from players in } \\
\text { a reflection- } \\
\text { based } \\
\text { intervention } \\
\text { increase } \\
\text { coaches' self- } \\
\text { awareness of } \\
\text { developmentally } \\
\text { supportive } \\
\text { behaviors? }\end{array}$} & $\begin{array}{l}\text { Procedure: Player survey } \\
\text { results (from CCS and } \\
\text { CART-Q) reviewed with } \\
\text { coaches prior to } 2^{\text {nd }} \text { and } \\
3^{\text {rd }} \text { interviews } \\
\text { Measure: Interview- } \\
\text { based (with MI } \\
\text { techniques) }\end{array}$ & $\begin{array}{l}\text { Did hearing about } \\
\text { your players' } \\
\text { opinions last time } \\
\text { we spoke make a } \\
\text { difference in your } \\
\text { choices or } \\
\text { intentions while } \\
\text { coaching? If yes, } \\
\text { how did it impact } \\
\text { your decisions and } \\
\text { related behaviors? }\end{array}$ & $\begin{array}{l}\text { QUAL: Thematic } \\
\text { analysis of transcribed } \\
\text { interviews. } \\
\text { Looking for subthemes } \\
\text { that speak to changes in } \\
\text { awareness of behaviors. } \\
\text { Begin with subthemes } \\
\text { for awareness of } \\
\text { behavior goals / } \\
\text { intentional behavior. }\end{array}$ \\
\hline & & $\begin{array}{l}\text { Is there anything } \\
\text { else you intend on } \\
\text { changing? }\end{array}$ & \\
\hline \multirow[t]{2}{*}{$\begin{array}{l}\text { 2. Based on } \\
\text { player- and self- } \\
\text { report does } \\
\text { a reflection- } \\
\text { based } \\
\text { intervention } \\
\text { change coaches' } \\
\text { developmentally } \\
\text { supportive } \\
\text { behaviors (i.e., } \\
\text { their positive } \\
\text { coaching of } \\
\text { children)? }\end{array}$} & $\begin{array}{l}\text { Procedure: Player survey } \\
\text { results (from CCS and } \\
\text { CART-Q) reviewed with } \\
\text { coaches prior to } 2^{\text {nd }} \text { and } \\
3^{\text {rd }} \text { interviews } \\
\text { Measure: Interview- } \\
\text { based (with MI } \\
\text { techniques) }\end{array}$ & $\begin{array}{l}\text { Did hearing about } \\
\text { your players' } \\
\text { opinions last time } \\
\text { we spoke make a } \\
\text { difference in your } \\
\text { choices or } \\
\text { intentions while } \\
\text { coaching? If yes, } \\
\text { how did it impact } \\
\text { your decisions and } \\
\text { related behaviors? }\end{array}$ & $\begin{array}{l}\text { QUAL: Thematic } \\
\text { analysis of transcribed } \\
\text { interviews. } \\
\text { Looking for subthemes } \\
\text { that speak to changes in } \\
\text { behaviors. }\end{array}$ \\
\hline & & $\begin{array}{l}\text { Is there anything } \\
\text { else you intend on } \\
\text { changing? }\end{array}$ & \\
\hline \multirow[t]{2}{*}{$\begin{array}{l}\text { 2a. If yes, what } \\
\text { specific changes } \\
\text { occur in coaches' } \\
\text { self-reported } \\
\text { behaviors? }\end{array}$} & $\begin{array}{l}\text { Interview responses } \\
\text { regarding behavior will } \\
\text { serve as data }\end{array}$ & $\begin{array}{l}\text { What new } \\
\text { behaviors have } \\
\text { you tried since we } \\
\text { spoke last to help }\end{array}$ & $\begin{array}{l}\text { QUAL: Thematic } \\
\text { analysis of transcribed } \\
\text { interviews. }\end{array}$ \\
\hline & & & (continued) \\
\hline
\end{tabular}




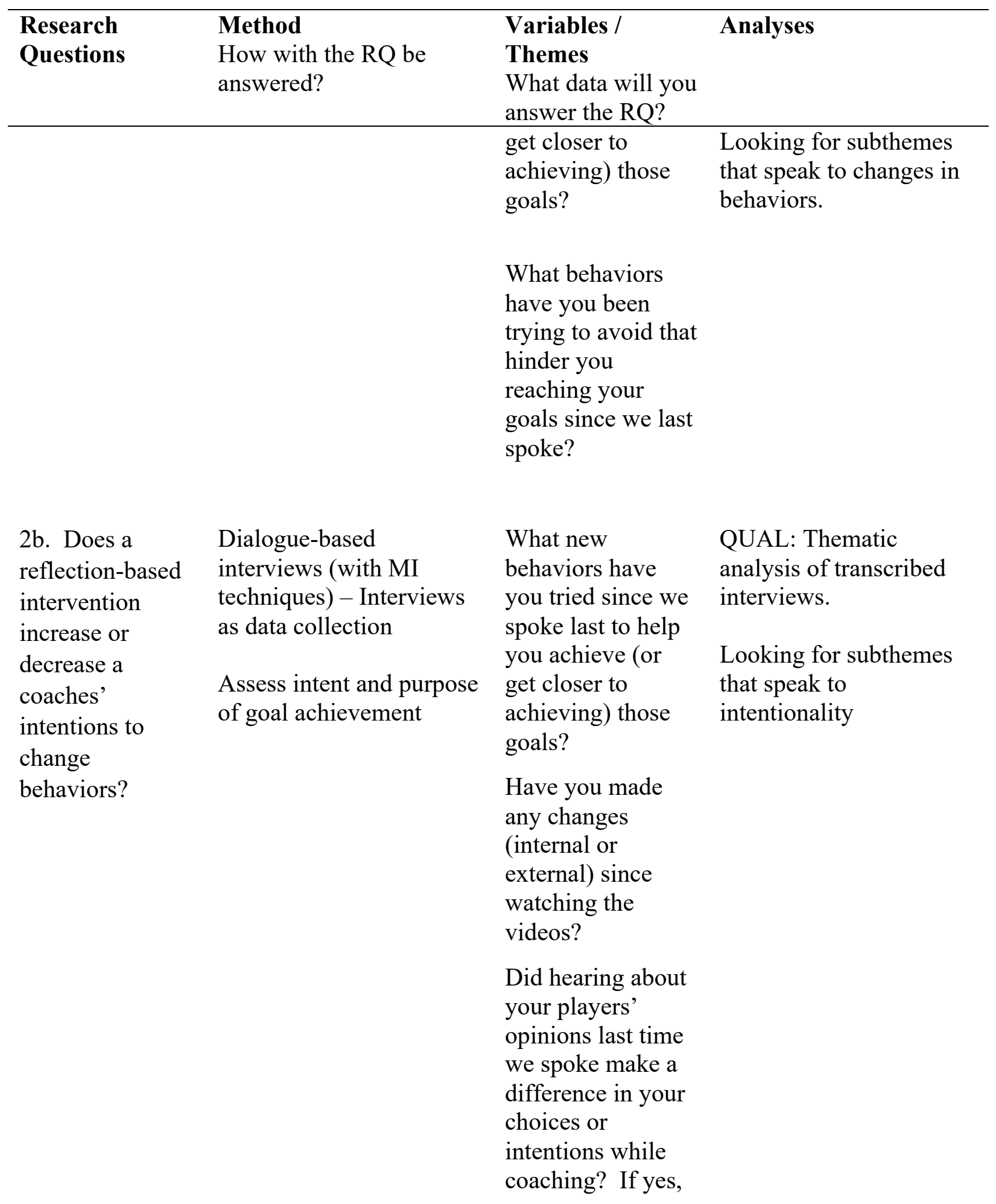

(continued) 


\begin{tabular}{|c|c|c|c|}
\hline $\begin{array}{l}\text { Research } \\
\text { Questions }\end{array}$ & $\begin{array}{l}\text { Method } \\
\text { How with the RQ be } \\
\text { answered? }\end{array}$ & $\begin{array}{l}\text { Variables / } \\
\text { Themes } \\
\text { What data will you } \\
\text { answer the RQ? }\end{array}$ & Analyses \\
\hline & & $\begin{array}{l}\text { how did it impact } \\
\text { your decisions and } \\
\text { related behaviors? } \\
\text { Is there anything } \\
\text { else you intend on } \\
\text { changing? } \\
\text { For changes you } \\
\text { have made or } \\
\text { intend to make, } \\
\text { why are those } \\
\text { changes important } \\
\text { to you? }\end{array}$ & \\
\hline $\begin{array}{l}\text { 2c. Does a } \\
\text { reflection-based } \\
\text { intervention } \\
\text { result in actual } \\
\text { change in } \\
\text { coaching } \\
\text { behaviors, as } \\
\text { measured by } \\
\text { players } \\
\text { perception of } \\
\text { change? }\end{array}$ & $\begin{array}{l}\text { Player survey results at } \\
\text { pre and post will assess } \\
\text { change } \\
\text { Interview responses } \\
\text { regarding behavior will } \\
\text { serve as data }\end{array}$ & $\begin{array}{l}\text { Have you made } \\
\text { any changes } \\
\text { (internal or } \\
\text { external) since } \\
\text { watching the } \\
\text { videos? } \\
\text { Did hearing about } \\
\text { your players' } \\
\text { opinions last time } \\
\text { we spoke make a } \\
\text { difference in your } \\
\text { choices or } \\
\text { intentions while } \\
\text { coaching? If yes, } \\
\text { how did it impact } \\
\text { your decisions and } \\
\text { related behaviors? } \\
\text { Is there anything } \\
\text { else you intend on } \\
\text { changing? }\end{array}$ & $\begin{array}{l}\text { QUAL: Thematic } \\
\text { analysis of transcribed } \\
\text { interviews. } \\
\text { Looking for subthemes } \\
\text { that speak to changes in } \\
\text { behaviors. }\end{array}$ \\
\hline
\end{tabular}




\begin{tabular}{|c|c|c|c|}
\hline $\begin{array}{l}\text { Research } \\
\text { Questions }\end{array}$ & $\begin{array}{l}\text { Method } \\
\text { How with the RQ be } \\
\text { answered? }\end{array}$ & $\begin{array}{l}\text { Variables / } \\
\text { Themes } \\
\text { What data will you } \\
\text { answer the RQ? }\end{array}$ & Analyses \\
\hline $\begin{array}{l}\text { d. Does video } \\
\text { review in } \\
\text { a reflection- } \\
\text { based } \\
\text { intervention } \\
\text { affect coaches' } \\
\text { developmentally } \\
\text { supportive } \\
\text { behaviors? }\end{array}$ & $\begin{array}{l}\text { Procedure: Review of } \\
\text { video from practice and } \\
\text { competition individually } \\
\text { and discussed in } \\
\text { interview } \\
\text { Measure: Interview- } \\
\text { based (with MI } \\
\text { techniques) }\end{array}$ & $\begin{array}{l}\text { Have you made } \\
\text { any changes } \\
\text { (internal or } \\
\text { external) since } \\
\text { watching the } \\
\text { videos? }\end{array}$ & $\begin{array}{l}\text { QUAL: Thematic } \\
\text { analysis of transcribed } \\
\text { interviews. } \\
\text { Looking for subthemes } \\
\text { that speak to changes in } \\
\text { behaviors. }\end{array}$ \\
\hline $\begin{array}{l}\text { 2e. Does input } \\
\text { from players in } \\
\text { a reflection- } \\
\text { based } \\
\text { intervention } \\
\text { affect coaches' } \\
\text { developmentally } \\
\text { supportive } \\
\text { behaviors? }\end{array}$ & $\begin{array}{l}\text { Procedure: Player survey } \\
\text { results (from CCS and } \\
\text { CART-Q) reviewed with } \\
\text { coaches prior to } 2^{\text {nd }} \text { and } \\
3^{\text {rd }} \text { interviews } \\
\text { Measure: Interview- } \\
\text { based (with MI } \\
\text { techniques) }\end{array}$ & $\begin{array}{l}\text { Did hearing about } \\
\text { your players' } \\
\text { opinions last time } \\
\text { we spoke make a } \\
\text { difference in your } \\
\text { choices or } \\
\text { intentions while } \\
\text { coaching? If yes, } \\
\text { how did it impact } \\
\text { your decisions and } \\
\text { related behaviors? }\end{array}$ & $\begin{array}{l}\text { QUAL: Thematic } \\
\text { analysis of transcribed } \\
\text { interviews. } \\
\text { Looking for subthemes } \\
\text { that speak to changes in } \\
\text { behaviors. }\end{array}$ \\
\hline $\begin{array}{l}\text { 2f. Specifically, } \\
\text { for player } \\
\text { perceptions, do } \\
\text { perceptions of } \\
\text { positive rapport } \\
\text { and caring } \\
\text { coaching } \\
\text { improve more } \\
\text { over the season } \\
\text { for teams who } \\
\text { participate in the } \\
\text { study than for } \\
\text { other teams in } \\
\text { the league? }\end{array}$ & $\begin{array}{l}\text { Player surveys, pre-post, } \\
\text { using the CCS and } \\
\text { CART-Q. Control and } \\
\text { intervention groups } \\
\text { surveyed for players }\end{array}$ & $\begin{array}{l}\text { Survey results and } \\
\text { time } \\
\text { DVs = Caring } \\
\text { (CCS); Closeness, } \\
\text { Commitment, } \\
\text { Complementarity } \\
\text { (CART-Q) } \\
2 \text { IVs = Time (pre- } \\
\text { and post- } \\
\text { intervention); and } \\
\text { Group } \\
\text { (intervention and } \\
\text { control) }\end{array}$ & $\begin{array}{l}\text { QUANT: Four Separate } \\
\text { 2x2 ANOVAs (Time x } \\
\text { Group), one for each DV } \\
\text { (Caring, Commitment, } \\
\text { Closeness, and } \\
\text { Complementarity). }\end{array}$ \\
\hline
\end{tabular}




\begin{tabular}{|c|c|c|c|}
\hline $\begin{array}{l}\text { Research } \\
\text { Questions }\end{array}$ & $\begin{array}{l}\text { Method } \\
\text { How with the RQ be } \\
\text { answered? }\end{array}$ & $\begin{array}{l}\text { Variables / } \\
\text { Themes } \\
\text { What data will you } \\
\text { answer the RQ? }\end{array}$ & Analyses \\
\hline $\begin{array}{l}\text { 3. Do coaches } \\
\text { believe that } \\
\text { the reflection- } \\
\text { based } \\
\text { intervention, } \\
\text { which utilized } \\
\text { dialogue, video } \\
\text { review, and input } \\
\text { from } \\
\text { players, made } \\
\text { them willing to } \\
\text { self-report fault } \\
\text { in their coaching } \\
\text { behaviors? }\end{array}$ & $\begin{array}{l}\text { Satisfaction survey post } \\
\text { season }\end{array}$ & $\begin{array}{l}\text { QUAN- } \\
\text { Satisfaction survey } \\
\text { variable assessing } \\
\text { helpfulness of } \\
\text { intervention }\end{array}$ & $\begin{array}{l}\text { QUANT: Descriptive } \\
\text { statistical analysis of } \\
\text { satisfaction survey }\end{array}$ \\
\hline $\begin{array}{l}\text { 3a. Do coaches } \\
\text { believe the } \\
\text { intervention is } \\
\text { supportive? }\end{array}$ & $\begin{array}{l}\text { Satisfaction survey post } \\
\text { season }\end{array}$ & $\begin{array}{l}\text { QUAN- } \\
\text { Satisfaction survey } \\
\text { variable assessing } \\
\text { helpfulness of } \\
\text { intervention }\end{array}$ & $\begin{array}{l}\text { QUANT: Descriptive } \\
\text { statistical analysis of } \\
\text { satisfaction survey }\end{array}$ \\
\hline $\begin{array}{l}\text { 3b. Do coaches } \\
\text { believe the } \\
\text { intervention is } \\
\text { useful? }\end{array}$ & $\begin{array}{l}\text { Satisfaction survey post } \\
\text { season }\end{array}$ & $\begin{array}{l}\text { QUAN- } \\
\text { Satisfaction survey } \\
\text { variable assessing } \\
\text { helpfulness of } \\
\text { intervention }\end{array}$ & $\begin{array}{l}\text { QUANT: Descriptive } \\
\text { statistical analysis of } \\
\text { satisfaction survey }\end{array}$ \\
\hline $\begin{array}{l}\text { 3c. Do coaches } \\
\text { believe the } \\
\text { intervention is } \\
\text { free from } \\
\text { judgment? }\end{array}$ & $\begin{array}{l}\text { Satisfaction survey post } \\
\text { season }\end{array}$ & $\begin{array}{l}\text { QUAN- } \\
\text { Satisfaction survey } \\
\text { variable assessing } \\
\text { helpfulness of } \\
\text { intervention }\end{array}$ & $\begin{array}{l}\text { QUANT: Descriptive } \\
\text { statistical analysis of } \\
\text { satisfaction survey }\end{array}$ \\
\hline
\end{tabular}




\section{Chapter IV}

\section{Results}

\section{Overview}

This chapter presents the current study's qualitative findings and quantitative results. Qualitative findings include saturated data collected from the five youth basketball coaches' direct quotes about the targeted topics discussed related to research questions one, two, and three. Highlighted were the coaches' thoughts and perceptions about their intentions, awareness, and behaviors, as well as perceived changes that are thematically tracked from Interview One to Interview Four. Selected quotes support qualitative results as appropriate. For the quantitative results, players' responses to the CART-Q and CCS are presented, as they relate to the research questions. Also, coaches' responses to the post-season Satisfaction Survey are included.

Descriptive analyses and comparisons of means among the sample's selected sub-groups (two-way analysis of variance and descriptive statistics) are presented. Variables of interest are those included in the CART-Q and CCS, such as caring, commitment, connection, and complementarity of coaches to players. Coach responses from the coach satisfaction survey are used to support the fidelity of the intervention used in this study. These quantitative and qualitative findings are organized by research question.

\section{Participant Numbers, Measurement Reliabilities, and Assumptions}

Seven youth coaches were successfully recruited to participate in the intervention portion of this study. After the first interview, one coach asked to be removed from the study and the other coach stopped responding to messages and phone calls regarding the study. After two emails and phone call attempts, contact was ceased. Considering that attrition, there were five 
participant coaches that completed the study through all interviews and the concluding satisfaction survey.

A total of 108 players completed the player surveys; 53 were players for intervention coaches, and 55 were players on control teams. All 108 players completed the Time 1 survey. However, seven out of 108 players did not complete the Time 2 survey due to attrition or unavailability. Upon cleaning the data, the researcher attempted to verify if missing post-season responses from seven players were impactful or affecting reliability. Across all 24 variables (11 from the CART-Q and 13 from the CCS), only four were flagged as moderately significant, indicating that the players who did not complete the post-season surveys were somewhat different than the rest of the participant group. As a result, they were dropped from the data set. The final sample included 101 players who completed both Time 1 and Time 2 surveys; 50 in the intervention group and 51 in the control group. The data for time 1 and time 2 were screened for data entry errors.

Fifty cases were randomly chosen to confirm that the data was correctly entered into SPSS. The researcher did not detect any errors during the screening process. The researcher assessed missing data through frequency tables. The researcher also assessed for reliabilities, normality, homogeneity of variances, and independence prior to conducting statistical analysis. After pre-screening the data, Cronbach's Alpha were calculated to assess the internal reliability and consistency of each coaching style factors and outcome scales and subscales. Specifically, for the CART-Q, each scale and subscale for closeness, commitment, and complementarity were assessed separately for Time 1 and Time 2 data. 


\section{Coach Athlete Relationship Questionnaire}

Time 1 reliabilities- CART-Q. Cronbach's alpha reliability coefficients ranged from .46 to .90 for the coach-athlete relationship variables (closeness, commitment, and complementarity) at Time 1, with an overall Cronbach's alpha reliability coefficient of .86. Closeness and Commitment factors showed acceptable reliability based on the critical criterion of $r>.70$ (Pallant, 2013), whereas Complementarity was less than critical at .46.

Time 2 reliabilities- CART-Q. Cronbach's alpha reliability coefficients ranged from .41 to .43 for the coach-athlete relationship variables (closeness, commitment, and complementarity) at Time 2, with an overall Cronbach's alpha reliability coefficient of .60. All variables failed to meet the critical criterion of $r>.70$ (Pallant, 2013). Table 5 contains the Cronbach's alpha coefficients, mean, standard deviation, skewness and kurtosis obtained in this study for Time 1 and Time 2 for the CART-Q.

Table 5

CART-Q Results for Time 1 and Time 2

\begin{tabular}{|c|c|c|c|c|c|c|c|c|}
\hline Item & \multicolumn{4}{|c|}{ TIME 1} & \multicolumn{4}{|c|}{ TIME 2} \\
\hline & $\bar{M}$ & SD & Skewness & Kurtosis & $\bar{M}$ & SD & Skewness & Kurtosis \\
\hline 1 & 6.89 & .42 & -.74 & -.03 & 6.12 & .70 & -.53 & .43 \\
\hline 2 & 6.53 & .85 & -.87 & .26 & 5.47 & 1.68 & -.87 & -.53 \\
\hline 3 & 6.00 & .88 & -.63 & -.06 & 6.45 & .79 & .24 & .53 \\
\hline 4 & 6.06 & .66 & -.33 & -.68 & 5.87 & 1.17 & -1.42 & 2.1 \\
\hline 5 & 6.46 & .94 & -1.47 & .70 & 6.86 & .47 & -.340 & 10.49 \\
\hline 6 & 5.87 & .67 & -.98 & 1.84 & 6.63 & .58 & -1.33 & .82 \\
\hline 7 & 6.72 & .81 & -2.71 & .46 & 6.90 & .30 & -2.71 & 5.44 \\
\hline 8 & 6.89 & .37 & -3.56 & 12.94 & 6.50 & .73 & -1.40 & 1.52 \\
\hline 9 & 6.64 & .71 & -2.20 & 4.64 & 6.46 & .64 & -.76 & -.43 \\
\hline 10 & 5.93 & .84 & -.44 & -.39 & 6.29 & .78 & -.81 & -.05 \\
\hline 11 & 6.01 & .64 & -.01 & -.50 & 6.50 & .66 & -.95 & -.21 \\
\hline $\begin{array}{l}\text { CLOSENESS } \\
\text { (items } 3,5,8,9 \text { ) }\end{array}$ & 6.46 & .60 & & & 6.56 & .38 & & \\
\hline COMMITMENT & 5.72 & .92 & & & 6.07 & .69 & & \\
\hline (1te & & & & & & & & (continued) \\
\hline
\end{tabular}




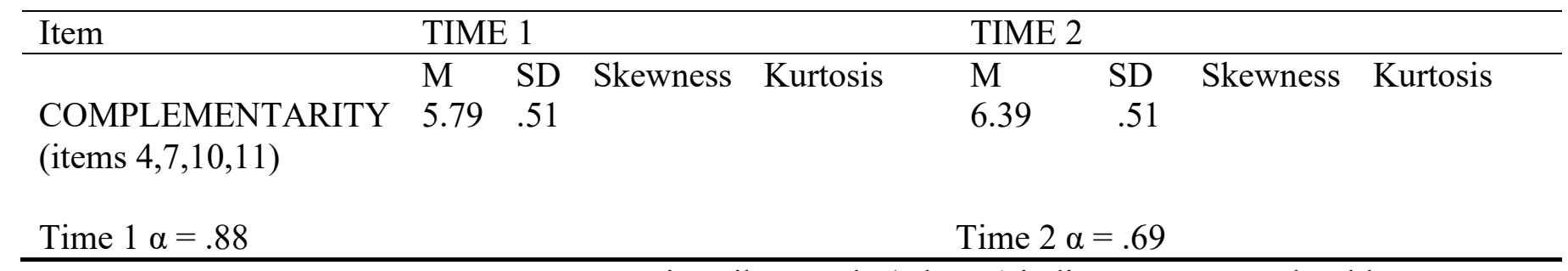

Note: Responses were on a 7-point Likert scale (where 1 indicates poor coach-athlete relationship quality and 7 indicates good coach-athlete relationship quality)

Normality of distributions- CART-Q. To assess normality for the independent and dependent variables, descriptive statistics were used to examine skewness, kurtosis, scatter plots, histograms, and standard error coefficients. Results for the Kolmogorov-Smirnov statistics indicated all variables violated the assumption of normality. As a result, the researcher examined the data for potential outliers.

Identifying potential (univariate) outliers- CART-Q. The researcher used three techniques to identify and detect potential outliers which included box plots, histograms and zscores with an absolute value of 2.68. If potential outliers exceeded one technique, then the researcher flagged the case, but the value was left unchanged. However, if potential outliers exceed all three techniques, then the outliers were removed. Only two cases exceeded the z-score test with an absolute value of 2.68 or higher on a single variable on one technique. Therefore, no participant's scores violated all three techniques, and no participants were removed.

\section{Caring Climate Scale}

Time 1 reliabilities- CCS. Cronbach's alpha reliability coefficient is from .94 for the coach caring variables at Time 1, which displays acceptable reliability based on the critical criterion of $r>.70$ (Pallant, 2013).

Time 2 reliabilities- CCS. Cronbach's alpha reliability coefficient is .95 at Time 2, which also meets critical criterion of $r>.70$ for acceptable reliability (Pallant, 2013). Table 6 
contains the Cronbach's alpha coefficients, mean, standard deviation, skewness and kurtosis obtained in this study for Time 1 and Time 2 for the CCS.

Table 6

CCS Results for Time 1 and Time 2

\begin{tabular}{ccccccccc}
\hline Item & \multicolumn{4}{c}{ TIME 1 } & \multicolumn{5}{c}{ TIME 2 } \\
\hline & $\mathrm{M}$ & SD & Skewness & Kurtosis & M & SD & Skewness & Kurtosis \\
1 & 4.9 & .30 & -2.73 & 5.54 & 4.88 & .35 & -3.10 & 9.38 \\
2 & 4.91 & .29 & -2.93 & 6.71 & 4.89 & .34 & -3.28 & 10.99 \\
3 & 4.84 & .50 & -3.14 & 8.55 & 4.84 & .48 & -3.01 & 8.59 \\
4 & 4.66 & .52 & -1.14 & .22 & 4.68 & .53 & -1.41 & 1.08 \\
5 & 4.65 & .65 & -2.12 & 4.65 & 4.68 & .56 & -1.62 & 1.69 \\
6 & 4.66 & .52 & -1.14 & .22 & 4.67 & .51 & -.1 .20 & .37 \\
7 & 4.70 & .46 & -.90 & -1.21 & 4.71 & .48 & -1.24 & .23 \\
8 & 4.55 & .62 & -1.10 & .15 & 4.55 & .64 & -1.14 & .20 \\
9 & 4.91 & .29 & -2.93 & 6.71 & 4.89 & .34 & -3.28 & 10.99 \\
10 & 4.90 & .30 & -2.71 & 5.54 & 4.88 & .35 & -3.10 & 9.38 \\
11 & 4.46 & .62 & -.96 & 1.14 & 4.52 & .58 & -.74 & -.44 \\
12 & 4.92 & .27 & -3.16 & 8.12 & 4.91 & .32 & -3.82 & 15.45 \\
13 & 4.89 & .34 & -3.28 & 10.99 & 4.88 & .38 & -3.42 & 11.85 \\
& \multicolumn{3}{c}{ TIME 1 overall $\alpha=.94$} & & TIME 2 overall $\alpha=.95$ \\
\hline
\end{tabular}

Note: Responses were on a 5-point Likert scale (where 1 indicates low coach caring and 5 indicates high coach caring)

Normality of distributions- CCS. To assess normality for the independent and dependent variables, descriptive statistics were used to examine skewness, kurtosis, scatter plots, histograms, and standard error coefficients. Results for the Kolmogorov-Smirnov statistics indicated that once again, all variables violated the assumption of normality. As a result, the researcher examined the data for potential outliers.

Identifying potential (univariate) outliers- CCS. The researcher used three techniques to identify and detect potential outliers which included box plots, histograms and z-scores with an absolute value of 2.68. One case exceeded the z-score test with an absolute value of 2.68 or higher on a single variable on one technique, and a second case exceeded the z-score assessment 
with an absolute value of 2.68 or higher and was noted as an outlier on the boxplot test.

However, since neither of the potential outliers exceed all three techniques, no participants were removed.

\section{Research Question One}

The first research question asked: Does a reflection-based intervention increase youth coaches' self-awareness of their coaching behaviors? There are also three subparts to question one, which asked: Does dialogue in a reflection-based intervention increase coaches' selfawareness of developmentally supportive behaviors?; Does video review in a reflection-based intervention increase coaches' self-awareness of developmentally supportive behaviors?; and Does input from players in a reflection-based intervention increase coaches' self-awareness of developmentally supportive behaviors? This question is addressed thematically with qualitative data from coach interviews.

Increases in coach awareness. While the potential increase in coach awareness (and its impact on coaching behavior) is the overarching theme of this dissertation, this topic was addressed though the interview questions and responses, leading to the metacognitive question that was presented to coaches in the final interview. In the dialogue-based repeated interviews, themes surrounding change, the reason for change, the desire to change, and the awareness for the need to change were sought out. In the initial interview, question regarding the coach's intentions were followed up with questions regarding the coach's perceived behavior. In a thematic analysis of the transcribed interviews, the following subthemes emerged regarding coach awareness.

Communication. Coaches overwhelmingly endorsed communication as a primary factor in their coaching that is impactful on youth. When asked how their methods of communication 
would improve the youth sport experience or increase the benefits of the sport experience, it was clear that some coaches start off their season or coach career very aware of what will and will not benefit youth players, and some are "winging it", according to Coach D. One strong theme that emerged as interview progressed was that coaches who do not have a definitive plan for what and how to communicate to players often make changes based on player performance. For example, Coach C stated, "I notice I say the same thing a few different ways, because it's hard to know what will make sense to each kid". The researcher followed up, "Can you give me an example?”. To which Coach C replied, "Like dribbling with your head up. I might say "head up" or "chin up", but if that doesn't really work, I might give them a specific target to look at...like me or the hoop."

This statement was then followed up with a comment that signals awareness of intention, after the follow up question addressing the perceived need for using different communication techniques. Coach $\mathrm{C}$ responded, "It [What I say] always need to be constructive though...positive. It's my job to help the kids learn and have fun."

Other indicators that change, or the need for change, in coaching behavior, specific to improvement are comments that signal a realization of lack of awareness. For example, Coach A states, "I try to get on the level of the kids so they feel the power is a bit more equal". To which the researcher followed up with, "So this is something new you are doing?". Coach A concluded, "Yeah, so I don't tower over them."

The content and mode of communication are important elements of coaching and such indications of awareness and willingness to change is promising. When considering the need for developmentally supportive behavior in youth sport, any increase in awareness to those needs is valuable. 
In the early interviews, coaches noted physical skills, fortitude, positive social interaction, leadership skills, and decision-making as the primary developmental behaviors they believed coaches were responsible for promoting. As interviews progressed, their categorization of developmentally supportive behaviors expanded. This may be due to experience and comfort with the cohort of players, however, question five in interviews two through four specifically asked if new behaviors were attempted since the previous interview. For four of the five coach respondents, there was change indicated. Coach A noticed "when I have a plan for practice, it helps us get a lot more done. But it requires more work on my part to think ahead.” Coach B stated, "I check in with the kids often to make sure they are in a good place to play. If they are having a hard time at school or at home, and it makes them less focused. I need to do what I can to help." Coach C noted, "We [coaches] can get consumed by winning. That happens a lot. If we do that, the kids do that. So keeping track of effort is more important than focusing on talent or performance sometimes." And Coach D reported, "When I started coaching, I was winging it at first. But the girls need structure and predictability. They need to care and need to know that I care. So now I try to ensure we have a routine."

While it does not appear that changes were easy for participant coaches, it does seem that coaches in this study grew in their appreciation for and awareness of the need to focus on developmentally supportive behaviors. By making changes in techniques, focus, and coaching behaviors, youth coaches are better able to achieve their goal of improving the sport experience for their players.

Video review. As a prompting element for change, coaches gave feedback on the video review they completed on three occasions throughout the study. When asked if reviewing video footage of their coaching was useful or surprising, coaches generally stated that they were not 
shocked by what they saw. With limited sounds available on the videos, due to a significant amount of ambient noise, coaches often noted their body language as a form of communication. Several pointed out crossed arms or hands on hips as potentially negative cues that they were giving kids. For example, Coach A noticed "I talk with my hands a lot so that may be [interpreted as] a bit much for some kids." Coach B reported "I look mad sometimes, even when I don't think I really am.”

As stated earlier, coaches tend to use the responsivity (or lack of responsivity) of players as a gauge for successful coaching. Understanding that non-verbal cues might convey unintended messages signals an increase in awareness for coaching behaviors. Willingness to acknowledge and potentially make change to such cues is an important step to increasing developmentally supportive behaviors.

Player input. Before interview two, the researcher shared the results of the initial player responses to the Coach-Athlete Relationship Questionnaire (CART-Q) and the Caring Climate Scale (CCS) with coaches. Players rated coaches as lower on athletes being "treated fairly" and "listen(ed) to, and on coaches "caring about athletes" and coaching "helping" (from CART-Q). They also reported lower scores on "ease" around coach and "commitment" to coach (from CCS). These survey results were conveyed to coaches in the follow-up interview and several coaches responded thoughtfully. Coach A replied, “Wow, that's interesting. I guess we didn't take much time to get to know one another. We kind of just jumped in. I'll have to think about how to do that better." Coach C replied, "Yeah, I guess that makes sense. My team is really varied on ability, so it may be that kids who are more skilled feel neglected. I have had to spend a lot of time with the ones who are struggling just to get them to do something." 
In the second and third follow-up interviews, coaches were asked if hearing players' perspectives impacted their choices or behaviors. While a few noted that they were not sure or they did not notice any intentional changes, others were more aware and responded with what changes they perceived. Coach B recalled the researcher stating "the kids weren't as connected (coach making quotation marks with hands) as they could be. We did a trip to a [local college] game as a team, which I thought might help them click.” The researcher followed up to clarify, “Click with you as a coach or with each other as teammates?" Coach B stated, "Both. Just the fact that I'm there outside of practice or a game should say something."

While the input wasn't coming directly from players to their coach, feedback from players through survey data did appear to provoke thought often in participant coaches, and sometimes lead to action. Increased thought and action signals an increase in awareness and intention of developmentally supportive behaviors in volunteer youth coaches.

\section{Research Question Two}

The second research question asked if based on player- and self-report, does a reflectionbased intervention change coaches' developmentally supportive behaviors? If yes, what specific changes occur in coaches' self-reported behaviors? Does the reflection-based intervention increase or decrease a coaches' intention to change behavior? Does actual change occur, based on the perceptions of players? Does video review and player input impact coaches' developmentally supportive behaviors? And finally, is there a difference in player perceptions of caring and positive rapport of coaches who engage in reflection? This question is addressed by other qualitative (interview) and quantitative (survey) data.

Intention and changes in coach self-reported behaviors. Throughout the follow up interviews, coaches report a greater understanding of their role and a deeper appreciation of how 
impactful they can be on their youth players' sport experience. When asked what changes coaches have enacted, there is reported intention for and attempts to change. Coach $\mathrm{C}$ responded, "I have found that it is important to make each kid feel special and important to they want to be there, and even work harder. Working in small groups helps this." Coach E stated, "I sometimes let the kids lead the warm-ups or pick a game at the end. That seems to make them happy. They take things more seriously, it seems, when they are in charge."

These responses signal a different approach to running a practice with the intention of improving the sport experience for youth participants, ultimately by increasing developmentally supportive behaviors. Again, using changes in players' behavior (i.e., improvements in any developmental area) as a means to gauge successful coaching, since that was a theme in all five coaches' comments in interview one, is a common factor for all coach participants.

When coaches were asked specifically if there were behaviors that they were trying to avoid since the start of the season and the initial interview, coaches were hesitant to commit to anything specific. However, when asked why changes are important to them, coaches were quick to reference developmentally important goals, such as social and sport skills improvements, as well as overall enjoyment. Coach B noted, "Sometimes you can see when something changes in a kid. They go from just showing up, to really trying, to wanting to get better. Often a tough practice or game will separate the kids who really want to play from those who just want to socialize." Coach C stated, "I try to give them some freedom when I can. If players can learn to solve problems in sport, it just might help them in life."

Coach responses show a positive trend in intention for increasing player development in multiple areas. Willingness to change and awareness that change is valuable is a major part of 
the struggle in educating volunteer youth coaches. Therefore, reflection-based interventions seem initially promising.

Video review- seeing is believing. Though the video element of this study was limited, there were some useful elements that came out of this additional layer of reflection. Coaches were asked to review video snippets on their own of themselves coaching and were then asked general what they thought about what they saw. Then they assessed whether or not they made any changes based on reviewing the videos. Overall, coaches commented on body language that they were not aware they were engaging in until reviewing the videos. Coach A noted, "I put my hand on my hips and awful lot, and cross my arms." Coach D recalled, "On the video, I look like I'm mad, but I know I really wasn't. Maybe a player made a mistake... or maybe it was the ref [chuckles], but I don't remember actually being mad [laughs]."

There were also some verbal elements that were noticed by coaches during video review. This was more prevalent in follow-up interview four, as the videos prior to the final round had poorer sound quality. Volume and tone of voice, as well as the words that were spoken all were brought up as things coaches noticed when reviewing video of themselves coaching. Coach D stated, "My voice is higher [pitched] so I feel I need to yell during games I guess. I told the kids the next practice that I am not yelling AT them, but I am yelling TO them... so they can hear me". Coach E said, "I need to be able to tell kids when they do something wrong, so they can get better. I see that I usually go right for the end result...I am a tell it like it is kinda person.”

Having the opportunity to self-critique and discuss behaviors during the intervention offered participant coaches a unique opportunity to see what their players see and experience. For this study, seeing coaching missteps in action was intended to increase awareness and behavior change, which goes beyond traditional coach education. 
Assessment of change post video review. When asked in the follow-up interviews if reviewing the videos of themselves coaches lead to making changes, coaches were less responsive in follow-up interview two, but increasingly more responsive in follow-up interviews three and four. For example, Coach A noted that hands on hips, crossed arms, and talking with hands were noticeable on the video. In follow-up interview three, this coach stated that there has been an attempt to engage in those behaviors less. The primary reasons being the potential for misinterpretation by the players of that behaviors, as well as it [talking with hands] being "a bit much for the kids." As for changes in verbal behavior, there was some shifting reported by coaches. Coach D admitted, "So I didn't change the yelling, but I did explain it to them." Coach E stated, "It's hard for me to sugar coat things, but I think some kids respond better to that kinda talk...so I'm trying."

While the changes made may not be perfect, coaches comments suggest that the realization for the need to change certain behavioral elements, as well as the desire and willingness to enact those changes, is present. This supports the notion that reflection throughout the sports season may result in desired and actual change in intention, thoughts, and actions.

Themes and subthemes, as well as frequency of codes in quotes are displayed in Table 7. Table 7

Qualitative Themes and Code Frequencies

\begin{tabular}{llc}
\hline Primary Theme & Sub-theme & $\begin{array}{l}\text { Total number of applicable } \\
\text { quotes from coaches (n=5) }\end{array}$ \\
\hline Changes in Communication & $\begin{array}{l}\text { Verbal- words used } \\
\text { Non-verbal- body language, } \\
\text { tone and volume of voice } \\
\text { Content shift- from skills to } \\
\text { other measures of success } \\
\text { Mutual respect is important }\end{array}$ & 37 \\
& & 13 \\
(continued)
\end{tabular}




\begin{tabular}{llc}
\hline Primary Theme & Sub-theme & $\begin{array}{c}\text { Total number of applicable } \\
\text { quotes from coaches (n= 5) }\end{array}$ \\
\hline Increases in coach Self- & $\begin{array}{l}\text { Players changes as a measure of } \\
\text { coaching success (skill, social, } \\
\text { Awareness }\end{array}$ & 35 \\
& Planning ahead & 28 \\
& Decision-making improvements & 15 \\
& Increased focus on enjoyment & 14 \\
(for players) & 37 \\
Changes in Coach & Desire to make change & 28 \\
responsiveness & Willingness to make change & \\
\hline
\end{tabular}

Changes in player perceptions of coach behaviors- survey results. With pre and post survey information from players on teams where their coach was participating in the reflection activities, as well as players from control group teams, a change in player perceptions can be tracked across the season.

\section{Coach-Athlete relationship questionnaire (CART-Q)}

Responses to the direct perspective CART-Q at Time 1 resulted in an overall mean score of $5.99(\mathrm{SD}=.71)$. Within the 11-item questionnaire are three subscales including four Closeness items (e.g. 'I like my coach;' 'My coach likes me'), three Commitment items (e.g. 'I am committed to my coach;' 'My coach is committed to me'), and four Complementarity items (e.g. 'When I am coached by my coach, I adopt a friendly stance;' 'My coach adopts a friendly stance'). Of the direct perspective subscales, Commitment received the lowest mean score of $5.72(\mathrm{SD}=.92)$ while Complementarity and Closeness were higher at $5.79(\mathrm{SD}=.62)$ and 6.46 $(\mathrm{SD}=.60)$, respectively, as shown in Table 4 above. However, the post-hoc comparisons using Levene's test due to unequal variance did not reveal any significant team differences.

CART-Q for intervention versus control players. A two-way ANOVA with repeated measures was conducted on time with control and intervention as the group factors. Responses to the CART-Q was the dependent variable (DV) here were also two independent variables (IVs) 
including time (pre-and post-intervention) and group (intervention and control). There was not a significant main interaction effect for the coach relationship, $F(1,37)=1.54, p=.14$ or for the Time 2 effect, $\mathrm{F}(1,16)=1.01, p=.42$. However, there was a statistically significant result for Time $1 F(1,25)=.34, p=.04$.

A two-way ANOVA with repeated measures was conducted with each of the subscales in the CART-Q, again using the CART-Q subscale, including closeness, commitment, and complementarity as the dependent variables (DVs) and two independent variables (IVs) including time (pre-and post-intervention) and group (intervention and control). For closeness, there was no significance at Time $1, \mathrm{~F}(1,9)=1.77, p=.09$. However, Time 2 was found to be significant, $\mathrm{F}(1,6)=2.51, p=.03$, as well as the interaction of closeness from Time 1 and Time $2, \mathrm{~F}(1,13)=4.30, p=.00$. For commitment, significance was shown at Time $1, \mathrm{~F}(1,11)=7.12$, $p=.00$, Time $2 \mathrm{~F}(1,7)=5.27, p=.00$, and for the Time 1 Time 2 interaction $\mathrm{F}(1,21)=3.47, p$ $=.00$. For complementarity, no significance was found for Time $1 \mathrm{~F}(1,12)=1.70, p=.09$, Time $2 \mathrm{~F}(1,10)=1.05, p=.42$, and for the Time 1 Time 2 interaction $\mathrm{F}(1,22)=1.11, p=.36$.

Table 8

Two-Way ANOVA for Cart-Q Closeness Subscale

\begin{tabular}{|c|c|c|c|c|c|}
\hline Source & $\begin{array}{l}\text { Type III } \\
\text { Sum of } \\
\text { Squares }\end{array}$ & $\mathrm{df}$ & $\begin{array}{l}\text { Mean } \\
\text { Square }\end{array}$ & $\mathrm{F}$ & Sig. \\
\hline Corrected Model & 17.00 & 28 & .61 & 5.30 & .00 \\
\hline Intercept & 89.65 & 1 & 89.65 & 782.88 & .00 \\
\hline ClosenessT1 & 1.82 & 9 & .20 & 1.77 & .09 \\
\hline ClosenessT2 & 1.72 & 6 & .29 & 2.51 & .03 \\
\hline Closeness T $1 *$ Closeness T 2 & 6.39 & 13 & .49 & 4.29 & .00 \\
\hline Error & 8.25 & 72 & .12 & & \\
\hline Total & 254.00 & 101 & & & \\
\hline Corrected Total & 25.25 & 100 & & & \\
\hline
\end{tabular}


Table 9

Two-Way ANOVA for CART-Q Commitment Subscale

\begin{tabular}{|c|c|c|c|c|c|}
\hline Source & $\begin{array}{l}\text { Type III } \\
\text { Sum of } \\
\text { Squares }\end{array}$ & $\mathrm{df}$ & $\begin{array}{l}\text { Mean } \\
\text { Square }\end{array}$ & $\bar{F}$ & Sig. \\
\hline Corrected Model & 20.53 & 39 & .53 & 6.80 & .00 \\
\hline Intercept & 83.73 & 1 & 83.73 & 71081.53 & .00 \\
\hline CommitmentT1 & 6.07 & 11 & .55 & 7.12 & .00 \\
\hline CommitmentT2 & 2.86 & 7 & .41 & 5.27 & .00 \\
\hline CommitmentT1*CommitmentT2 & 5.64 & 21 & .27 & 3.47 & .00 \\
\hline Error & 4.72 & 61 & .08 & & \\
\hline Total & 254.00 & 101 & & & \\
\hline Corrected Total & 25.25 & 100 & & & \\
\hline
\end{tabular}

Table 10

Two-Way ANOVA for CART-Q Complementarity Subscale

\begin{tabular}{llllll}
\hline Source & $\begin{array}{l}\text { Type III } \\
\text { Sum of } \\
\text { Squares }\end{array}$ & df & $\begin{array}{c}\text { Mean } \\
\text { Square }\end{array}$ & F & Sig. \\
& 15.24 & 46 & .33 & 1.79 & .02 \\
Corrected Model & 88.77 & 1 & 88.77 & 479.10 & .00 \\
Intercept & 3.60 & 12 & .30 & 1.62 & .09 \\
ComplementarityT1 & 1.72 & 6 & .29 & 2.51 & .11 \\
ComplementarityT2 & 3.21 & 27 & .12 & .64 & .89 \\
ComplementarityT1*ComplementarityT2 & 10.01 & 54 & .19 & & \\
Error & 254.00 & 101 & & & \\
Total & 25.25 & 100 & & & \\
Corrected Total & & & & & \\
\hline
\end{tabular}

\section{Caring Climate Scale (CCS)}

The CCS was used to assess the extent to which the athletes perceive the environment that their coach provides were inviting and supportive. The CCS is a 13-item measure that assesses individuals' perceptions of caring within a specific context (Newton et al., 2007). In the analysis for this dissertation, CCS scores are collected at Time 1 and Time 2 . The mean for the 
$\mathrm{CCS}$ was $4.53(\mathrm{SD}=.44)$, with a range of item means from $4.46-4.92(\mathrm{SD}=.27-.62)$, as shown in Table 5 above.

CCS for intervention and control players. A two-way ANOVA with repeated measures was conducted on time with control and intervention as the group factors. Responses to the CCS was the dependent variable (DV) here were also two independent variables (IVs) including time (pre-and post-intervention) and group (intervention and control). There was a no significant main interaction effect for coach caring, and an F score was not able to be reported due to insufficient degrees of freedom. Time $1 \mathrm{~F}(1,5)=1.17, p=.33$ and Time $2 F(1,8)=1.13, p$ $=.35$ were also not found to be significant. The post-hoc comparisons using Levene's test due to unequal variance did not reveal any significant team differences.

Table 11

Two-Way ANOVA for Caring in CCS

\begin{tabular}{|c|c|c|c|c|c|}
\hline Source & $\begin{array}{l}\text { Typ } \\
\text { Sun } \\
\text { Squ }\end{array}$ & $\overline{\mathrm{df}}$ & $\begin{array}{c}\text { Mean } \\
\text { Square }\end{array}$ & $\bar{F}$ & Sig. \\
\hline Corrected Model & 3.99 & 17 & .23 & .92 & .56 \\
\hline Intercept & 39.54 & 4 & 39.54 & 154.36 & .00 \\
\hline CaringT1 & 1.50 & 5 & .30 & 1.17 & .33 \\
\hline CaringT2 & 2.31 & 8 & .29 & 1.13 & .35 \\
\hline Caring $\mathrm{T} 1 *$ Caring $\mathrm{T} 2$ & .00 & 0 & - & - & - \\
\hline Error & 21.26 & 83 & .26 & & \\
\hline Total & 254.00 & 101 & & & \\
\hline Corrected Total & 25.25 & 100 & & & \\
\hline
\end{tabular}

\section{Research Question Three}

The third and final research question is metacognitive in nature. This question asked whether coaches believe that reflection through dialogue and video review made them willing to self-report fault in their coaching behaviors? Do they believe such an intervention is supportive, useful, and free from judgement? These queries were answered with quantitative data from a 
brief coach satisfaction survey administered at the end of the season, as well as qualitative data from interview four.

The journey of reflection. Coaches participating in this reflection intervention went through many steps. They were asked to engage in activities that had the potential to make them more self-aware, and according to the results, those activities were successful, at least for some participant coaches. The other factor to consider, however, is how strongly coaches believe that such an intervention was useful and supportive. To get to this metacognitive question, coaches were asked in the final interview to reflect on their season and this interactive experience. Points discussed in previous interviews were brought up as prompts to encourage coaches to see the entire journey, start to finish.

Coach satisfaction survey. Coaches were asked to complete a 10-item satisfaction survey at the conclusion of the season to assess their perspectives on the efficiency and effectiveness of the intervention. There were items to assess coaching improvements, thoughtfulness, awareness, willingness to acknowledge faults, continued use, supportiveness of the intervention, utility, lack of judgment, and belief that the intervention should be expanded to future teams. The mean score for item one, which assessed whether the intervention was worth the time it took was $4.2(\mathrm{SD}=.84)$. The mean for all other items as listed above was 4.9 (SD $=.45$ ). Descriptive statistics were run to assess measures of central tendency and variability. For item one, $\mu=4.20$, and for all other items, $\mu=4.90$. These results are displayed in Table 12 . 
Table 12

Coach Satisfaction Survey Descriptives

\begin{tabular}{cccccc}
\hline Item & \multicolumn{5}{c}{ Post-Season Survey } \\
\hline & $\mathrm{M}$ & $\mathrm{SD}$ & Skewness & Kurtosis & $\mathrm{N}$ \\
1 & 4.20 & .84 & -.51 & -.61 & 5 \\
2 & 4.90 & .45 & -2.24 & 5.00 & 5 \\
3 & 4.90 & .45 & -2.24 & 5.00 & 5 \\
4 & 4.90 & .45 & -2.24 & 5.00 & 5 \\
5 & 4.90 & .45 & -2.24 & 5.00 & 5 \\
6 & 4.90 & .45 & -2.24 & 5.00 & 5 \\
7 & 4.90 & .45 & -2.24 & 5.00 & 5 \\
8 & 4.90 & .45 & -2.24 & 5.00 & 5 \\
9 & 4.90 & .45 & -2.24 & 5.00 & 5 \\
10 & 4.90 & .45 & -2.24 & 5.00 & 5 \\
\hline
\end{tabular}

Note: Responses were on a 5-point Likert scale (where 1 indicates strong disagreement and 5 indicates strong agreement to fidelity items) 


\section{Chapter V}

\section{Discussion, Implications, and Conclusions}

The purpose of this research was to examine the role of a dialogue-based intervention, based in counseling techniques, on coaching behaviors and player perceptions using surveys and interviews. The study was designed to offer new ideas in the coaching field, where traditional education for volunteer youth coaches as it currently stands, is not ideal. Another objective is to enhance the current literature on how counseling techniques can be effectively used in the coaching realm. In this chapter, I discuss my findings regarding the role of coach behaviors on youth player perceptions of caring and commitment, as well as the impact and feasibility of a dialogue-based coaching intervention over one 3-month-long basketball season. Additionally, I discuss the implications of the findings from this study, especially for practice and policy in youth sports. Lastly, concluding points are offered.

\section{Discussion of Findings as Related to Research Questions}

The findings from the analysis of both quantitative and qualitative data are organized by theme to answer each research question. The primary themes addressed are self-awareness, intentionality, and behavior change as a result of the intervention, as well as fidelity of the intervention.

These responses serve to answer the following research questions:

Primary research question: Does a reflection-based intervention that utilizes dialogue, video review, and player input facilitate self-awareness, intention to improve coaching behaviors, and positive behavior changes in youth coaches? 


\section{Does the intervention facilitate Self-Awareness and Intentionality?}

1. Does a reflection-based intervention increase youth coaches' self-awareness and intention of their coaching behaviors?

1a. Does dialogue in a reflection-based intervention increase coaches' self-awareness of developmentally supportive behaviors?

1b. Does video review in a reflection-based intervention increase coaches' selfawareness of developmentally supportive behaviors?

1c. Does input from players in a reflection-based intervention increase coaches' selfawareness of developmentally supportive behaviors?

\section{Does the intervention facilitate Behavior Change?}

2. Based on player- and self-report does a reflection-based intervention change coaches' developmentally supportive behaviors (i.e., their positive coaching of children)?

2a. If yes, what specific changes occur in coaches' self-reported behaviors?

2b. If yes, does coaches' behaviors change as measured by players' perception of change?

2c. Does video review in a reflection-based intervention affect coaches' implementation of developmentally supportive behaviors?

2d. Does input from players in a reflection-based intervention affect coaches' developmentally supportive behaviors?

2e. Specifically, for player perceptions, do perceptions of positive rapport and caring coaching improve more over the season for teams who participate in the study than for other teams in the league? 
Fidelity: Was the intervention done the way it was supposed to be done?

3. Do coaches believe that the reflection-based intervention, which utilized dialogue, video review, and input from players, made them willing to self-report fault in their coaching behaviors?

3a. Do coaches believe the intervention was supportive?

3b. Do coaches believe the intervention was useful?

3c. Do coaches believe the intervention was free from judgment?

Finally, there is a discussion of the framework for utility of this intervention, which I created from the data collected and analyzed throughout the study, literature review, and my personal experiences in the field of coaching.

\section{Self-Awareness and Intentionality- Addressing Research Question 1}

As stated earlier, without self-awareness, and without the acknowledgment of the importance of their role, coaches cannot be the mentor they claim to desire to be and their youth sport participants need them to be. Coaches in this study stated that their reasons for getting into coaching were mostly practical in nature, for instance, they had a child playing or another coach was not available, but also their reasons were goal-oriented. Three out of the five participant coaches mentioned being a role model or mentor for youth sport participants. The outlined goals by most participant coaches included teaching sport skills, social skills, and problem solving skills, as well as enjoyment of sport for the players. This information supports the notion that volunteer youth coaches have positive intentions, however, when asked what behaviors will help coaches achieve their stated goals, participant coaches in this study were less prolific Millar et al., 2011; Partington \& Cushion, 2013). More importantly, this finding may help align coaches 
with better means of understanding 'how' and 'why' they can and should promote a positive environment (Lemyre et al., 2007).

It was clear, as was indicated in the field notes on numerous occasions, that with the questions the researcher was asking, coachers were having "ah-ha" moments frequently throughout this study. This is promising to counteract the previous finding coaches' reported belief systems and actions during training or competition often do not align (Partington \& Cushion, 2013; Gilbert \& Trudel, 2004). They were not especially self-aware, not out of a lack of desire to understand how they were going to achieve their goals, but rather that the concept of self-awareness and its importance was never presented to them in a coaching context.

To answer Research Question 1, coaches’ responses to Interview Questions 3 and 4 can be examined and compared across the multiple completed interviews. The stated goals address the next sub-question regarding developmentally supportive behaviors. The intervention asks the same style of question at various points throughout the season, which allows each coach the time to think though progress that may or may not have occurred since the previous discussion.

While responses varied from coach to coach, it was evident that from interview one to interview four, there was progressively greater depth of thought occurring. Coaches exhibited progressive change, which aligns with the desire to learn more efficiently and effectively, and put meaning to their experiences/ stated in previous literature as a coaching goal (Wiersma et al., 2005; Nelson, Cushion, \& Potrac, 2006; Gilbert \& Trudel, 2001). Since coaches were asked to consider their goals, and how they were combatting presumed barriers to those goals, it resulted in thoughtful problem solving. This was evidenced by both a greater quantity and greater quality of responses to those questions from interview to interview. Knowing that there is often misalignment 
between coach goals and behaviors, such progress should be considered a positive and impactful result (McCallister et al., 2000).

Developmentally supportive behaviors. While exact coaching behaviors were not tracked in this study, coach perceptions and player perceptions were collected. When asked about increasing developmentally supportive behaviors, coaches mentioned having the kids be more engaged, and having more fun as being important objectives (McGladrey et al., 2010; Petipas et al., 2005; McCallister et al., 2000). For example:

Coach A: I want the kids to learn to play the game, and feel good about themselves. Researcher: How do you help that happen?

Coach A: Well, keeping their attention isn't always easy. Young kids need to keep moving and stay interested. If the drills we do are short, they usually can stay focused. It is when a kid struggles with a particular drill that makes it tough, because I need to spend some extra time.

Researcher: How do you manage that with the rest of the team?

Coach A: I might ask the assistant to jus in to help the kid one on on...or I will. That way we can keep the rest of the team moving. If they slow down too much, they don't seem to have as much fun.

Researcher: How do you know?

Coach A: I can see it in their faces, and in their efforts. Hard work can be fun if it's social and they are being really active.

Researcher: Did you always do that?

Coach A: Yeah, but I think I do it more now. 
Engagement, fun, etc. are most definitely developmentally supportive in nature (Fry \& Gano-Overway, 2010; Gano-Overway et al., 2009; Gould et al., 2012) . With the dialogue and video review elements of this intervention, there is again a progressive nature to the reported outcomes by coaches. In interview one, coaches were often "not sure" of what they needed to do to reach their stated goals. After talking through different ideas of how they might move closer to those goals, as well as reviewing video evidence of what behaviors they had been engaging in, responses became much more specific, which adds a dimension of awareness missing from previous studies (Partington \& Cushion, 2013; Cushion et al., 2003). For example, for Coach B, responses went from "not sure" to "I had to really think about it, but I found this great team building exercise online that I tried... and I think the kids really liked it." The increasing detail is a good sign that such behaviors are specific and measurable, and therefore more likely achievable (Doran, 1981).

Coaches were also asked specifically what behaviors they were and were not trying to engage in. Many participant coaches referred to their initially stated goals, or asked to be reminded of them, when answering this question. For example, Coach $\mathrm{C}$ referenced wanting to help the kids understand the game (i.e., improve sport skills). Initially, the coach's response was about what needed to be taught (i.e., ball handling). In later interviews, however, the coach's response was focused on how that goal could be achieved. Coach $\mathrm{C}$ noted detailed language when explaining the sport concept, as well as keeping a calm demeanor with a "positive tone of voice". It was the video review that made Coach C aware that the previous "tone of voice" could be perceived as negative. Combining that video observation with a brief discussion of player surveys, which were initially low on commitment and being at ease, Coach $\mathrm{C}$ stated that it was "worth trying some changes". 
Another example of this with Coach E, responding to question 5- What new behaviors have you tried since we spoke last to help you achieve [your stated] goals?:

Coach E (Interview 2): I'm not sure. I do want the team to learn and be social, but we have such a short amount of time together. It can be hard to tell how much good I'm doing.

Coach E: (Interview 3): I've started letting the team pick a game ort a drill at the middle and end of practice... kind of like a reward. I think they have fun doing that.

Coach E (Interview 4): I still let them pick games and stuff. But I also started asking them to tell me and the team one thing they want to get better at this practice and at the next game. It's good to hear they are thinking about goals, sometimes anyway.

Coach commentary gives good insight into the way each coach was thinking throughout this intervention, however changes in survey responses from intervention vs. control group players are even more telling. For all three subscales of the CART-Q, commitment, complementarity and closeness, intervention group players scores increased from pre-season to post-season, though not enough to be statistically significant for complementarity. Control group players stayed the same on average, or even decreased slightly. For the caring climate scale, the most significant indicators in coach change were the items regarding athletes being treated with respect, coaches being kind to athletes, and coaches being accepting and welcoming of all athletes. If players were able to sense a shift in their coach's behaviors and goals through an increase in developmentally supportive behaviors, then the intervention was successful, as positive coaching increased over the duration of the season. 
Table 13

Group Differences Over Time for Two-Way ANOVAs

\begin{tabular}{llllll}
\hline Source & $\begin{array}{l}\text { Type III } \\
\text { Sum of } \\
\text { Squares }\end{array}$ & df & $\begin{array}{c}\text { Mean } \\
\text { Square }\end{array}$ & F & Sig. \\
& 6.39 & 13 & .49 & 4.29 & .00 \\
\hline ClosenessT1*ClosenessT2 & 5.64 & 21 & .27 & 3.47 & .00 \\
CommitmentT1*CommitmentT2 & 3.21 & 27 & .12 & .64 & .89 \\
ComplementarityT1*ComplementarityT2 & .00 & 0 & - & - & - \\
CaringT1*CaringT2 & & & & & \\
\hline
\end{tabular}

\section{Behavior Change- Addressing Research Question 2}

Positive coaching is most visible in behavior. What does a coach actively do to support a player's and a team's achievement of developmental advances through sport? Throughout this intervention, much like was stated above for self-awareness, there was a progressive pattern for behavior change. But unlike self-awareness, behavior change appeared to plateau at the final interviews. This progress and plateau were indicated in coach statements about not knowing exactly what to do, to coming up with and testing out new ideas, to feeling like they have exhausted their resources. Since the purpose of this study was not to educate the participant coaches on new coaching techniques, results for behavior change were reliant on the coach's background (i.e., previous coach education). With that in mind, the desire to change was apparent in coach commentary, but the depth of behavior change appears limited as was seen in earlier literature (Kenow \& Williams, 1999; Cushion et al., 2003). If brainstorming ideas on what to change and how to change it were incorporated, the intervention would likely have been more impactful on the overall behavior change that was seen in this study.

Coaches did note changing their tone of voice (i.e., volume), getting on the level of the athletes (i.e., kneeling or sitting) rather than towering over them, and being more cautious of their posture, as several noted that their stance with crossed arms or hands on hips looked more 
negative than they intended at the video review. Coaches also pointed out altering their drills at practice to give kids who were struggling more options to help them feel successful and adding something fun (i.e., a game) at the end of practice to reward effort. For example:

Coach B (Interview 2): If I see a player really struggling in a particular activity or with a certain skill, I feel I should stop and make corrections, so that they don't get into bad habits.

Coach B (Interview 3): I think feel players singled out if I just stop a drill in the middle and make corrections. I find if I address the corrections to the entire team and have the players show each other a move, they like that better, and get less embarrassed.

Coach B (Interview 4): Now I see the players helping each other out when they forget or make mistakes. Being able to give criticism in a constructive way is just as important as being able to receive it.

Changes in the player surveys from pre- to post season indicate that change occurred and was perceived by players. The scores for caring, commitment, and complementarity all increased for participation coaches, which signals an increase in positive behaviors demonstrated with players. The same elevation was not present for control participant coaches.

Such a finding supports previous literature, that human interaction (i.e., discussion) as a primary intervention for behavior change (Hineyard \& Kreuter, 2006). A cueing event acts as a "teachable moment" and increases awareness, produces a strong emotional response, and causes a redefinition of an individual's self-concept or social role (McBride et al., 2003). In-depth interviews for leaders tasked with enacting change led to more competence and confidence through self-awareness was high and behaviors were intentional (Higgs \& Rowland, 2010). 


\section{Fidelity- Addressing Research Question 3}

Based on the Coach Satisfaction Survey administered at the end of the season, participant coaches report being pleased overall with the reflection-based intervention they agreed to participate in. On a 1 - 5 Likert scale, the mean for all responses was 4.8 , This includes feeling supported (RQ 3a), and believing the intervention was useful (RQ 3b), and free from judgment (RQ 3c). The mean response for increased willingness to admit fault in coaching behaviors was also 4.8. The supportiveness set up by the researcher was likely a key element in this increase, but increased appreciation for self-awareness was also important. Understanding that change can be useful and is not a weakness is an important step. This supports previous findings that support participants' acknowledgement of lack of change was the result of poor self-awareness (Higgs \& Rowland, 2010).

By encouraging participant coaches to focus on the "intention-behavior gap", recognizing fault became a motivation for change rather than an insurmountable hurdle (Schwarzer, 2008). Coaches responses varies, but the message was consistent. In order for the team to grow, and the players to learn, the coach must also be flexible and allow him or herself to be educated throughout the season. It appears that participant coaches were more aware of "teachable moments" due to the cueing brought on by dialogue and video, which helped them to redefine fault as an opportunity (McBride et al., 2003).

\section{Worldview of the Researcher}

Not only did my experiences as a coach, past athlete, parent, and researcher shape how I conceptualized this study, but my worldviews did as well. Working under the constructivist worldview, I was seeking to understand the world in which I teach, parent, and coach. In order to be more objective I relied on the responses of the interview and survey participants' responses 
and my conclusions on how they interpret the world. Additionally, I constructed knowledge by seeking to further understand the social context. As a pragmatist, I used mixed methodology to understand all aspects of the research problem. I used triangulation of various data collection techniques and analyses to find how the research I completed fits into a larger construct.

\section{Conclusions}

In this dissertation, reflective practice among a group of youth sport coaches through the use of repeated interview and video review, with the intent to inspire greater awareness, malleability, and positive behavior change was used. The use of MI techniques promoted though in participant coaches and allowed the researcher to assist in increasing self-awareness in a supportive and non-judgmental way. This directly addresses the gap in the types of education volunteer youth coaches are receiving, which do not align with their coaching goals. This study can serve as a template for new practices that may be explored further to benefit coaches and youth sport participants alike.

After four dialogue-based interviews, three reflective exercises with video review of coaching behaviors, two survey responses from intervention and control players (pre- and post-), and a final summative survey with coaches, the positive effects found in this study are promising. From the first to second interviews, thematic analysis reveals increases in selfawareness of participant youth coaches, as shown in a lot of "ah-ha" moments during the discussion with the researcher. As the interviews progressed, the focus of each coach deepened and became more specific and purposeful. These ideas, stemming from reflective dialogue, are fuel for purposeful behavior change, which can improve coaches' goal achievement and players' developmental advances alike. 
If implemented thoughtfully and with the support of league directors and coaches, increasing coach education for volunteer youth sport coaches via more effective means, such as repeated dialogue, can be done as a part of their existing practice and game schedule. Improving coach support and education can increase the lasting positive impacts these volunteer coaches have on young sport participants.

\section{Limitations}

This study was limited by the nature of the data collected and by the sample selected. For example, the data were collected through interviews and surveys, which allows for little to no control over participants' responses. While Motivational Interviewing (MI) techniques were used to guide participant coaches, there was little new information provided by the researcher. Participants could respond in a way to enhance their self-image, or they may respond arbitrarily without thinking deeply about their answers. This study was limited to volunteer youth basketball coaches in a mid-Atlantic state and their willingness to participate in a lengthy intervention throughout the season. Ensuring coaches who truly would benefit from such an intervention may be difficult without initial buy-in from the coach and the league if this study were to be repeated. Therefore, the results may not be generalized to other populations, such as Middle School, High School, College, or Professional coaches.

The researcher was a fellow coach and a supported part of the participating leagues, therefore future attempts at such an intervention may require more preparatory work to ensure adequate participation. The video element used in this study resulted in poor sound quality for the majority of videos collected. Coaches were able to use non-verbal elements of behavior to comment on changes needed, but for future, enhanced audio collection would be advisable. 
Other limitations involve demographic considerations. First, there is a slight overrepresentation of male coaches in this study. All of this study's coach participants identify as White, which may make it difficult to generalize this study's findings to non-White coaches. Finally, the mid-Atlantic town where the study was conducted is limited in its youth sport resources, especially for females. This may result in a higher level of success in an intervention such as the one completed for this study, as compared to an area with more resources or more highly trained coaches available.

\section{Framework for Utility of Intervention with Future Coaches}

On the surface, engaging in a discussion with coaches appears to be a relatively simple way to promote positive coaching and self-awareness. For this intervention, however, it was the expertise of the researcher that allowed for deeper dialogue surrounding behavior, intention, and change. Motivational Interviewing techniques are simple, but do take practice, therefore if this intervention were to be used with future coaches, proper training would be important to consider.

Frequency also appears to be an important factor in the success of this intervention.

Dialogue in a supportive environment can be enjoyable and increase self-awareness; but just like any other behavior, practice makes perfect. It is unlikely that a one-time discussion would have resulted in the same positive effects. Incorporating a brainstorming or idea sharing element may also be useful. As some coaches are more experienced and better educated that others, the person directing the dialogue may be able to incorporate ideas for positive change within the MI discussion. This will allow the coach to feel as if he/she was a part of the idea, and make the experiences more personal.

Finally, buy-in from coaches is important, as well as from league directors. A league director would likely be one of the best people to continue such an intervention as his/her job is 
to check in on coaches, to ensure coaches are abiding by the goals of the league, and help to improve the overall player experience. They must be the one to create a vision and/or philosophy for the way coaches do their job and support them in doing so.

Figure 6. Framework for dialogue-based reflection intervention.

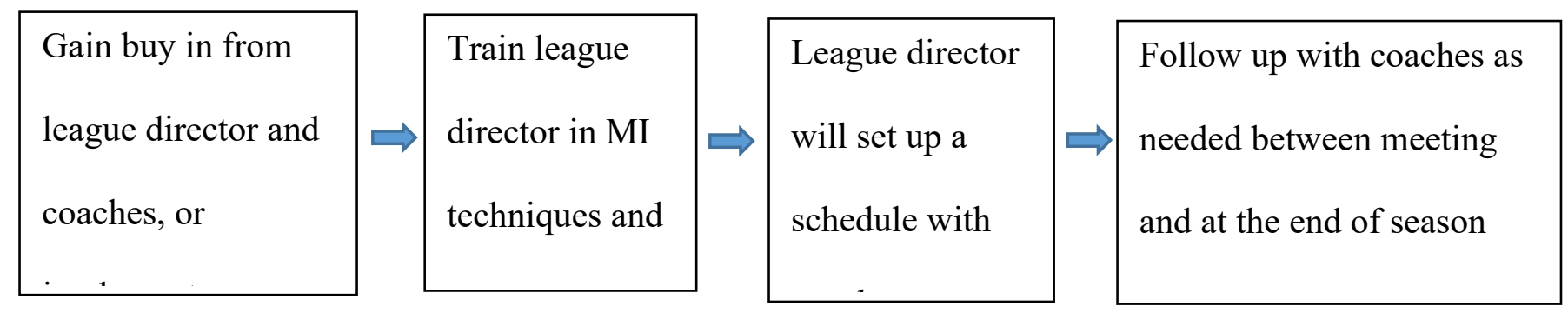

Figure 6. Framework for dialogue-based reflection intervention when used with future teams.

The framework presented in this chapter could be used with a follow-up study to further examine the role of the league director as well as educational elements that were not included in this dialogue-based intervention.

Coaches provide valuable input. Coaches were asked to recall the best and worst aspects of the intervention in order to give the researcher feedback on their subjective experiences throughout the season. Coaches unanimously endorsed the value of having conversations with "fellow coaches" and "experts" in sport and mentorship. Discussions led to lots of "increases", according to participant coaches, such as increases in planning, positive interaction, communication, and perhaps most importantly, awareness. Negatives of the intervention reported by coaches included most frequently, time. While it was clearly beneficial to have multiple discussions throughout the season, finding the best time to make it happen wasn't always easy. Also, two participant coaches commented on the "repetitiveness" of the questions in the discussion. As this was for research purposes, uniformity was important. The 
predictability, however, did restrict the conversation at times. So for future use of this type of intervention, even more flexibility may be advantageous.

\section{Utilizing This Intervention in a Broader Scope}

Brief contact interventions are not a new concept, and have been shown to be effective in the medical, psychology, and education fields for decades, but such interventions are gaining more traction recently due to decreased time and resources (Harris et al., 2014; Turner \& Sanders, 2006; Dinger et al., 2005). There is a dose effect, suggesting that a lot of feedback in a short amount of time may actually be ideal, not overwhelming a some may assume (MacLeod, Coates, \& Hetherton, 2008). By decreasing barriers of distance and time, it makes the sharing of information more possible. When resources are low and need is high, telepsychology and telehealth are the go-to, logical interventions, and technology is proving to improve our awareness, if we utilize it properly (Ringel, Mishna, \& Sanders, 2017).

Video coaching for a variety of purposes is also being utilized more frequently, to improve health and fitness, skills and education, and numerous other self-improvement objectives (Alley et al., 2014; Hu et al, 2014; Kidman \& Hanrahan, 2010; Ives, Straub, \& Shelley, 2002). Whether the goal is effective sports coaching, or another behavior change objective, increased self-awareness through reflective practices, such as conversation, can be pervasively beneficial. Openness to admitting fault and learning through experience can also be a valuable component to success in many areas of life. 


\section{References}

Abraham, A., \& Collins, D. (1998). Examining and extending research in coach development. Quest, 50(1), 59-79.

Allen, J. B., \& Hodge, K. (2006). Fostering a learning environment: Coaches and the motivational climate. International Journal of Sports Science \& Coaching, 1(3), 261-277.

Alley, S., Jennings, C, Plotnikoff, R.C., \& Vandelanotte, C. (2014). My activity coach: Using video-coaching to assist a web-based computer-tailored physical activity intervention: a randomized controlled trial protocol. BMC public health, 14(1), 738.

Anderson, L. W., \& Krathwohl, D. R. (2001). A taxonomy for learning, teaching and assessing: A revision of Bloom's taxonomy. New York: Longman.

Apache, R. R. (2004). Youth first: a parent orientation program for youth sports. Strategies, $17(6), 29-32$.

Apodaca, T. R., \& Longabaugh, R. (2009). Mechanisms of change in motivational interviewing: a review and preliminary evaluation of the evidence. Addiction, 104(5), 705-715.

Baker, J., Côté, J., \& Abernethy, B. (2003). Sport-specific practice and the development of expert decision-making in team ball sports. Journal of Applied Sport Psychology, 15(1), $12-25$.

Barnett, N. P., Smoll, F. L., \& Smith, R. E. (1992). Effects of enhancing coach-athlete relationships on youth sport attrition. The Sport Psychologist, 6(2), 111-127.

Bell, M. (1997). The development of expertise. Journal of Physical Education, Recreation \& Dance, 68(2), 34-38.

Bolton, G. (2010). Reflective practice: Writing and professional development. Thousand Oaks: Sage. 
Boud, D., Keogh, R., \& Walker, D. (1985). Promoting reflection in learning: A model. Reflection: Turning experience into learning. New York: Routledge.

Boyd, E. M., \& Fales, A. W. (1983). Reflective learning: Key to learning from experience. Journal of Humanistic Psychology, 23(2), 99-117.

Bronfenbrenner, U. (1999) Environments in developmental perspective: theoretical and operational models, in: S. L. Friedman \& T. D. Wachs (Eds.), Measuring environment across the life span. Emerging methods and concepts (pp. 3-28). Washington: American Psychological Association.

Burnard, P. (1991). A method of analyzing interview transcripts in qualitative research. Nurse Education Today, 11(6), 461-466.

Camiré, M., Trudel, P., \& Forneris, T. (2014). Examining how model youth sport coaches learn to facilitate positive youth development. Physical Education and Sport Pedagogy, 19(1), 1-17.

Carson, F. (2008). Utilizing video to facilitate reflective practice: Developing sports coaches. International Journal of Sports Science \& Coaching, 3(3), 381-390.

Cassidy, T. G., Jones, R. L., \& Potrac, P. (2008). Understanding sports coaching: The social, cultural and pedagogical foundations of coaching practice. London: Routledge.

Citizenship Through Sports Alliance. (2005). 2005 youth sports national report card. Retrieved from http://www.sportsmanship.org/News/1105\%20Report\%20Card-Fgrade.pdf

Charon, R. (2001). Narrative medicine: A model for empathy, reflection, profession, and trust. JAMA, 286(15), 1897-1902.

Church, A. H., \& Bracken, D. W. (1997). Advancing the state of the art of 360-degree feedback: 
Guest editors' comments on the research and practice of multi-rater assessment methods. Group \& Organization Management, 22(2), 149-161.

Clarke, N. (2006). Developing emotional intelligence through workplace learning: Findings from a case study in healthcare. Human Resource Development International, 9(4), 447-465.

Committee on Sports Medicine and Fitness, \& Committee on School Health. (2001). Organized sports for children and preadolescents. Pediatrics, 107(6), 1459-1462.

Conroy, D. E., \& Coatsworth, J. D. (2006). Coach training as a strategy for promoting youth social development. The Sport Psychologist, 20(2), 128-144.

Copeland, W. D., \& Decker, D. L. (1996). Video cases and the development of meaning making in preservice teachers. Teaching and Teacher Education, 12(5), 467-481.

Côté, J. (2006). The development of coaching knowledge. International Journal of Sports Science \& Coaching, 1(3), 217-222.

Côté, J., Baker, J., \& Abernethy, B. (2007). Practice and play in the development of sport expertise. Handbook of Sport Psychology, 3, 184-202

Côté, J., \& Gilbert, W. (2009). An integrative definition of coaching effectiveness and expertise. International Journal of Sports Science \& Coaching, 4(3), 307-323.

Côté, J., \& Hay, J. (2002). Children's involvement in sport: A developmental perspective. Boston: Allyn \& Bacon.

Côté, J., Yardley, J., Hay, J., Sedgwick, W., \& Baker, J. (1999). An exploratory examination of the coaching behavior scale for sport. Avante, 5(3), 82-92.

Creswell, J.W. (1998). Qualitative inquiry and research design: Choosing among five traditions. Los Angeles, CA: Sage.

Creswell, J. W., Hanson, W. E., Clark-Plano, V. L., \& Morales, A. (2007). Qualitative research 
designs: Selection and implementation. The Counseling Psychologist, 35(2), 236-264.

Crouch, M., \& McKenzie, H. (2006). The logic of small samples in interview-based qualitative research. Social Science Information, 45(4), 483-499.

Cushion, C. J., Armour, K. M., \& Jones, R. L. (2003). Coach education and continuing professional development: Experience and learning to coach. Quest, 55(3), 215-230.

Cutcliffe, J. R. (2003). Reconsidering reflexivity: Introducing the case for intellectual entrepreneurship. Qualitative Health Research, 13(1), 136-148.

Dewey, J. (1938). The theory of inquiry. New York: Holt, Rinehart \& Wiston.

Dewey, J. (1933). How we think: A restatement of the reflective thinking to the educative process. DC Health.

DiClemente, C. C., \& Velasquez, M. M. (2002). Motivational interviewing and the stages of change. Motivational interviewing: Preparing people for change, 2, 201-216.

Dinger, M. K., Heesch, K.C., \&. McClary, K.R. (2005). Feasibility of a minimal contact intervention to promote walking among insufficiently active women. American Journal of Health Promotion, 20(1), 2-6

Dixon, M., Lee, S., \& Ghaye, T. (2013). Reflective practices for better sports coaches and coach education: Shifting from a pedagogy of scarcity to abundance in the run-up to Rio 2016. Reflective Practice, 14(5), 585-599.

Doran, G. T. (1981). There's a SMART way to write management's goals and objectives. Management review, 70(11), 35-36.

Douge, B., \& Hastie, P. (1993). Coach effectiveness. Sport Science Review, 2(2), 14-29.

DuBois, D. L., Holloway, B. E., Valentine, J. C., \& Cooper, H. (2002). Effectiveness of 
mentoring programs for youth: A meta-analytic review. American Journal of CommunityPsychology, 30(2), 157-197.

DuBois, D. L., Neville, H. A., Parra, G. R., \& Pugh-Lilly, A. O. (2002). Testing a new model of mentoring. In J. E. Rhodes (Ed.), A critical view of youth mentoring (pp. 21-57). New Directions for Youth Development, no. 93. San Francisco, CA: Jossey-Bass.

DuBois, D. L., Portillo, N., Rhodes, J. E., Silverthorn, N., \& Valentine, J. C. (2011). How effective are mentoring programs for youth? A systematic assessment of the evidence. Psychological Science in the Public Interest, 12(2), 57-91.

Duval, T. S., \& Silvia, P. J. (2002). Self-awareness, probability of improvement, and the self serving bias. Journal of Personality and Social Psychology, 82(1), 49.

Erickson, K., Côté, J., \& Fraser-Thomas, J. (2007). Sport experiences, milestones, and educational activities associated with high-performance coaches' development. The Sport Psychologist, 21(3), 302-316.

Falcão, W. R., Bloom, G. A., \& Gilbert, W. D. (2012). Coaches’ perceptions of a coach training program designed to promote youth developmental outcomes. Journal of Applied Sport Psychology, 24(4), 429-444.

Fendler, L. (2003). Teacher reflection in a hall of mirrors: Historical influences and political reverberations. Educational Researcher, 32(3), 16-25.

Finlay, L., \& Gough, B. (Eds.). (2008). Reflexivity: A practical guide for researchers in health and social sciences. Hoboken, NJ: John Wiley \& Sons.

Flett, M. R., Sackett, S. C., \& Camiré, M. (2016). Understanding effective coaching: 
Antecedents and consequences. In R. Thelwell, C. Harwood, \& I. Greenlees (Eds.), The Psychology of Sports Coaching: Research and Practice (pp. 156-169). New York, NY: Routledge.

Ford, P. R., Ward, P., Hodges, N. J., \& Williams, A. M. (2009). The role of deliberate practice and play in career progression in sport: the early engagement hypothesis. High Ability Studies, 20(1), 65-75.

Fowler, J. (2008). Experiential learning and its facilitation. Nurse Education Today, 28(4), $427-$ 433.

Fraser-Thomas, J. L., Côté, J., \& Deakin, J. (2005). Youth sport programs: An avenue to foster positive youth development. Physical Education \& Sport Pedagogy, 10(1), 19-40.

Fraser-Thomas, J., \& Côté, J. (2009). Understanding adolescents’ positive and negative developmental experiences in sport. The Sport Psychologist, 23(1), 3-23.

Fraser-Thomas, J. L., Côté, J., \& Deakin, J. (2005). Youth sport programs: An avenue to foster positive youth development. Physical Education \& Sport Pedagogy, 10(1), 19-40.

Frey, M., Laguna, P., \& Ravizza, K. (2003). Collegiate athletes' mental skill use and perceptions of success: An exploration of the practice and competition settings. Journal of Applied Sport Psychology, 15(2), 115-128.

Fry, M. D., \& Gano-Overway, L. A. (2010). Exploring the contribution of the caring climate to the youth sport experience. Journal of Applied Sport Psychology, 22(3), 294-304.

Fukkink, R. G., Trienekens, N., \& Kramer, L. J. (2011). Video feedback in education and training: Putting learning in the picture. Educational Psychology Review, 23(1), 45-63. 
Gano-Overway, L. A., Newton, M., Magyar, T. M., Fry, M. D., Kim, M. S., \& Guivernau, M. R. (2009). Influence of caring youth sport contexts on efficacy-related beliefs and social behaviors. Developmental Psychology, 45(2), 329.

Ghaye, T. (2007). Is reflective practice ethical? (The case of the reflective portfolio). Reflective Practice, 8(2), 151-162.

Ghaye, T., \& Lillyman, S. (2008). The reflective mentor. London: Quay.

Ghaye, T., Melander-Wikman, A., Kisare, M., Chambers, P., Bergmark, U., Kostenius, C., \& Lillyman, S. (2008). Participatory and appreciative action and reflection (PAAR)democratizing reflective practices. Reflective Practice, 9(4), 361-397.

Gilbert, W., Gallimore, R., \& Trudel, P. (2009). A learning community approach to coach development in youth sport. Journal of Coach Education, 2(2), 3-23.

Gilbert, W. D., \& Trudel, P. (2004). Role of the coach: How model youth team sport coaches frame their roles. The Sport Psychologist, 18(1), 21-43.

Gilbert, W. D., \& Trudel, P. (2001). Learning to coach through experience: Reflection in model youth sport coaches. Journal of Teaching in Physical Education, 21(1), 16-34.

Gilbert, W., \& Trudel, P. (1999). An evaluation strategy for coach education programs. Journal of Sport Behavior, 22(2), 234.

Glauser, A. S., \& Bozarth, J. D. (2001). Person-Centered Counseling: The Culture Within. Journal of Counseling \& Development, 79(2), 142-147.

Goodstone, M. S., \& Diamante, T. (1998). Organizational use of therapeutic change: Strengthening multisource feedback systems through interdisciplinary coaching. Consulting Psychology Journal: Practice and Research, 50(3), 152.

Gould, D., \& Carson, S. (2011). Young athletes' perceptions of the relationship between 
coaching behaviors and developmental experiences. International Journal of Coaching Science, 5(2), 3-29.

Gould, D., Collins, K., Lauer, L., \& Chung, Y. (2007). Coaching life skills through football: A study of award winning high school coaches. Journal of Applied Sport Psychology, 19(1), $16-37$.

Gould, D., Flett, R., \& Lauer, L. (2012). The relationship between psychosocial developmental and the sports climate experienced by underserved youth. Psychology of Sport and Exercise, 13(1), 80-87.

Groom, R. \& Cushion, C. (2004). Coaches perceptions of the use of video analysis: A case study. Insight, 7(3), 56-58.

Guest, G., Bunce, A., \& Johnson, L. (2006). How many interviews are enough? An experiment with data saturation and variability. Field Methods, 18(1), 59-82. doi:10.1177/1525822X05279903

Hahn, C. (2008). Doing qualitative research using your computer: A practical guide. Thousand Oaks, CA: Sage.

Harris, S.K., Louis-Jacques, J., \& Knight, J.R. (2014). Screening and brief intervention for alcohol and other abuse. Adolescent Medicine: State of the Art Reviews, 25(1), 126-156.

Higgs, M., \& Rowland, D. (2010). Emperors with clothes on: The role of self-awareness in developing effective change leadership. Journal of Change Management, 10(4), 369-385.

Hinyard, L. J., \& Kreuter, M. W. (2007). Using narrative communication as a tool for health behavior change: a conceptual, theoretical, and empirical overview. Health Education \& Behavior, 34(5), 777-792.

Hodge, K. P. (1989). Character-building in sport: Fact or fiction. New Zealand Journal of Sports 
Medicine, 17(2), 23-25.

Hofmann, S. G., Asnaani, A., Vonk, I. J., Sawyer, A. T., \& Fang, A. (2012). The efficacy of cognitive behavioral therapy: A review of meta-analyses. Cognitive Therapy and Research, 36(5), 427-440.

Hollembeak, J., \& Amorose, A. J. (2005). Perceived coaching behaviors and college athletes' intrinsic motivation: A test of self-determination theory. Journal of Applied Sport Psychology, 17(1), 20-36.

Holt, N. L. (Ed.). (2016). Positive youth development through sport. New York, NY: Routledge. Holt, N. L., Tink, L. N., Mandigo, J. L., \& Fox, K. R. (2008). Do youth learn life skills through their involvement in high school sport? A case study. Canadian Journal of Education, 31(2), 281-304.

Hu, Y., Peyre, S.E., Arriaga, A.F., Osteen, R.T., Corso, K.A., Weiser, T.G., Swanson, R.S...Greenberg, C.C. (2012). Postgame analysis: using video-based coaching for continuous professional development. Journal of the American College of Surgeons, 214, 115-124.

Hubbs, D. L., \& Brand, C. F. (2005). The paper mirror: Understanding reflective journaling. Journal of Experiential Education, 28(1), 60-71.

Ives, J. C., Straub, W. F., \& Shelley, G. A. (2002). Enhancing athletic performance using digital video in consulting. Journal of Applied Sport Psychology, 14(3), 237-245.

Jarvis, P. (2004). Adult education and lifelong learning. $3^{\text {rd }}$ Ed. London: Routledge.

Jarvis, P. (1992). Reflective practice and nursing. Nurse Education Today, 12(3), 174-181.

Jowett, S., \& Ntoumanis, N. (2004). The coach-athlete relationship questionnaire (CART-Q): Development and initial validation. Scandinavian Journal of Medicine \& Science in 
Sports, 14(4), 245-257.

Keegan, R. J., Harwood, C. G., Spray, C. M., \& Lavallee, D. E. (2009). A qualitative investigation exploring the motivational climate in early career sports participants:

Coach, parent and peer influences on sport motivation. Psychology of Sport and Exercise, $10(3), 361-372$.

Kenow, L., \& Williams, J. M. (1999). Coach-athlete compatibility and athlete's perception of coaching behaviors. Journal of Sport Behavior, 22(2), 251.

Kidman, L., \& Hanrahan, S.J. (2010). The coaching process: A practical guide to becoming an effective sports coach. Routledge: New York, NY.

Kinsella, E. A. (2010). The art of reflective practice in health and social care: Reflections on the legacy of Donald Schön. Reflective Practice, 11(4), 565-575.

Kirschenbaum, H., \& Jourdan, A. (2005). The current status of Carl Rogers and the personcentered approach. Psychotherapy: Theory, Research, Practice, Training, 42(1), 37.

Knowles, Z., Borrie, A., \& Telfer, H. (2005). Towards the reflective sports coach: Issues of context, education and application. Ergonomics, 48(11-14), 1711-1720

Knowles, Z., Gilbourne, D., Borrie, A., \& Nevill, A. (2001). Developing the reflective sports coach: A study exploring the processes of reflective practice within a higher education coaching programme. Reflective Practice, 2(2), 185-207.

Kolb, D. (1984). Experiential learning as the science of learning and development. New Jersey: Prentice Hall.

Kolb, D. A. (2014). Experiential learning: Experience as the source of learning and development ( $2^{\text {nd }}$ ed.). New Jersey: Pearson.

Krueger, R. A., \& Casey, M. A. (2014). Focus groups: A practical guide for applied research. 
Los Angeles, CA: Sage.

Larrivee, B. (2000). Transforming teaching practice: Becoming the critically reflective teacher. Reflective Practice, 1(3), 293-307.

Leary, M. R., \& Buttermore, N. R. (2003). The evolution of the human self: Tracing the natural history of self-awareness. Journal for the Theory of Social Behaviour, 33(4), 365-404.

Lemyre, F., Trudel, P., \& Durand-Bush, N. (2007). How youth-sport coaches learn to coach. The Sport Psychologist, 21(2), 191-209.

Lerner, R. M., Almerigi, J. B., Theokas, C., \& Lerner, J. V. (2005). Positive youth development a view of the issues. The Journal of Early Adolescence, 25(1), 10-16.

Levine, R. B., Kern, D. E., \& Wright, S. M. (2008). The impact of prompted narrative writing during internship on reflective practice: a qualitative study. Advances in Health Sciences Education, 13(5), 723-733.

Lew, D. N. M., \& Schmidt, H. G. (2011). Writing to learn: can reflection journals be used to promote self-reflection and learning? Higher Education Research \& Development, 30(4), 519-532.

Lincoln, Y. S., \& Guba, E. G. (1985). Naturalistic inquiry. Newbury Park, CA: Sage Publications, Inc.

Lisko, S. A., \& O'dell, V. (2010). Integration of theory and practice: Experiential learning theory and nursing education. Nursing Education Perspectives, 31(2), 106-108.

Loughran, J. J. (2002). Effective reflective practice: In search of meaning in learning about teaching. Journal of Teacher Education, 53(1), 33-43.

Lundahl, B. W., Kunz, C., Brownell, C., Tollefson, D., \& Burke, B. L. (2010). A meta-analysis 
of motivational interviewing: Twenty-five years of empirical studies. Research on Social Work Practice, 20(2), 137-160.

Lustria, M. L. A., Noar, S. M., Cortese, J., Van Stee, S. K., Glueckauf, R. L., \& Lee, J. (2013). A meta-analysis of web-delivered tailored health behavior change interventions. Journal of Health Communication, 18(9), 1039-1069.

MacLeod, A. K., Coates, E., \& Hetherton, J. (2008). Increasing well-being through teaching goal-setting and planning skills: Results of a brief intervention. Journal of Happiness Studies, 9(2), 185-196.

Mageau, G. A., \& Vallerand, R. J. (2003). The coach-athlete relationship: A motivational model. Journal of Sports Science, 21(11), 883-904.

Mallett, C. J., Trudel, P., Lyle, J., \& Rynne, S. B. (2009). Formal vs. informal coach education. International Journal of Sports Science \& Coaching, 4(3), 325-364.

Mann, K., Gordon, J., \& MacLeod, A. (2009). Reflection and reflective practice in health professions education: a systematic review. Advances in Health Sciences Education, 14(4), 595.

Martens, R. (1996). Successful coaching (4th ed.). Champaign, IL: Human Kinetics.

Martin, S. B., Jackson, A. W., Richardson, P. A., \& Weiller, K. H. (1999). Coaching preferences of adolescent youths and their parents. Journal of Applied Sport Psychology, 11(2), 247262.

McBride, C. M., Emmons, K. M., \& Lipkus, I. M. (2003). Understanding the potential of teachable moments: the case of smoking cessation. Health Education Research, 18(2), $156-170$. 
McCallister, S. G., Blinde, E. M., \& Weiss, W. M. (2000). Teaching values and implementing philosophies: Dilemmas of the youth sport coach. Physical Educator, 57(1), 35.

McCullick, B., Schempp, P., Mason, I., Foo, C., Vickers, B., \& Connolly, G. (2009). A scrutiny of the coach education program scholarship since 1995. Quest, 61(3), 322-335.

McGladrey, B. W., Murray, M. A., \& Hannon, J. C. (2010). Developing and practicing an athlete-centered coaching philosophy. Youth First: The Journal of Youth Sport, 2(5), 4-9.

Mearns, D., Thorne, B., \& McLeod, J. (2013). Person-centered counselling in action (4 ${ }^{\text {th }}$ ed.). Los Angeles: Sage.

Merkel, D. L. (2013). Youth sport: Positive and negative impact on young athletes. Open Access Journal of Sports Medicine, 4, 151.

Mezirow, J. (1981). A critical theory of adult learning and education. Adult Education, 32(1), 324.

Miles, M. B., Huberman, A. M., \& Saldana, J. (2013). Qualitative Data Analysis: A Methods Sourcebook and the Coding Manual for Qualitative Researchers. Thousand Oaks, CA: Sage.

Millar, S. K., Oldham, A. R., \& Donovan, M. (2011). Coaches' self-awareness of timing, nature and intent of verbal instructions to athletes. International Journal of Sports Science \& Coaching, 6(4), 503-513.

Miller, W. R., \& Mount, K. A. (2001). A small study of training in motivational interviewing: Does one workshop change clinician and client behavior? Behavioral and Cognitive Psychotherapy, 29(4), 457-471.

Miller, W. R., \& Rollnick, S. (2012). Motivational interviewing: Helping people change (3 ${ }^{\text {rd }}$ ed.). New York: Guilford Press. 
Miller, W. R., \& Rollnick, S. (2004). Talking oneself into change: Motivational interviewing, stages of change, and therapeutic process. Journal of Cognitive Psychotherapy, 18(4), 299-308.

Miller, W., \& Rollnick, S. (2003). Motivational interviewing: Preparing people for change. Journal for Healthcare Quality, 25(3), 46.

Moon, J. A. (2004). A handbook of reflective and experiential learning: Theory and practice. New York: Routledge.

Moon, J. A. (1999). Reflection in learning and professional development: Theory and practice. New York: Routledge.

Morgan, D. 1998. Practical strategies for combining qualitative and quantitative methods: Applications to health research. Qualitative Health Research, 8, 362-76.

Morrow, K. V., \& Styles, M. B. (1995). Building relationships with youth in program settings: A study of Big Brothers/Big Sisters. Philadelphia: Public/Private Ventures.

Nelson, L. J., \& Cushion, C. J. (2006). Reflection in coach education: The case of the national governing body coaching certificate. The Sport Psychologist, 20(2), 174-183.

Nelson, L. J., Cushion, C. J., \& Potrac, P. (2006). Formal, non-formal and informal coach learning: A holistic conceptualization. International Journal of Sports Science \& Coaching, 1(3), 247-259.

Newton, M., Fry, M., Watson, D., Gano-Overway, L., Kim, M. S., Magyar, M., \& Guivernau, M. (2007). Psychometric properties of the caring climate scale in a physical activity setting. Revista de Psicología del Deporte, 16(1). 
Novack, D. H., Suchman, A. L., Clark, W., Epstein, R. M., Najberg, E., \& Kaplan, C. (1997).

Calibrating the physician: personal awareness and effective patient care. $J A M A, 278(6)$, $502-509$.

Nunnally J.C., \& Bernstein I.H. (1994). Psychometric theory (3rd ed). New York: McGraw-Hill.

Partington, M., \& Cushion, C. (2013). An investigation of the practice activities and coaching behaviors of professional top-level youth soccer coaches. Scandinavian Journal of Medicine \& Science in Sports, 23(3), 374-382.

Patton, M. Q. (2005). Qualitative research. Hoboken: Wiley \& Sons.

Perry, G., \& Talley, S. (2001). Online video case studies and teacher education: A new tool for preservice education. Journal of Computing in Teacher Education, 17(4), 26-31.

Petitpas, A. J., Cornelius, A. E., Van Raalte, J. L., \& Jones, T. (2005). A framework for planning youth sport programs that foster psychosocial development. The Sport Psychologist, 19, 63-80.

Polkinghorne, D. E. (1989). Phenomenological research methods. In R. S. Valle \& S. Halling (Eds.), Existential phenomenological perspectives in psychology (pp. 41-60). New York: Plenum.

Poirier, M. K., Clark, M. M., Cerhan, J. H., Pruthi, S., Geda, Y. E., \& Dale, L. C. (2004, March). Teaching motivational interviewing to first-year medical students to improve counseling skills in health behavior change. In Mayo Clinic Proceedings (Vol. 79, No. 3, pp. $327-$ 331). Elsevier.

Prochaska, J. O., \& DiClemente, C. C. (1982). Transtheoretical therapy: Toward a more integrative model of change. Psychotherapy: Theory, Research \& Practice, 19(3), 276. 
Prochaska, J. O., Norcross, J. C., \& DiClemente, C. C. (1995). Changing for good. New York: Avon Books.

Raykov, T., \& Marcoulides, G.A. (2008). An introduction to applied multivariate analysis. New York: Taylor \& Francis.

Rhodes, J. E., Spencer, R., Keller, T. E., Liang, B., \& Noam, G. (2006). A model for the influence of mentoring relationships on youth development. Journal of Community Psychology, 34(6), 691-707.

Ridley, C. R., Mollen, D., \& Kelly, S. M. (2011). Beyond microskills: Toward a model of counseling competence. The Counseling Psychologist, 39(6), 825-864.

Ringel, S., Mishna, F., \& Sanders, J. (2017). Developing a reflective self in cyber space. Psychoanalytic Psychology, 34(1), 87-95.

Robbins, J. E., \& Rosenfeld, L. B. (2001). Athletes' perceptions of social support provided by their head coach, assistant coach, and athletic trainer, pre-injury and during rehabilitation. Journal of Sport Behavior, 24(3), 277.

Rogers, C. R. (1945). The nondirective method as a technique for social research. American Journal of Sociology, 50(4), 279-283.

Rogers, C. R. (1986). Reflections of feelings. Person-Centered Review, 1, 125-140.

Rogers, C. R., Lyon, H. C., \& Tausch, R. (2013). On becoming an effective teacher: Personcentered teaching, psychology, philosophy, and dialogues with Carl R. Rogers and Harold Lyon. New York: Routledge.

Rollnick, S., \& Miller, W. R. (1995). What is motivational interviewing? Behavioral and Cognitive Psychotherapy, 23(4), 325-334. 
Rosaen, C. L., Lundeberg, M., Cooper, M., Fritzen, A., \& Terpstra, M. (2008). Noticing noticing: How does investigation of video records change how teachers reflect on their experiences? Journal of Teacher Education, 59(4), 347-360.

Roter, D. L., Larson, S., Shinitzky, H., Chernoff, R., Serwint, J. R., Adamo, G., \& Wissow, L. (2004). Use of an innovative video feedback technique to enhance communication skills training. Medical Education, 38(2), 145-157.

Russell, T. (2005). Can reflective practice be taught? Reflective Practice, 6(2), 199-204.

Scannell, K. (2002). Writing for our lives: physician narratives and medical practice. Annals of Internal Medicine, 137(9), 779-781.

Schön, D. A. (1987). Educating the reflective practitioner: Toward a new design for teaching and learning in the professions. San Francisco: Jossey-Bass.

Schön, D. (1983). The reflective practitioner. New York, NY: Routledge.

Schwandt, T.A. (2014). The Sage Dictionary of Qualitative Inquiry. 4th edition. Thousand Oaks, CA: Sage.

Schwarzer, R. (2008). Modeling health behavior change: How to predict and modify the adoption and maintenance of health behaviors. Applied Psychology, 57(1), 1-29.

Slater, A., \& Tiggemann, M. (2010). "Uncool to do sport": A focus group study of adolescent girls' reasons for withdrawing from physical activity. Psychology of Sport and Exercise, 11(6), 619-626.

Smith, M., \& Cushion, C. J. (2006). An investigation of the in-game behaviors of professional, top-level youth soccer coaches. Journal of Sports Sciences, 24(4), 355-366.

Smith, R. E., \& Smoll, F. L. (1997). Coach-mediated team building in youth sports. Journal of Applied Sport Psychology, 9(1), 114-132. 
Smith, R. E., Smoll, F. L., \& Cumming, S. P. (2007). Effects of a motivational climate intervention for coaches on young athletes' sport performance anxiety. Journal of Sport and Exercise Psychology, 29(1), 39-59.

Smith, R. E., Smoll, F. L., \& Curtis, B. (1979). Coach effectiveness training: A cognitive behavioral approach to enhancing relationship skills in youth sport coaches. Journal of Sport Psychology, 1(1), 59-75.

Smoll, F. L., Cumming, S. P., \& Smith, R. E. (2011). Enhancing coach-parent relationships in youth sports: Increasing harmony and minimizing hassle. International Journal of Sports Science \& Coaching, 6(1), 13-26.

Smoll, F. L., Smith, R. E., Barnett, N. P., \& Everett, J. J. (1993). Enhancement of children's self esteem through social support training for youth sport coaches. Journal of Applied Psychology, 78(4), 602.

Spalding, E., Wilson, A., \& Mewborn, D. (2002). Demystifying reflection: A study of pedagogical strategies that encourage reflective journal writing. Teachers College Record, 104(7), 1393-1421.

Spencer, R. (2004). Studying relationships in psychotherapy: An untapped resource for youth mentoring. In G. Noam \& N. Fiore (Eds.), Theory, practice and research (pp. 31-44). New Directions for Youth Development, no. 103. San Francisco: Jossey-Bass.

Stein, J., Bloom, G. A., \& Sabiston, C. M. (2012). Influence of perceived and preferred coach feedback on youth athletes' perceptions of team motivational climate. Psychology of Sport and Exercise, 13(4), 484-490.

Tripp, T. R., \& Rich, P. J. (2012). The influence of video analysis on the process of teacher change. Teaching and Teacher Education, 28(5), 728-739. 
Trudel, P., Côté, J., \& Bernard, D. (1996). Systematic observation of youth ice hockey coaches during games. Journal of Sport Behavior, 19(1), 50.

Trudel, P., Culver, D., \& Werthner, P. (2013). Considerations for coach development administrators. In P. Potrac, W. Gilbert, \& J. Denison (eds.), Routledge Handbook of Sports Coaching (pp. 375). New York: Routledge.

Turner, K., \& Sanders, M.R. (2006). Help when it's needed first: a controlled evaluation of brief, preventive behavioral family intervention in a primary care setting. Behavior therapy, $37(2), 131-142$.

Valli, L. (1996). Learning to teach in cross-cultural settings. Teacher Thinking in Cultural Contexts, 282.

van Manen, M. (1995). On the epistemology of reflective practice. Teachers and Teaching, 1(1), $33-50$.

Vella, S., Oades, L., \& Crowe, T. (2011). The role of the coach in facilitating positive youth development: Moving from theory to practice. Journal of Applied Sport Psychology, $23(1), 33-48$.

Vimeo: high quality digital video. Retrieved from https://vimeo.com.

Washington, M., \& Reade, I. (2013). Coach: The open system's manager. In P. Potrac, W. Gilbert, \& J. Denison (Eds.) Routledge Handbook of Sports Coaching (pp. 297-308). New York: Routledge.

Weiss, M. R., \& Fretwell, S. D. (2005). The parent-coach/child-athlete relationship in youth sport: Cordial, contentious, or conundrum? Research Quarterly for Exercise and Sport, $76(3), 286-305$. 
Whitehead, S., \& Biddle, S. (2008). Adolescent girls' perceptions of physical activity: A focus group study. European physical education review, 14(2), 243-262.

Whitehead, J., \& Fitzgerald, B. (2007). Experiencing and evidencing learning through self-study: New ways of working with mentors and trainees in a training school partnership. Teaching and Teacher Education, 23(1), 1-12.

Wiersma, L. D., \& Sherman, C. P. (2005). Volunteer youth sport coaches' perspectives of coach education/certification and parental codes of conduct. Research Quarterly for Exercise and Sport, 76(3), 324-338.

Wright, T., Trudel, P., \& Culver, D. (2007). Learning how to coach: the different learning situations reported by youth ice hockey coaches. Physical Education and Sport Pedagogy, 12(2), 127-144. 


\section{Appendix A}

\section{Coach Interview Guide \#1}

Thank you for participating in this interview. I am interested in getting your point of view on coaching. There are no right or wrong answers to these questions, I just want to hear your perspectives and ideas, as well as about some of your first-hand experiences as a coach. Specifically, I am looking to hear about your goals as a coach and how you work towards achieving those goals. Also, I'd like to hear about what you feel you do well and what you feel you could improve. Perhaps you will have some coaching stories to share regarding that.

\section{A. Introduction - 5-8 min.}

1. Why did you get into coaching youth sports?

2. What do you feel your primary responsibilities are as a youth coach?

\section{B. Intention Questions - 10-12 min.}

3. What are your goals as a youth coach, or what do you hope to achieve in your time working with your youth players (top 3)?

4. Are there variables you think might get in the way of you reaching your goals?

\section{Behavior Questions - 7-10 min.}

5. What behaviors do you engage in that help you achieve (or get closer to achieving) those goals?

6. What behavior do you try to avoid, so that they do not hinder reaching your stated coaching goals?

\section{Specifics/Scenarios - 5-7 $\mathrm{min}$.}

7. Can you think of any scenarios that you officiated in the past year where you were able to make the game a better experience for youth in terms of their psychological or social development? 
8. If you could coach the game however you'd like, but your ultimate objective had to be creating a positive sport experience for youth development, how would you do it? [Get 2-3 examples]

9. Why can't you do that now? [For each example they provide]

a. Do you think there are changes you could make to help that happen?

\section{E. For these specific situations, how would you make the call?}

10. In a setting where you asked a player to play \#5 on a man-to-man defense, and he or she is consistently guarding \#10 instead (along with another of his/her teammates). How would you handle the situation as a coach?

a. Would your behavior and verbal communication the first time around and the fifth time around vary?

11. At this age level (7-12) children have varying talent levels, but they are all able to participate with the team in some capacity? How might you encourage a less skilled player to be more confident on the court? How about a more skilled player? What words might you specifically use in these scenarios?

a. Would your communication or behavior change from practice to a game situation?

\section{F. Fill in coaches on players' post-survey results regarding coaching behaviors.}




\section{Appendix B}

\section{Coach Interview Guide \#2}

Thank you for participating in this interview. Since the last time we spoke, I just want to hear your perspectives and ideas, as well as about some of your first-hand experiences as a coach. Specifically, I am looking to hear about your goals as a coach and how you have been working towards achieving those goals. Also, I'd like to hear about what you feel you do well and what you feel you could improve. Perhaps you will have some coaching stories to share regarding that.

\section{A. Review - 5-8 min.}

1. How has your season been going so far? Have your players been successful?

2. Last time we spoke, you mentioned as your primary responsibilities as a youth coach. Do you feel you have been successful in achieving any of these? If yes, which ones and how?

\section{B. Intention Questions - 10 min.}

3. Of your top 3 goals listed last time, have you been successful in reaching any of these (or are you getting close)? If yes, which ones and how?

4. You mentioned that might get in the way of you reaching your goals. How have you been combating that disruption? Have you used your previously stated "helpful" behaviors (from Interview \#1, question 5)?

\section{Behavior Questions - 7-10 min.}

5. What new behaviors have you tried since we spoke last to help you achieve (or get closer to achieving) those goals?

6. What behaviors have you been trying to avoid that hinder you reaching your goals since we last spoke?

\section{Reflection - 15 min.}

7. Did you have an opportunity to look over the videos I sent? If yes, how often? 
8. What did you find useful about the videos? [Get 2-3 examples]

9. Was there anything you saw in the videos that really surprised you?

10. Have you made any changes (internal or external) since watching the videos?

11. Did hearing about your players' opinions last time we spoke make a difference in your choices or intentions while coaching? If yes, how did it impact your decisions and related behaviors?

12. Is there anything else you intend on changing?

13. For changes you have made or intend to make, why are those changes important to you?

F. Fill in coaches on players' post-survey results regarding coaching behaviors. 


\section{Appendix C}

\section{Coach Interview Guide \#3}

Thank you for participating in this interview. Since the last time we spoke, I just want to hear your perspectives and ideas, as well as about some of your first-hand experiences as a coach. Specifically, I am looking to hear about your goals as a coach and how you have been working towards achieving those goals. Also, I'd like to hear about what changes you have made, if any, to improve the sport experience for your players. Perhaps you will have some coaching stories to share regarding that.

\section{A. Review - 5-8 min.}

1. How has your season been going so far? Have your players been successful (how?)?

2. Last time we spoke, you mentioned as your primary responsibilities as a youth coach. Do you feel you have been successful in achieving any of these? If yes, which ones and how?

\section{B. Intention Questions - 10 min.}

3. Of your top 3 goals listed in our first conversation, you mentioned last time. Any other success in reaching these goals (or are you getting close)? If yes, which ones and how?

4. You mentioned that might get in the way of you reaching your goals last time we spoke. How have you been combating that disruption? Have you tried anything new?

\section{Behavior Questions - 7-10 min.}

5. What (other) new behaviors have you tried since we spoke last to help you achieve (or get closer to achieving) those goals?

6. What behaviors have you been trying to avoid that hinder you reaching your goals since we last spoke? 


\section{Reflection - 15 min.}

7. Did you have an opportunity to look over the videos I sent? If yes, how often?

8. What did you find useful about the videos? [Get 2-3 examples] (Follow up on conversation in Interview \#2)

9. Was there anything you saw in the videos that really surprised you?

10. Have you made any changes (internal or external) since watching the videos?

11. Is there anything else you intend on changing?

12. For changes you have made or intend to make, why are those changes important to you?

\section{E. Fill in coaches on players' post-survey results regarding coaching behaviors.}




\section{Appendix D}

\section{Coach Interview Guide \#4}

Thank you for participating in this interview. Since the last time we spoke, I just want to hear your perspectives and ideas, as well as about some of your first-hand experiences as a coach. Specifically, I am looking to hear about your goals as a coach and how you have been working towards achieving those goals. Also, I'd like to hear about what changes you have made, if any, to improve the sport experience for your players. Perhaps you will have some coaching stories to share regarding that.

\section{A. Review - 5-8 min.}

1. Your season is just about finished; how has it been going? Have your players been successful (how?)?

2. Last time we spoke, you mentioned as your primary responsibilities as a youth coach. Do you feel you have been successful in achieving any of these? If yes, which ones and how?

\section{B. Intention Questions - 10 min.}

3. Of your top 3 goals listed in our first conversation, you mentioned last time. Any other success in reaching these goals (or are you getting close)? If yes, which ones and how?

4. You mentioned that might get in the way of you reaching your goals last time we spoke. How have you been combating that disruption? Have you tried anything new?

\section{Behavior Questions - 7-10 min.}

5. What (other) new behaviors have you tried since we spoke last to help you achieve (or get closer to achieving) those goals? 
6. What behaviors have you been trying to avoid that hinder you reaching your goals since we last spoke?

\section{Reflection - 15 min.}

7. Throughout the season, you have been doing a lot of thinking and talking (with me). What have been the best aspects of this experience for you? The worst aspects?

\section{E. Impact- 5 min.}

13. What aspects of this process were the most impactful?

14. Were there any aspects of this process that you found pointless? Unenjoyable? Frustrating?

15. What are the top 3 "take away messages" you will have from this experience?

Please complete this brief satisfaction survey. Thank you for your participation in this process. I hope it has been helpful! 


\section{Appendix E}

\section{Coach-Athlete Relationship Questionnaire (CART-Q)}

\begin{tabular}{|c|c|c|c|c|c|c|c|c|c|}
\hline \multicolumn{4}{|c|}{ Strongly Disagree } & \multicolumn{3}{|c|}{ Moderately } & \multicolumn{3}{|c|}{ Strongly Agree } \\
\hline 1. & I am close to my coach & 1 & 2 & 3 & 4 & & & 6 & 7 \\
\hline 2. & I am committed to my coach & 1 & 2 & 3 & 4 & & & 6 & 7 \\
\hline 3. & I like my coach & 1 & 2 & 3 & 4 & & & 6 & 7 \\
\hline 4. & $\begin{array}{l}\text { When I am coached by my coach, I am at } \\
\text { ease }\end{array}$ & 1 & 2 & 3 & 4 & & & 6 & 7 \\
\hline 5. & I trust my coach & 1 & 2 & 3 & 4 & & & 6 & 7 \\
\hline 6. & $\begin{array}{l}\text { I feel that my sport career is promising with } \\
\text { my coach }\end{array}$ & 1 & 2 & 3 & 4 & & & 6 & 7 \\
\hline 7. & $\begin{array}{l}\text { When I am coached by my coach, I am } \\
\text { responsive to his/her efforts }\end{array}$ & 1 & 2 & 3 & 4 & & & 6 & 7 \\
\hline 8. & I respect my coach & 1 & 2 & 3 & 4 & & & 6 & 7 \\
\hline 9. & $\begin{array}{l}\text { I appreciate my coach's sacrifices in order } \\
\text { to improve performance }\end{array}$ & 1 & 2 & 3 & 4 & & & 6 & 7 \\
\hline 10. & $\begin{array}{l}\text { When I am coached by my coach, I am } \\
\text { ready to do my best }\end{array}$ & 1 & 2 & 3 & 4 & & & 6 & 7 \\
\hline & $\begin{array}{l}\text { When I am coached by my coach, I adopt } \\
\text { a friendly stance }\end{array}$ & 1 & 2 & 3 & 4 & & & 6 & 7 \\
\hline
\end{tabular}

Scoring System:

\begin{tabular}{|l|l|}
\hline & items \\
\hline Closeness & $3,5,8,9$ \\
\hline Commitment & $1,2,6$ \\
\hline Complementarity & $4,7,10,11$ \\
\hline & \\
\hline
\end{tabular}

Jowett, S., \& Ntoumanis, N. (2004). The Coach - Athlete Relationship Questionnaire (CART - Q): Development and initial validation. Scandinavian Journal of Medicine and Science in Sports, 14, 245-257. 


\section{Appendix F}

\section{Caring Climate Scale (CCS)}

\begin{tabular}{|c|c|c|c|c|c|}
\hline $\begin{array}{l}\text { Read each statement and think about how much } \\
\text { you believe the statement describes your team. Then } \\
\text { choose the answer that shows how much you agree or } \\
\text { disagree with each statement. }\end{array}$ & 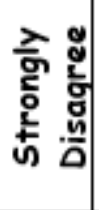 & 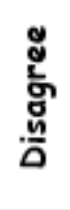 & 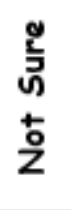 & $\frac{1}{\frac{1}{x}}$ & 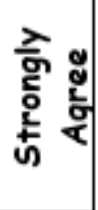 \\
\hline 1) On this team, athletes are treated with respect. & 1 & 2 & 3 & 4 & 5 \\
\hline 2) On this team, the coaches respect athletes. & 1 & 2 & 3 & 4 & 5 \\
\hline 3) On this team, the coaches are kind to athletes. & 1 & 2 & 3 & 4 & 5 \\
\hline 4) On this team, the coaches care about athletes. & 1 & 2 & 3 & 4 & 5 \\
\hline $\begin{array}{l}\text { 5) On this team, athletes feel that they are treated } \\
\text { fairly. }\end{array}$ & 1 & 2 & 3 & 4 & 5 \\
\hline 6) On this team, the coaches try to help athletes. & 1 & 2 & 3 & 4 & 5 \\
\hline $\begin{array}{l}\text { 7) On this team, the coaches want to get to know all the } \\
\text { athletes. }\end{array}$ & 1 & 2 & 3 & 4 & 5 \\
\hline 8) On this team, the coaches listen to athletes. & 1 & 2 & 3 & 4 & 5 \\
\hline $\begin{array}{l}\text { 9) On this team, everyone likes athletes for who they } \\
\text { are. }\end{array}$ & 1 & 2 & 3 & 4 & 5 \\
\hline $\begin{array}{l}\text { 10) On this team, the coaches accept athletes for who } \\
\text { they are. }\end{array}$ & 1 & 2 & 3 & 4 & 5 \\
\hline 11) On this team, athletes feel comfortable. & 1 & 2 & 3 & 4 & 5 \\
\hline 12) On this team, athletes feel safe. & 1 & 2 & 3 & 4 & 5 \\
\hline 13) On this team, athletes feel welcome every day. & 1 & 2 & 3 & 4 & 5 \\
\hline
\end{tabular}

NOTE: We have made the items specific to the sample we are surveying: leaders \& campers; teachers \& students; coaches \& athletes, etc. In addition, we have made the stem specific to the sample: On this team/In this program/In this class, etc.

SCORING: Sum the responses for all 13 items and divide by 13 to calculate the mean scale score:

$(\mathrm{Cl}+\mathrm{C} 2+\mathrm{C} 3+\mathrm{C} 4+\mathrm{C} 5+\mathrm{C} 6+\mathrm{C} 7+\mathrm{C} 8+\mathrm{C} 9+\mathrm{Cl0}+\mathrm{Cl1}+\mathrm{Cl2}+\mathrm{Cl3}) / 13$

\section{REFERENCE:}

Newton, M., Fry, M.D., Watson, D., Gano-Qxerway _L, Kim, M., Magyar, M., \& Guivernau, M. (2007). Psychometric properties of the Caring Climate Scale in a physical activity setting. Revista de Psiocologia del Deporte, 16, 67-84. 


\section{Appendix G}

\section{Field Note Form}

\section{Date:}

\section{Descriptive Content}

1. Physical setting:

2. Role of participants in the setting.

3. Social environment and the way in which participants interacted within the setting:

4. Any meaning of what was observed from the perspectives of the participants:

5. Any exact quotes or close approximations of comments that relate directly to the purpose of the study:

6. Any impact I (the researcher) might have had on the situation observed:

\section{Reflective Content}

1. ideas, impressions, thoughts, and/or any criticisms you have about what you observed.

2. Any unanswered questions or concerns that have arisen from analyzing the observation data.

3. Points for clarification or correction in other parts of field notes.

4. Insights about what I observed and speculation as to why I believe specific phenomenon occurred.

5. Any thoughts that you may have regarding any future observations.

Adapted from Schwandt, T.A. (2014). The Sage Dictionary of Qualitative Inquiry. 4th edition. Thousand Oaks, CA: Sage. 


\section{Appendix H}

\section{Coach Demographics Questionnaire}

Please complete the following information about yourself and your officiating relative to your role as an official in the sport of interest for this interview.

1. How many years have you coached this sport? $\rightarrow$ (Number of years)

2. Do you plan to coach this sport next year? $\rightarrow \quad \square$ No $\quad \square$ Yes

3. Do you coach any youth sports? $\rightarrow \quad \square$ No $\quad \square$ Yes

$\rightarrow$ If yes, what sport(s) do you coach?

4. Have you played basketball? $\rightarrow$

$\square$ No $\quad \square$ Yes

$\rightarrow$ If yes, what sport(s) do you coach?

Recreationally: (number of years, rounding up)

Competitively in High School: (number of years, rounding up)

Competitively in College: (number of years, rounding up)

Other: (number of years, rounding up) 
5. What is your age?

6. What is your race (please check all that apply):

$\square$ Caucasian

$\square$ African-American

$\square$ Hispanic-American

$\square$ Asian-American

$\square$ Native American

$\square$ Other

7. Have you had any formal training as a coach? $\rightarrow \square$ No $\square$ Yes

If you answered yes to question 7, please complete question a-d below. If you answered no, go to question 8 .

a. Do you have a coaching certification? $\rightarrow \square$ No $\square$ Yes If yes, from what organization?

b. Have you participated in other coaching workshops or seminars? $\rightarrow \quad \square$ No $\quad \square$ Yes If yes, please explain:

c. Do you have a physical education or recreation college degree? $\rightarrow \square$ No $\quad \square$ Yes d. I did my training with another organization: 
7. How much time do you devote to coaching activities for this sport?

a. Hours - The average number of hours per week when the sport is in season.

b. W__ Weeks - The number of weeks in the season (include all prep and educational activities).

c. Hours - Estimate the total number of hours (not weekly average) you devote to coaching-related activities during the off season.

Thanks for all your help! 


\section{Appendix I}

\section{Coach Satisfaction Survey}

\begin{tabular}{|c|c|c|c|c|c|}
\hline $\begin{array}{l}\text { Please read each statement and think about how } \\
\text { much you believe the statement describes your experience } \\
\text { throughout this coaching intervention. Then choose the } \\
\text { answer that shows how much you agree or disagree with } \\
\text { each statement. }\end{array}$ & $\begin{array}{l}\text { ते } \\
\text { D } \\
\text { o } \\
\text { 心 }\end{array}$ & 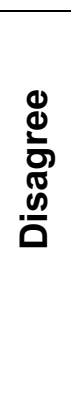 & $\begin{array}{l}\stackrel{0}{5} \\
\text { ஸे } \\
\stackrel{0}{2}\end{array}$ & 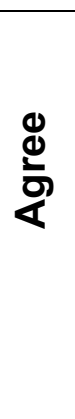 & 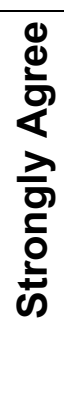 \\
\hline 1) This coaching intervention was worth my time. & & & & & \\
\hline $\begin{array}{l}\text { 2) This intervention helped me to improve my } \\
\text { coaching. }\end{array}$ & & & & & \\
\hline $\begin{array}{l}\text { 3) This intervention has made me a more thoughtful } \\
\text { coach. }\end{array}$ & & & & & \\
\hline $\begin{array}{l}\text { 4) I am now more aware of what I can do to help my } \\
\text { players. }\end{array}$ & & & & & \\
\hline $\begin{array}{l}\text { 5) I am now more willing to acknowledge fault in my } \\
\text { coaching behaviors. }\end{array}$ & & & & & \\
\hline $\begin{array}{l}\text { 6) I plan to continue to use what I have learned in } \\
\text { future coaching. }\end{array}$ & & & & & \\
\hline $\begin{array}{l}\text { 7) I believe this intervention is/was supportive of my } \\
\text { coaching. }\end{array}$ & & & & & \\
\hline 8) I believe this intervention is useful. & & & & & \\
\hline $\begin{array}{l}\text { 9) I did not feel negatively judged throughout the } \\
\text { intervention experience. }\end{array}$ & & & & & \\
\hline $\begin{array}{l}\text { 10) I believe this intervention should be expanded to } \\
\text { more teams/leagues. }\end{array}$ & & & & & \\
\hline
\end{tabular}




\title{
Appendix J
}

\section{Only Minimal Risk \\ Parental or Guardian Consent (Without HIPAA)}

\author{
Principal Investigator James Wyant, Ph.D. \\ Department \\ Coaching and Teaching Studies \\ Protocol Number \\ 17118476561711847656 \\ Study Title \\ Co-Investigator(s) \\ Use of Reflective Practices to Improve Self-Awareness in Youth Sport Coaches \\ Stephanie R. McWilliams, M.A.
}

\section{Contact Persons: Stephanie R. McWilliams, M.A., (304) 293-0834, srmcwilliams@mail.wvu.edu}

In this study, youth participants were asked to complete two surveys assessing the behaviors of their coach. It will likely take about 15 minutes to complete these surveys, and your child's identity were kept confidential.

In the event your child experiences any side effects or injury related to this research, you should contact Dr. James Wyant at (304) 293-0839. (After hours contact: Stephanie McWilliams at (304) 293-0834). If you have any questions, concerns, or complaints about this research, you can contact Dr. James Wyant at (304) 293-0839.

For information regarding your child's rights as a research subject, to discuss problems, concerns, or suggestions related to the research, to obtain information or offer input about the research, contact the Office of Research Integrity and Compliance (304) 293-7073.nts about this research, you can contact Dr. James Wyant at (304) 293-0839.

In addition if you would like to discuss problems, concerns, have suggestions related to research, or would like to offer input about the research, contact the Office of Research Integrity and Compliance at 304-293-7073. In addition if you would like to discuss problems, concerns, have suggestions related to research, or would like to offer input about the research, contact the Office of Research Integrity and Compliance at 304-293-7073.

\section{Introduction}

This research is being conducted to fulfill the requirements for a doctoral dissertation in Coaching and Teaching Studies in the Department of Coaching and Teaching Studies at West Virginia University, under the supervision of Dr. James Wyant. Your child, , has been asked to participate in this research study, which has been explained to you and your child by co-investigator, Stephanie R. McWilliams, M.A.

\section{Purpose(s) of the Study}

The purpose of this study is to learn more about coaching behaviors and their effects on youth sport participants. A total of approximately 100 subjects at all sites are expected to participate in this study. The purpose of this study is to learn more about coaching behaviors and their effects on youth sport participants. A total of approximately 100 subjects at all sites are expected to participate in this study. 


\section{Description of Procedures}

This study involves the completion of two surveys on two separate occasions and will take approximately 15 minutes for your child to complete. Your child was asked to fill out a questionnaire regarding his or her coach. This will take approximately 15 minutes. Your child does not have to answer all the questions. You will have the opportunity to see the questionnaire before signing this consent form.

Videos of the coach will also be taken at practice and during competition. Your child may be included in those videos incidentally.

The study was performed at West Virginia University, College of Physical Activity and Sport Sciences as well as at your sporting location. Approximately 100 subjects are expected to participate in this study.5 minutes. Your child does not have to answer all the questions. You will have the opportunity to see the questionnaire before signing this consent form.

\section{Risks and Discomforts}

There are no known or expected risks to your child from participating in this study, except for the mild frustration associated with answering the questions. There are no known or expected risks to your child from participating in this study, except for the mild frustration associated with answering the questions.

\section{Alternatives}

Your child does not have to participate in this study.

\section{Benefits}

Your child may not receive any direct benefit from this study. The knowledge gained from this study may eventually benefit others. Your child may not receive any direct benefit from this study. The knowledge gained from this study may eventually benefit others.

\section{Financial Considerations}

No payments were made for participating in the study.

No payments were made for participating in the study.

\section{Confidentiality}

Any information about your child that is obtained as a result of their participation in this research were kept as confidential as legally possible.

Your child's research records and test results, just like hospital records, may be subpoenaed by court order or may be inspected by the study sponsor or federal regulatory authorities without your additional consent.

Audiotapes or videotapes were kept locked up and were destroyed as soon as possible after the research is finished.

In any publications that result from this research, neither your child's name nor any information from which your child might be identified were published without your consent.t order or may be inspected by the study sponsor or federal regulatory authorities without your additional consent. 


\section{Voluntary Participation}

Refusal to participate or withdrawal will not affect your child's participation in League and will involve no penalty to you.

\section{Signatures}

Upon signing this consent, you will receive a copy.

I willingly consent to allow my child to participate in this research.

Signature of Parent or Guardian

Printed Name

Date

Time

My child appears to understand the research to the best of his or her ability and has agreed to participate.

Signature of Parent or Guardian

Printed Name

Date

Time

Signature of Investigator or Co-Investigator

Printed Name

Date

Time

Stephanie R. McWilliams

Date Time 